University of Louisville ThinkIR: The University of Louisville's Institutional Repository

Electronic Theses and Dissertations

$8-2016$

\title{
Principal self-efficacy in the implementation of a standards based teacher evaluation reform.
}

Jason Kennedy Neuss

University of Louisville

Follow this and additional works at: https://ir.library.louisville.edu/etd

Part of the Educational Leadership Commons

\section{Recommended Citation}

Neuss, Jason Kennedy, "Principal self-efficacy in the implementation of a standards based teacher evaluation reform." (2016).

Electronic Theses and Dissertations. Paper 2521.

https://doi.org/10.18297/etd/2521

This Doctoral Dissertation is brought to you for free and open access by ThinkIR: The University of Louisville's Institutional Repository. It has been accepted for inclusion in Electronic Theses and Dissertations by an authorized administrator of ThinkIR: The University of Louisville's Institutional Repository. This title appears here courtesy of the author, who has retained all other copyrights. For more information, please contact

thinkir@louisville.edu. 
PRINCIPAL SELF-EFFICACY IN THE IMPLEMENTATION OF A STANDARDS BASED TEACHER EVALUATION REFORM

\author{
By \\ Jason Kennedy Neuss \\ B.S., Western Kentucky University, 1997 \\ M.A., University of Louisville, 2009
}

\begin{abstract}
A Dissertation
Submitted to the Faculty of the

College of Education and Human Development of the University of Louisville in Partial Fulfillment of the Requirements

for the Degree of

Doctor of Education in Educational Leadership and Organizational Development

Department of Educational Leadership, Evaluation \& Organizational Development

University of Louisville

Louisville, Kentucky
\end{abstract}

August, 2016 



\title{
PRINCIPAL EFFICACY IN THE IMPLEMENTATION OF A STANDARDS BASED TEACHER EVALUATION REFORM
}

\author{
By \\ Jason Kennedy Neuss \\ B.S., Western Kentucky University, 1997 \\ M.A., University of Louisville, 2009 \\ A Dissertation Approved On \\ June 23, 2016 \\ by the following Dissertation Committee:
}

Dissertation Chair

Dr. Gaetane Jean-Marie

Committee Member

Dr. William Ingle

Committee Member

Dr. Jason Immekus

Committee Member

Dr. Judy Vanderhaar 


\section{DEDICATION}

This dissertation is for my parents who have supported me throughout my

educational career, for my wife who has withstood the life of a coach's wife and wife of a doctoral student, and for my boys who have unintentionally provided me with the greatest education of my life. For each of you, I am eternally grateful that your sacrifices afforded me the opportunity to grow as a practitioner and scholar. 


\section{ACKNOWLEDGMENTS}

I would like to acknowledge my dissertation committee for their willingness to both challenge and support me through this process. My chair, Dr. Gaetane Jean-Marie, has provided valuable feedback and encouragement over the course of the past year. She has challenged me to think differently and pushed me to stay focused at completing the dissertation. My committee, Dr. Gaetane Jean-Marie, Dr. William Ingle, Dr. Jason Immekus, and Dr. Judy Vanderhaar have improved this study immensely. Each was willing to provide numerous edits and suggested changes. Their efforts have challenged me to better understand the research process as both a means of extending the literature and improving our nation's schools. I am grateful for their investment in me as a scholar and practitioner. This process has been the most challenging yet enriching educational experience of my life.

Most importantly my wife, Eva, who has allowed me to pursue my personal and professional goals at the expense of hers. Her patience and support over the course of the past three years has been inspiring. For her I am eternally grateful. 


\title{
ABSTRACT \\ PRINCIPAL SELF-EFFICACY IN THE IMPLEMENTATION OF A STANDARDS BASED TEACHER EVALUATION REFORM
}

\author{
Jason Kennedy Neuss
}

June 23, 2016

States across the country are adopting new methods of determining teacher effectiveness. A method that has increased in popularity is the use of standards based teacher evaluation (SBTE). These systems are typically created by state legislation and approved for the scope of work associated with a state's Race to the Top (RTTT) application and federally approved Elementary and Secondary Education Act (ESEA) waiver application. The evaluation of teachers now relies on two key components - an administrator's rating of teacher performance and a rating of student academic growth. The enactment and implementation of teacher evaluation laws have changed the way administrators evaluate classroom instruction and are in direct contrast to previous evaluation systems in terms of format, timelines, measures, and opportunity costs incurred. One major concern is that although the method of evaluating teachers has changed, internal school infrastructures have not. Using Tschannen-Moran and Gareis (2004) measure of self-efficacy, this study will utilize multiple regression in order to determine how efficacious principals are with the implementation of a SBTE system and examine the relationship between school-related factors, principal characteristics, and principal efficacy in implementing SBTE. The results of this study have implications for 
the implementation of future reform efforts. Furthermore, it advances the existing literature on principal self-efficacy and teacher evaluation. 


\section{TABLE OF CONTENTS}

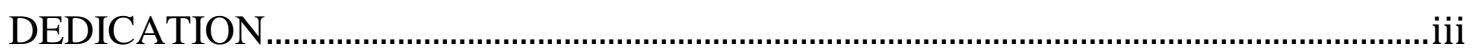

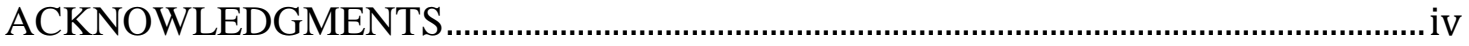

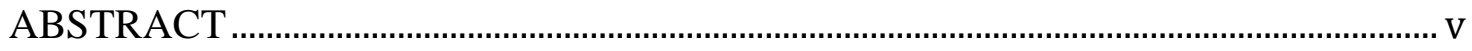

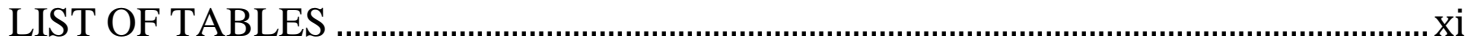

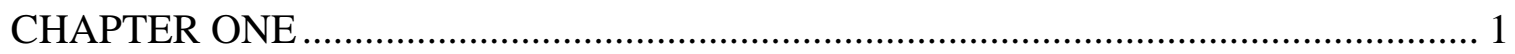

INTRODUCTION

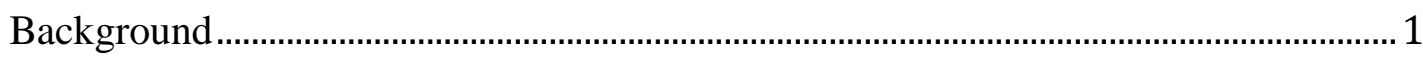

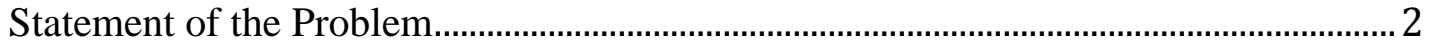

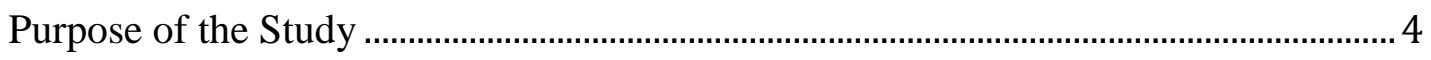

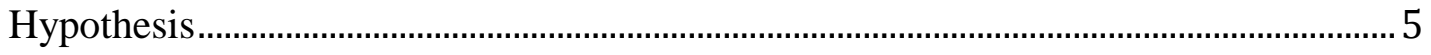

Hypothesis: Principal self-efficacy for Implementation of SBTE ........................ 5

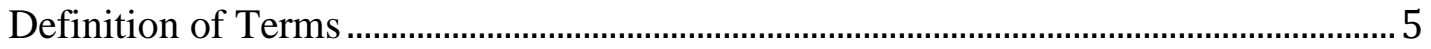

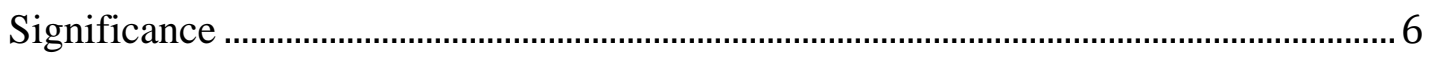

Delimitations

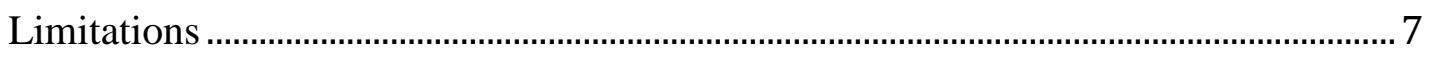

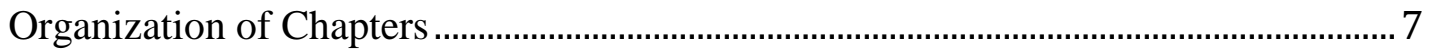

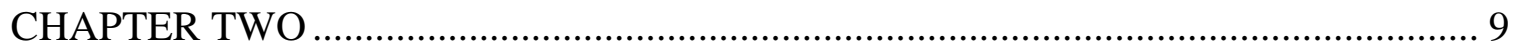

REVIEW OF LITERATURE

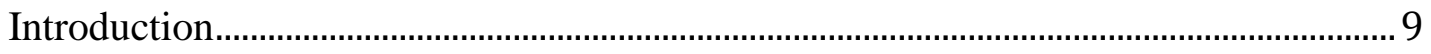

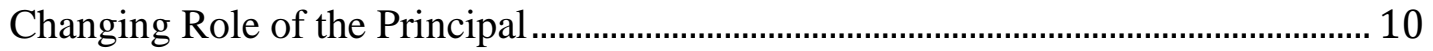




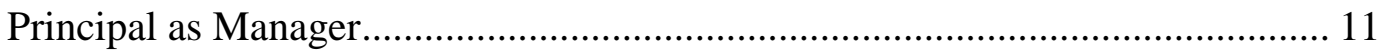

Principal as Instructional Leader ............................................................. 12

Principal as Transformational Leader .......................................................... 13

Instructional Reform to Increase Student Achievement ............................................... 15

Successful Implementation of School Based Instructional Reform ................... 19

Teacher Evaluation as a Reform Movement ........................................................................ 21

Purpose and History of Teacher Evaluation ................................................... 22

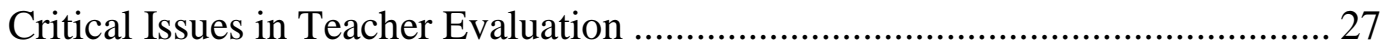

Ongoing Reform Efforts in Teacher Evaluation ......................................... 32

SBTE a Different Method of Measuring Teacher Effectiveness ......................... 33

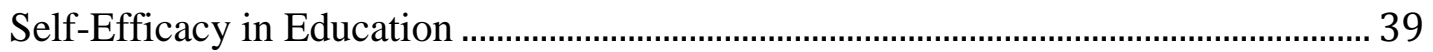

Measuring Self-Efficacy in Educational Settings ......................................... 42

Empirical Evidence on Principal Self-Efficacy ............................................. 46

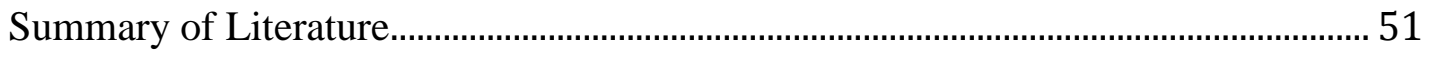

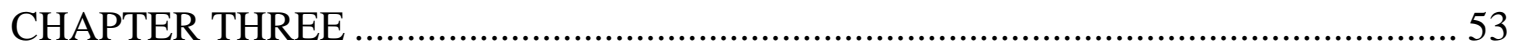

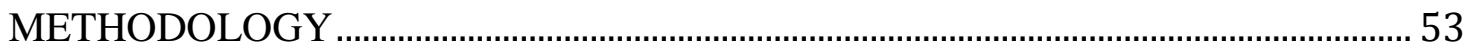

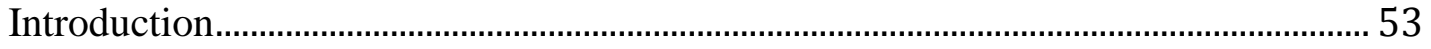

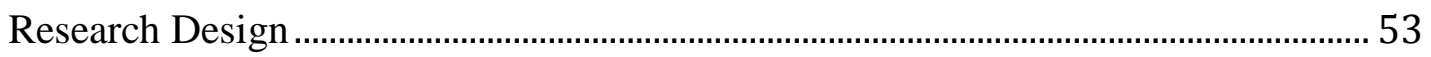

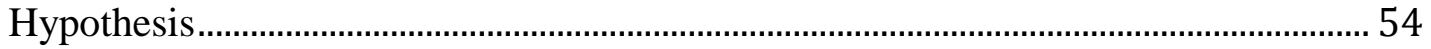

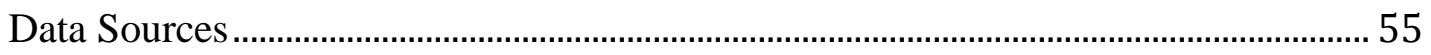

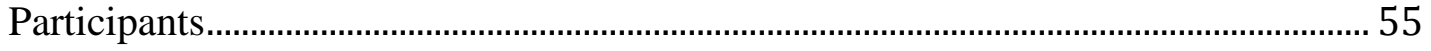

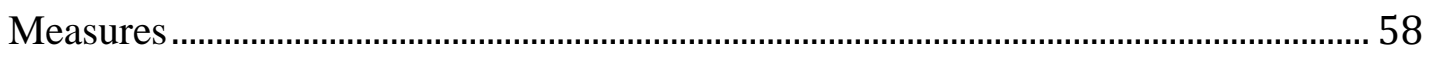

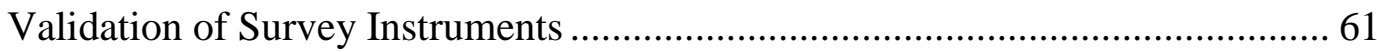




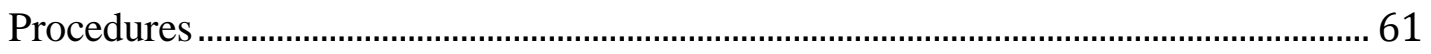

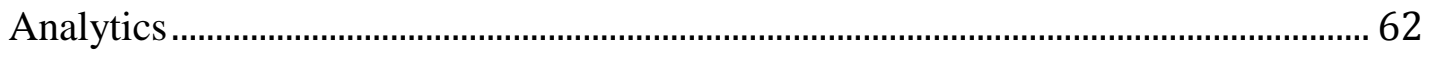

Methodological Limitations .................................................................................. 66

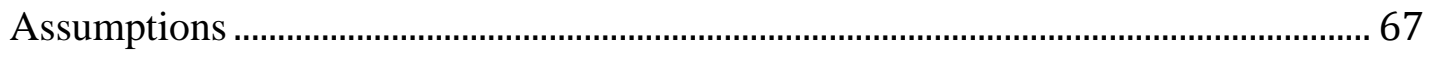

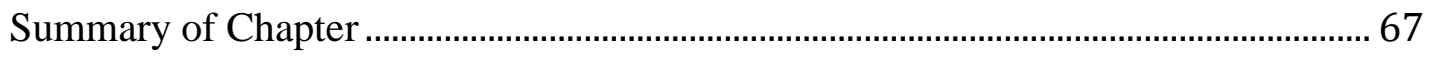

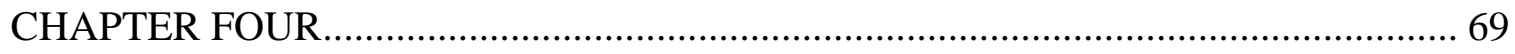

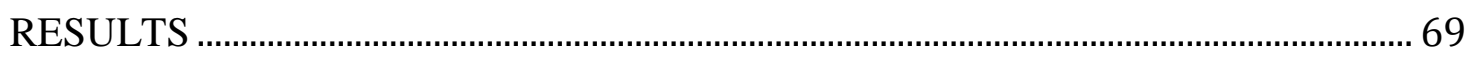

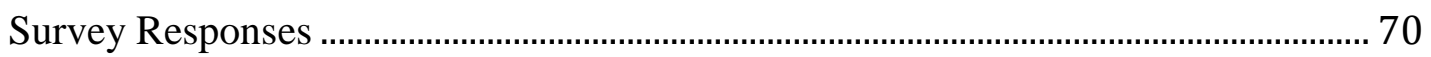

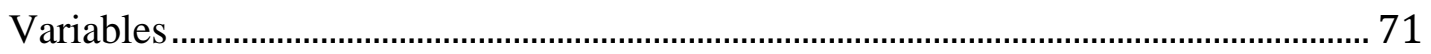

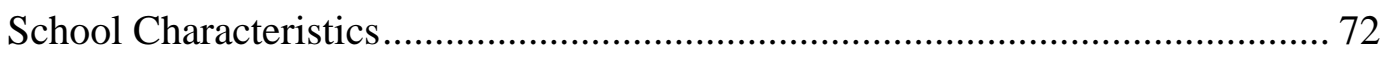

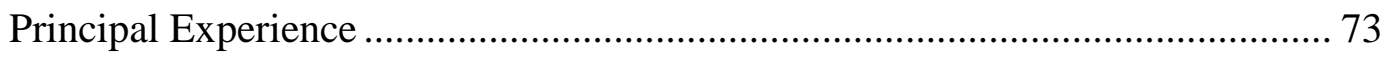

Principal Perception of SBTE ......................................................................... 74

Principal Sense of Self-efficacy Scale Results ………………………………...... 76

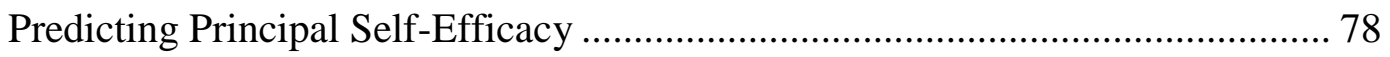

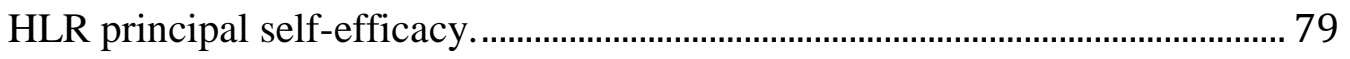

HLR principal self-efficacy for management..................................................... 80

HLR principal self-efficacy for instructional leadership.................................... 83

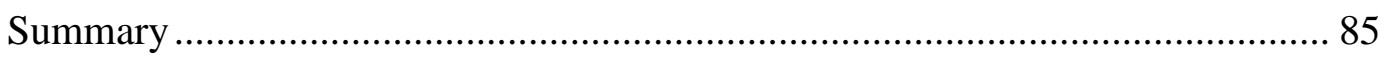

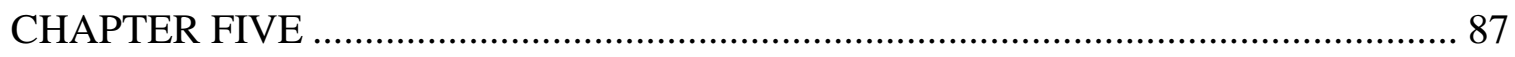

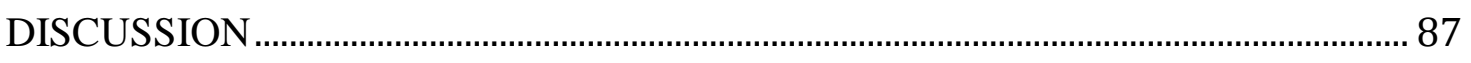

Summary of Results ................................................................................................. 89

Supporting Principal Implementation of SBTE ……………………………………. 90

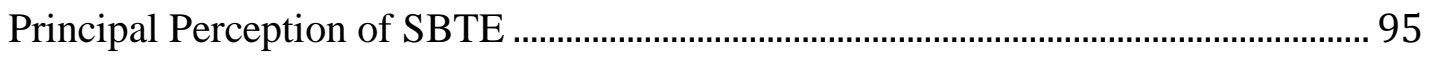


Principal Experience ……………………………………………………………….. 97

Implications for Practice and Policy...................................................................... 98

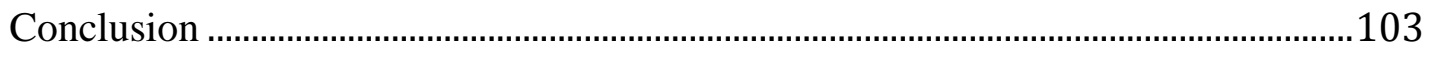

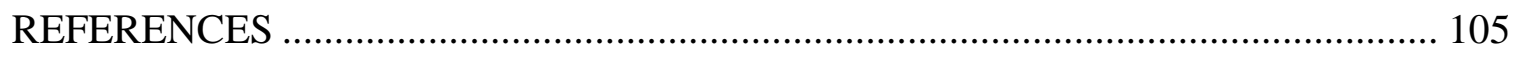

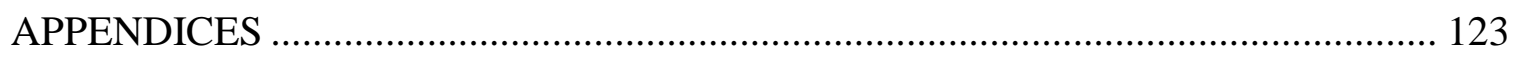

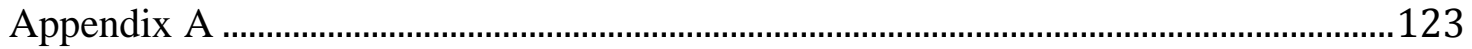

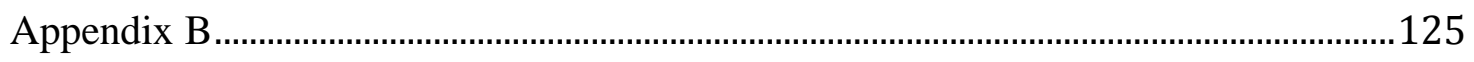

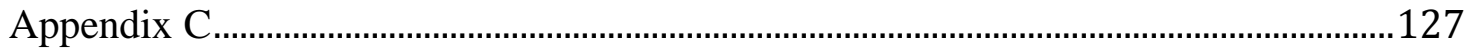

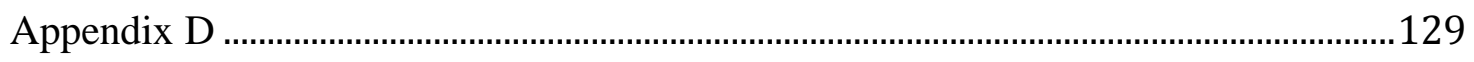

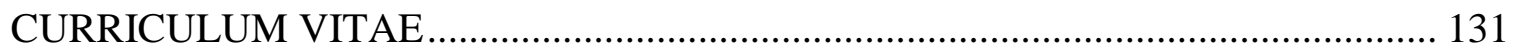




\section{LIST OF TABLES}

TABLE PAGE

1. Number of students scoring proficient or distinguished on state standardized assessments during the $2014-15$ school year ..................................56

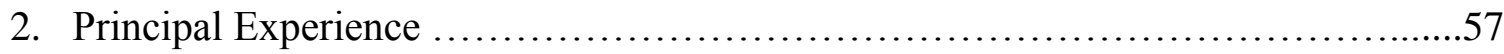

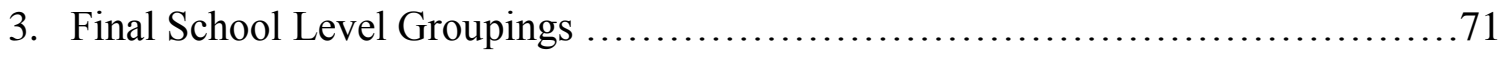

4. School Characteristics by School Level......................................73

5. Principal Experience..................................................... 74

6. Summative Scores for Principal Perceptions of SBTE $\ldots \ldots \ldots \ldots \ldots \ldots \ldots \ldots \ldots \ldots \ldots . . \ldots 5$

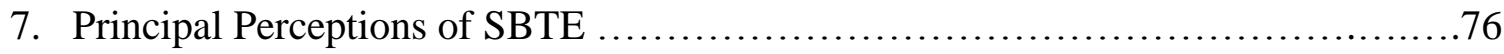

8. Principal Self-Efficacy.............................................. 77

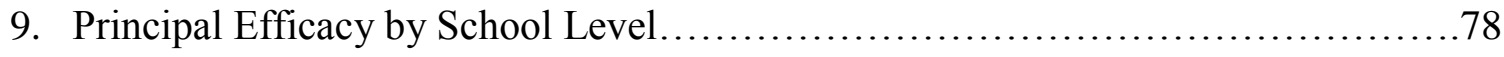

10. HLR Analysis Predicting Principal Self-Efficacy ............................... 80

11. HLR Analysis Predicting Principal Self-Efficacy for Management...................82

12. HLR Analysis Predicting Principal Self-Efficacy for Instructional Leadership.......84 


\section{CHAPTER ONE INTRODUCTION}

\section{Background}

Efforts to define and assess effective teaching are the result of increased accountability measures focused on student achievement. Research suggests the important role that effective teachers have on student learning (Darling-Hammond \& Ball, 1997; Hanushek, Kain, \& Rivkin, 1998; Haycock, 1998; Rockoff, 2004; Sanders \& Rivers, 1996; Stronge et al.,, 2011; Wright, Horn \& Sanders, 1997). Ensuring highly effective teachers are in every classroom requires a great deal of time and resources (Crum \& Sherman, 2008; Darling-Hammond, 2015; Ingle, 2015; Ingle, Willis, \& Fritz, 2015; May \& Supovitz, 2010). School leadership literature suggests that effective principals have the ability to improve a teacher's inquiry processes, reflection, exploration, experimentation, and ultimately what happens in the classroom (Blase \& Blase, 1999; Hallinger \& Heck, 1999; Louis, Leithwood, Wahlstrom, \& Anderson, 2010; Waters, Marzano \& McNulty, 2003; Young, Fuller, Brewer, Carpenter \& Mansfield, 2007). Principals' perceived ability to lead has been shown to correlate with school and classroom conditions, thus indirectly influencing student achievement and growth (Hallinger \& Heck, 2009; Leithwood \& Jantzi, 2008). Ensuring our nation's principals are prepared and efficacious in their ability to lead educational reforms is essential to creating a school culture focused on strong instructional practices. A critical piece of assessing and improving instruction is through the teacher evaluation process. 
Teacher quality and the use of teacher evaluation to improve our nation's schools is an important issue that has been at the center of federal educational reforms such as No Child Left Behind (NCLB), Race to the Top (RTTT) and the recently passed Every Student Succeeds Act (ESSA). A recent shift in the teacher evaluation process is the use of standards-based teacher evaluation (SBTE) systems (Murphy, Hallinger, \& Heck, 2013). In 2009, RTTT challenged states to revamp their teacher evaluation systems by offering financial incentives. In the two years following RTTT, nearly 31 states enacted teacher evaluation reforms (Umpstead, Pogodzinski, \& Lund, 2013). As a result, many states have turned to SBTE systems that incorporate multiple sources of evidence, including student achievement data, formal observations, and even student perceptions of his/her teachers' performance. SBTE systems seek to identify, measure, support, and develop instructional strategies that positively influence student achievement (Danielson $\&$ McGreal, 2000). Although teacher evaluation is recognized as fundamental to the effectiveness and efficiency of school districts (Young, 2008), there have been criticisms of the direction and form of teacher evaluation policies (Murphy, Hallinger \& Heck, 2013). Given the amount of time and resources devoted to the new evaluation system it is crucial that principals and teachers have a consistent understanding and appreciation for the process.

\section{Statement of the Problem}

SBTE systems changed the way administrators evaluate classroom instructional practices and in most cases are in direct contrast to previous evaluation systems, which focused heavily on teacher behaviors. Research on the implementation of SBTE reveals concerns with managing the additional tasks involved in the evaluation process and the 
training to become a certified evaluator (Dodson, 2015). With principals having a great deal of influence on the individuals in schools (Hallinger \& Heck, 1998) and in policy implementation, (Tuytens \& Devos, 2010; Vekeman, Devos, \& Tuytens, 2014) understanding principal self-efficacy for the implementation of SBTE becomes important to how they are prepared and supported throughout the process.

In large urban districts the variation among schools and the experience levels of principals provide challenges for district officials as they design training and professional development for the implementation of system-wide reforms. These challenges pose a concern as implementation research suggests how an individual makes sense of, and uses policy can significantly determine the outcome of the changes that take place in schools (Desimone, 2002; Spillane, Reiser \& Reimer, 2002). One major concern is that although the method of evaluating teachers has changed, internal school infrastructures have not. Countering these concerns will require principals to be efficacious in their planning and preparation for the rollout of the new system.

Little is known about principals' perceptions of their role and how it relates to successful school conditions (Urick \& Bowers, 2011). Despite the important role principals play in carrying out educational policy, current research on the role of the principal when implementing teacher evaluation (Tuytens \& Devos, 2010; Vekeman, Devos, Tuytens, 2014) and their perception of teacher evaluation is limited (Derrington \& Campbell, 2015; Jiang, Sporte \& Luppescu, 2015). Though an extensive body of research on self-efficacy is available in the existing research literature (e.g., Bandura, 1986, 2001; Goddard, 2001; McCormick, 2001; Pearlmutter, 1998), there is a lack of research studies that examine principal self-efficacy (PSE) during an instructional reform (Leithwood \& 
Jantzi, 2008; Tschannen-Moran \& Gareis, 2004). It is from this gap that the current analysis will attempt to provide a better understanding of principal self-efficacy during a system wide reform in evaluation. Because a significant amount of funding has been allocated to the new evaluation system, districts, and individual schools cannot afford to be ineffective with the implementation and support they provide.

\section{Purpose of the Study}

This study seeks to examine how efficacious principals are with the implementation of SBTE and further looks to examine the relationship between school related factors, principal perception of teacher evaluation, principal experience, and principal efficacy. To address the current gap in the literature and answer the research questions I will first identify the level of principal self-efficacy for the implementation of

SBTE. I will then identify principal perceptions of SBTE. Determining whether principal self-efficacy during the implementation of SBTE is directly related to school factors, principal experience, and perception of teacher evaluation will have implications for professional development, school based supports, and the implementation of future system wide reforms. Furthermore, it will serve as a starting point to address concerns with leadership preparation programs (Young et al., 2007).

\section{Research Question}

Through the study, I seek to examine the relationship between school related factors, principal experience, principal perception of teacher evaluation, and principal self-efficacy in the implementation of SBTE. The following research question will guide the study: to what extent does school characteristics and principal experience, and perception of teacher evaluation predict self-efficacy for SBTE implementation? 


\section{Hypothesis}

The following are the hypotheses regarding the primary question that guides the study:

Hypothesis: Principal self-efficacy for Implementation of SBTE

- Principal experience, perception of teacher evaluation, and school related factors will predict principal self-efficacy for SBTE implementation.

- Null $\left(\mathrm{H}_{0}\right)$ - principal experience, perception of teacher evaluation, and school related factors are not predictors of principal self-efficacy for SBTE implementation.

- Alternative $\left(\mathrm{H}_{1}\right)$ - principal experience, perception of teacher evaluation, and school related factors are predictors of principal self-efficacy for SBTE implementation.

\section{Definition of Terms}

The following terms are used in this study:

Annual Measurable Objective (AMO): The Kentucky Department of Education defines AMO as how much improvement a school needs to reach the ultimate goal of 100. AMO scores as based on multiple measures and determine the schools category of Distinguished, Proficient, or Needs Improvement.

Implementation: For the purpose of this study, implementation will refer to the execution of the plan and support of teachers with the new teacher evaluation system. Principal Self-Efficacy: Refers to the principal's belief in his/her capacity to execute behaviors necessary to produce specific performance attainments (Tschannen-Moran \& Gareis, 2004). 
Standards Based Teacher Evaluation (SBTE): A method of teacher evaluation that uses multiple measures of teacher effectiveness including value added model, student voice, peer observation, and principal observation to determine teacher effectiveness (Danielson, 1996).

Self-Efficacy: Refers to an individual's belief in his/her capacity to execute behaviors necessary to produce specific performance attainments (Bandura, 1977).

\section{Significance}

This study utilizes hierarchical multiple linear regression to test the ways school characteristics and principal experience, and perception of SBTE predict self-efficacy for SBTE implementation. The results provide extensions of Social Cognitive and SelfEfficacy Theory as well as useful implications for policy and practice. It adds to the limited research on principal self-efficacy for the implementation of school based reform efforts and provides a foundation to follow up on previous research looking at the link between standards based teacher evaluation scores and student achievement (Borman \& Kimball, 2005; Milanowski, Kimball \& White, 2004). Educational leaders, school administrators, and principal preparation programs will be able to use the results to guide professional development, internal school supports, and training to allow for consistent implementation of future instructional reforms in the district studied.

\section{Delimitations}

The delimitation of this study is the sample of principals and the timeline used to collect data. The schools in this study are from one urban district in the Southeastern U.S. and should be interpreted with caution when attempting to generalize to other schools. The second delimitation is with the timeline used to collect the data. The data 
collection process took place following the second round of observations, and as such, did not provide principal perceptions of SBTE following the end of year summative evaluations.

\section{Limitations}

The nature of this study has several limiting factors. The limitations in this study include the researcher's positionality, the use of a modified survey instrument, and the use of self-reporting. The researcher is a current evaluating administrator in the district being studied and is therefore familiar with many of the participants. To address this concern the researcher built safeguards into the instructions by assuring respondents that all identifying information would be removed and responses presented in the aggregate. The second limitation is the use of a modified survey instrument. Although the original survey instrument (Principal Sense of Efficacy Scale) was previously validated, it did not clearly answer the research question and required additional words or phrases. As a result the measure was subjected to a review by evaluating administrators in the district who checked for clarity and consistency with the instrument. Another limitation is the use of self-reporting. In an era of accountability principals may be hesitant to provide an accurate representation or assessment of their level of efficacy for fear of negative perceptions. As such it is possible that principals may intentionally rate themselves higher to inflate their overall score.

\section{Organization of Chapters}

This dissertation follows a traditional structure. This chapter provided an introduction to the topic of principal self-efficacy and the implementation of a reform in the teacher evaluation system. The remaining chapters of this study will be organized as 
follows: Chapter 2 will present a review of relevant literature on the changing role of the principal, transitioning to standards based teacher evaluation systems, implementation of instructional reforms, and self-efficacy. Chapter 3 will identify and explain the research design methodology, instrumentation, data collection procedures, and the statistical procedures used to analyze the data. Chapter 4 will present the study's results and analysis of the data. Finally, Chapter 5 will summarize the major results and include recommendations for future research. 


\section{CHAPTER TWO \\ REVIEW OF LITERATURE}

\section{Introduction}

Efforts to improve teacher quality through educational reforms have become increasingly common in light of the high stakes accountability era surrounding public education. Research suggests a direct relationship between teacher quality and increased student learning (Darling-Hammond \& Ball, 1997; Darling-Hammond, 2000; Hanushek, Kain, \& Rivkin, 1998; Rockoff, 2004; Sanders \& Rivers, 1996; Stronge, Ward \& Grant, 2011; Wright, Horn \& Sanders, 1997). This relationship places greater emphasis on teacher quality and is likely the result of accountability measures focused on student outcomes. One reform effort aimed at improving teacher quality is the implementation of standards based teacher evaluation (SBTE) systems. With the tremendous amount of resources being spent on these evaluation systems some question the need to reallocate the already strained school resources (Hallinger, Heck \& Murphy, 2014).

Regardless of one's opinion on the purpose and effectiveness of teacher evaluation, states and school districts are rushing to implement SBTE systems in hopes of improved student outcomes (Umpstead, Pogodzinski \& Lund, 2013). It is unclear, however, what supports have been put in place for the principals tasked with rolling out the new system in their buildings. In this literature review, the analysis focuses on the following areas: changing role of the principal, instructional reform efforts, the evolution of teacher evaluation to a standards based approach, and principal self-efficacy. While a 
brief historical explanation for the role of the principal and teacher evaluation is needed to frame the changing educational landscape, the primary focus will be to illustrate the role the principal has in shaping classroom instruction, and the importance of being efficacious in his/her ability to implement an evaluation reform in a large urban school district.

\section{Changing Role of the Principal}

The role of the building principal has changed dramatically since the inception of the one room schoolhouse. Goodwin, Cunningham, and Childress (2003) suggest leadership styles and the role of building leaders have transitioned from administrative manager, instructional leader, to the more recent idea of transformational leader. Furthermore, they assert this shift is likely due to the change in expectations, accountability, and responsibility. As high stakes accountability increases, principals' roles have expanded beyond that of manager and instructional leader to a transformational leader (Goodwin, Cunningham \& Childress, 2003; Hallinger, 1992; 2003). While Hallinger (2003) argues the definitions of instructional and transformational leadership styles have become less clear. I will argue that accountability measures have forced principals to move away from being the sole person responsible for the schools instructional program to creating a shared vision among stakeholders through a transformational leadership approach.

In this section, I provide a historical perspective on the changing role of the principal and how the increased demands placed on schools have resulted in shifting leadership approaches. Effective leaders understand that in order to be successful they must utilize their staff in a variety of leadership capacities through a distributed approach 
(Spillane, Halverson \& Diamond, 2004). Further, research has shown the direct and indirect influence principals have on teaching and learning (Brewer, 1993; Louis, Leithwood, Wahlstrom, \& Anderson, 2010; Sebastian \& Allensworth, 2012). Principals' effectiveness in improving classroom instructional practices will likely see increased student outcomes. With school accountability measures tied heavily to student achievement, principals' must find the time to support and develop their teachers.

\section{Principal as Manager}

From the 1920 's to 1970 's principals were primarily viewed as administrative managers tasked with maintaining an orderly environment (Valentine \& Prater, 2011). The principal was expected to be a consistent, assertive disciplinarian that removed behavioral obstacles. Their indirect impact on student achievement was experienced from ensuring smooth operation of daily procedures and supporting teachers with discipline (Brewer, 1993). It was not until the fallout of the societal changes in the 1960's and 1970 's that a scathing report suggesting the educational system in our country was failing that principals stepped into more of an instructional role.

The 1983 publication of A Nation at Risk challenged both educators and educational reformers to look at the issues facing public schools in America. Despite its surface level analysis of educational data, the widely publicized report was a wakeup call to Americans that our public schools are failing and if not repaired will ultimately threaten our nation's future. Regardless of the reports accuracy, it "has vastly enhanced federal government presence in American education" (Guthrie \& Springer, 2004, p. 7). It was during this time that instructional leadership models began to emerge (Hallinger, 2003). In his review of leadership roles for principals, Hallinger (2003) asserts that 
leadership is contextual and dependent on the needs of the building. This becomes increasingly important given the evolving role of principals due to increased pressure from both federal and state policy. Further, the managerial leadership of principals is limited in scope without an examination of instructional and transformational leadership to examine how the leader interacts with followers.

\section{Principal as Instructional Leader}

The top down leadership approach practiced in the 1980s and 1990s saw a greater focus by principals on curriculum and instruction (Bamburg \& Andres, 1991; Hallinger $\&$ Murphy, 1985). This focus on curriculum and instruction is not without its limitations considering the diverse roles and responsibilities of school principals. Hallinger and Murphy (2013) suggest the idea of effective instructional leadership "will remain the domain of a few extraordinary individuals who are able to overcome the odds in order to produce a positive impact on teaching and learning" (p. 12). While the instructional leadership approach placed the principal as the sole expert and authority over classroom instruction, it was a completely different leadership style that would change the role of the principal as they moved in to the NCLB years.

The next big shift in the role of the principal began in the years surrounding the enactment of No Child Left Behind (NCLB). In 2001 President George W. Bush took a bold step to ensure all students received a quality education from highly trained and qualified teachers. NCLB was a standards based educational reform, focused on raising the expectations for all students in an attempt at improving educational outcomes. A primary focus of NCLB was teacher quality and school accountability. NCLB forced schools into a data driven educational model by placing a great deal of emphasis on 
assessment scores. This emphasis on student outcomes challenged principals into more of transformational leadership approach utilizing a variety of stakeholders to accomplish a shared vision.

\section{Principal as Transformational Leader}

Hallinger (2003) identifies transformational leadership as one that seeks to build or increase the capacity of others and "focuses on developing the organization's capacity to innovate" (p. 330). This method of leading schools moves completely away from the top down approach and views the principal as the individual responsible for increasing the schools capacity to accomplish a shared vision. Geijsel et al., (2003) found transformational leadership affect both teacher commitment and effort. Furthermore, the effects of vision building and intellectual stimulation were found to be particularly significant. The findings by Geijsel et al., (2003) become increasingly important to the findings by Hallinger (2003) who explains that principals able to garner high levels of commitment perform at higher levels. This suggests transformational leadership will allow for higher performing and committed teachers. Despite concerns with generalizability of Geijsel et al., (2003) to urban education in the United States, the findings are particularly noteworthy to the present study as schools look to implement standards based teacher evaluation systems that include multiple components of assessing teacher effectiveness.

A critical component of transformational leadership is the development of the staff through what Hallinger (2003) identifies as a bottom up approach. Leithwood, Harris, and Hopkins (2008) provide support of this approach by indicating "school leadership has a greater influence on schools and students when it is distributed" (p. 27). 
Distributed leadership is a practice of which responsibilities are distributed to leaders, followers, and their situation (Spillane, Halverson \& Diamond, 2004). Heck and Hallinger (2009) support the idea that some leadership needs to be distributed, but fail to offer suggestions as to which and how practices should be distributed. Distributed leadership is a necessary component of the transformational approach to school improvement and is a direct result of the increased pressures placed on the building leaders. Because, as Hallinger (2003) suggests, leadership is largely contextual, how principals use their staff to accomplish a shared vision is shaped by the accountability measures driving school policy.

Marks and Printy (2003) offer the idea that principals may simultaneously fall into more than one than one leadership style. The authors utilize survey and interview data to determine leadership styles. Scatterplot analysis and hierarchical linear modeling were used to examine the variance in leadership styles. Marks and Printy (2003) concluded instructional and transformational leadership styles are intertwined into what the authors term an integrated leadership approach. Further, the authors found teaching quality was higher in schools with integrated leadership. Urick and Bowers (2014) used Latent Class Analysis (LCA) to test the results of Marks and Printy (2003) by using a national sample of 7,650 principals. Results confirm those of Marks and Printy (2003) providing support to the idea that leadership types are multidimensional. Further, Urick and Bowers (2014) suggest principal and school characteristics help predict leadership style. These results are particularly important for school districts looking identify and match principal candidates for specific schools. 
Years of educational reform efforts resulted in NCLB, Race to the Top (RTTT), and the Every Student Succeeds Act (ESSA) policies that have drastically changed the role of the principal and how teachers are evaluated. If principals are to be successful instructional leaders they must be able to communicate their intentions through a shared vision. The concern with communicating and implementing the shared vision is that the number of tasks, demands, and responsibilities placed on the principal have reduced the time available to successfully lead and evaluate teachers (Hallinger \& Murphy, 2013; Crum \& Sherman, 2008; May \& Supovitz, 2010). With funding and possible school sanctions tied to these federal policies, failure is out of the question. Despite research indicating the shortcomings of NCLB and AYP guidelines as accurate measures of school progress (Balfanz et al., 2007) federal and state legislation is not likely to go away.

The pressure for schools and districts to make continual growth have not only increased the demands placed on principals but have challenged them to adapt leadership practices better meeting the needs of their students. With the increased demands placed on principals and the many hats they wear throughout the day, carving out the time to successfully implement school based reforms may prove to be a monumental task. The above paragraphs illustrate how the role of the principal has changed from manager, instructional leader, and the recent concept of transformational leader. Federal policy however, has challenged principals to merge all three roles as they look to improve student outcomes and avoid sanctions.

\section{Instructional Reform to Increase Student Achievement}

The landscape of education has changed dramatically over the course of the past 30 years. NCLB, RTTT, and ESSA have changed the expectations for teacher quality 
and forced schools into a data driven accountability model. This focus on student outcomes challenged principals to reform instructional practices throughout their buildings. Leadership literature suggests principals shape the school environment through their work with teachers and students (Hallinger \& Heck, 1996; Murphy, Elliott, Goldring \& Porter, 2007; Seashore Louis, Leithwood, Wahlstrom, Anderson, 2010). Implementing school wide reforms is no easy task, as teachers may be reluctant to change (Payne, 2008; Ravitch, 2001; Tyack \& Cuban, 1995; Tyack \& Tobin, 1994). Labaree (1997) purports some of this reluctance may be the result of an unclear understanding of the purpose of education. Payne (2008), on the other hand, offers the idea that the lack of clarity is at the school level and that challenges with implementing reform often come from an unclear understanding of the instructional program and the role the teachers play in its implementation. The purpose of this section is to identify the efforts to improve teacher quality, the barriers to implementing teacher quality reform, and identifying successful implementation of school based reform efforts.

Efforts to improve the quality of teaching are the result of federal policy placing increased pressure on schools to make continual growth or risk facing harsh sanctions. As indicated above, changing traditional school systems has proven to be a difficult task. Tyack and Tobin (1994) provide a historical perspective on the challenges faced when making significant changes to traditional school systems. The authors discuss how educators are so ingrained in the traditional sense of education that they are reluctant to change and suggest, “organizational patterns that shape instruction are not ahistorical creations etched in stone. They are the historical product of particular groups with particular interests and values at particular times” (p. 476). Tyack and Tobin's (1994) 
views support the idea that federal policy and personal interests play a key role in efforts to improve the quality of teaching in our nations' schools. From this perspective context and intended outcomes become a major factor in reform efforts aimed at improving teacher quality. Hanushek and Rivkin (2006) suggest often times policy recommendations ignore labor market trends such as salary, distribution of teachers and characteristics of effective teachers. This blanket attempt at improving teacher quality may actually create more issues as it does not take into account the variation and unique needs of individual districts and schools. More importantly how teacher quality is measured becomes a one size fits all model ignoring the differences in school size and student population.

Understanding characteristics of quality teaching has led researchers to examine the relationship between teacher experience, certification, subject matter knowledge and knowledge of teaching and learning. While the findings on subject matter knowledge and student achievement have mixed results (Hashweh, 1987; Monk \& King, 1994), knowledge of teaching and learning have a much stronger relationship to student achievement (Ashton \& Crocker, 1987). In her policy analysis of teacher reform and student achievement, Darling-Hammond (2000) used both quantitative and qualitative measures of teacher quality and school inputs to identify policies related to positive student achievement. Darling-Hammond (2000) suggests that schools and districts looking to improve teaching should pay particular attention to policy investments, teacher preparation, and teacher certification. Furthermore, the "effects of well-prepared teachers on student achievement can be stronger than the influences on student background factors, such as poverty, language background, and minority status" (p. 33). If well- 
prepared teachers are the driving force behind student achievement gains, principals must begin focusing their attention to how this can be done within the context of their schools. Much of the challenge with implementing school based reforms is the learning process associated with putting externally mandated policies and procedures into place (Derrington \& Campbell, 2015). Successful reform efforts can take several years to see results, and in today's fast paced society many people are not willing to put the time and effort into understanding what they are doing and why they are doing it. Fullan (1992) offers seven reasons school based reforms fail to include; an unclear direction, complex problems, a focus on symbols rather than substance, impatience, a misunderstanding of the resistance, attrition of pockets of success, and a murky understanding of the change process. Payne (2008) offers yet another perspective in that schools have misguided efforts and are focused on too many initiatives. These findings suggest principals interested in initiating school wide reforms in instruction should focus their attention on excelling at one or two approaches at most. Additional challenges with school based reforms include changing the mindset of teachers and ensuring schools implement the program as its designers intended.

Changing the attitude of teachers can be one of the greatest hurdles to successful implementation of school based reforms. Challenging traditional school systems begins with changing the mindset of the classroom teachers tasked with implementing the reform. In their 1995 book, Tinkering with Utopia, Tyack and Cuban suggest teachers and students are socialized into school routines and often find it difficult to adapt to the changes. Changing traditional practices alter the systems and structures that teachers, and their students are familiar with. Often times this fear of the unknown is the cause for 
resistance. A second barrier to successful reform implementation is the idea that schools change reforms to meet their individual needs. Often times this counters the reformers intended implementation strategy and creates frustration when intended outcomes are not met. Keedy (2005) suggests that this is largely due to the divide between theory and practice. Understanding the above mentioned challenges will allow practitioners the opportunity to develop plans for the successful implementation of school based reforms.

\section{Successful Implementation of School Based Instructional Reform}

School reform affects all aspects of the school setting including the culture and climate within the building. Fowler (2009) offers that successful reform implementation is dependent on both the capacity and motivation of the principal. If practitioners are to successfully implement school based reforms they must not only understand the reasons for reform failures, but identify the characteristics of successful efforts. Despite challenges with implementing school based reforms several examples of successful implementation are available. In their qualitative analysis of high school reform implementation, White-Smith and White (2009) purport that principal perceptions of the reform itself is directly related to successful implementation. White-Smith and White (2009) conducted a case study analysis to examine principal perceptions during the first year of a reform implementation. The authors suggests that significant change can only occur if the principal is willing to push against engrained assumptions and reconceptualize change to transform traditional belief systems.

In describing activities used in the state of Florida to ensure quality implementation practices, Little (2003) identifies a process that includes identifying student needs and developing a research based plan which includes input from a variety 
of stakeholders. One such reform that has experienced success is the Comprehensive School Reform (CSR) model (Borman et al., 2003). In a meta-analysis of 29 different CSR models Borman et al., (2003) found that while outcomes varied by models, several experienced significant gains in student achievement. Despite the relatively low effect sizes of .09 to .15, Borman et al., suggest that CSR models benefit student achievement in both high poverty and advantaged contexts. An important piece to the results by Borman et al., (2003) is with the implementation components of CSR models identifying coherence and the use of scientifically based practices. While CSR models tend to counter the suggested practices of Payne (2008), that implementation should focus on a few key items, they are aligned with the best practices offered by Fullan (1992).

The above research suggests successful reform implementation requires strong communication to all stakeholders. A critical piece of communicating to stakeholders is understanding their perception of the reform and the process used for implementation. Clipa (2011) conducted a quantitative analysis outside the United States and found significant positive correlations between a teacher's age and length of service in education and their perception of teacher evaluation as a means of assessing teacher professionalism. Interestingly, Clipa (2011) found that if given the option teachers chose to be evaluated by someone outside their current school. The results suggest that the teachers perceive their current evaluators as ineffective in assessing teacher professionalism. Tuytens and Devos (2009) used Fullan's (2001) policy implementation theory to measure teacher perceptions about organizational change. Tuytens and Devos (2009) found that teachers were fairly positive about the new teacher evaluation policy but that there were concerns related to how the school was implementing the policy. The 
overall positive perception of teacher evaluation was also found by Jiang, Sporte, and Luppescu (2015) in their study on teacher evaluation implementation in Chicago Public Schools. The results from Clipa (2011), Jiange, Sporte, and Luppescu (2015), and Tyten and Devos (2009) suggest that understanding teacher perception of new policy is important to the success of the implementation.

Change in the school setting can be a daunting task for today's principals. With the ever growing list of tasks and the pressure to make continual growth in all aspects of the school, principals must communicate a clear purpose and direction for reform efforts. Payne (2008) urges caution and suggests that "poor implementation is harmful not just to the particular teachers and students who are immediately involved; it also undermines the idea that change is possible" (p. 155). The research suggests that for reform efforts to be successful they must use research based practices, be coherently aligned, and effectively communicated to all stakeholders (Borman et al., 2003; Little, 2003). When looking specifically at implementing teacher evaluation systems Halverson, Kelley and Kimball (2004) suggest that the principals understanding of their role and the evaluation system itself directly influenced implementation. The findings in this section become increasingly important in considering self-efficacy beliefs of principals during the implementation of a reform initiative such as teacher evaluation.

\section{Teacher Evaluation as a Reform Movement}

Over the course of the past century both the procedure and purpose of teacher evaluations have changed from supervisory to a method of determining teacher effectiveness (Ellett \& Teddlie, 2003). Much like the changing role of the principal, teacher evaluations have evolved to address the increased expectations placed on public 
schools (Hazi \& Rucinski, 2009). A recent shift in determining teacher effectiveness is through a SBTE system (Milanowski \& Heneman, 2001). SBTE differs from previous methods of evaluation as they use multiple sources of data to determine teacher effectiveness such as principal and peer observation, student growth and in some cases student perception of teacher performance.

A critical component of SBTE is in defining the characteristics of highly effective teachers. In order to understand how states have moved to a standards-based evaluation system it is important to understand the evolution of teacher evaluation. In the section that follows, a brief history of teacher evaluation is provided along with the reports and federal policies, such as A Nation at Risk, NCLB, RTTT, and ESSA that helped shape what we define as effective teaching. Additionally, a review of empirical research provides evidence on teacher effectiveness and identify the relationship between standards based teacher evaluation scores and student achievement.

\section{Purpose and History of Teacher Evaluation}

The purpose of many teacher evaluations in the late $19^{\text {th }}$ and early $20^{\text {th }}$ century was on supervising an untrained workforce and inspecting facilities and equipment (Hazi \& Rucinski, 2005). Much of what is recognized as teacher evaluation today began with the 1920's progressive movement. An influential figure during this time was William O'Shea, whose work in in New York City Public Schools changed the way teachers were evaluated (Cuban, 1993). His system of evaluating teachers in five separate areas as "satisfactory" or "unsatisfactory" included an observation and post observation meeting in which the teacher received feedback on the observed lesson. Much of the issue with this approach was that it forced teachers to deliver instruction that met the expectations of 
the evaluating administrator. Despite teacher concerns with the process and the scripted nature of the evaluation, O'Shea certainly opened the door for determining teacher effectiveness.

With teacher evaluation methods relatively unchanged in the post war era, the 1950 's to 1960 's saw a shift from progressivism to more of a scientific management approach of efficiency and productivity (Ellett \& Teddlie, 2003). This scientific, social efficiency approach saw checklists and rating scales become common practice in teacher evaluations. Much of this can be attributed to the Soviet launching of Sputnik and the creation of federally funded competency based teacher education programs (CBTE). CBTE programs were aimed at defining quantifiable teacher specific competencies (Bowles, 1973). This shift provided an opportunity for educational researchers to begin looking at the relationship between teacher behavior and student outcomes; additionally it allowed for determining teacher effectiveness and how that could be conceptualized (Ellett \& Teddlie, 2003). As a result of the research on teacher effectiveness the focus then moved to identifying how teachers "demonstrate competency to perform in a way that an effective teacher performs" (Medley, 1977, p. 13).

The 1983 publication of A Nation at Risk forced the country into an accountability mode of determining teacher effectiveness and ultimately reshaping the teacher evaluation process altogether. The years leading up to the National Commission on Excellence in Education's examination of the quality of education in the United States were a trying time. The report benefited from the emotional stress of the previous decades and struck a chord with the American population as a call to action, prompting many states to enact teacher evaluation systems (Furtwengler, 1995). The commission's 
report brought to light an inadequate teacher preparation system and decline in standardized assessment scores. The report also recommended that "salary, promotion, tenure, and retention decisions should be tied to an effective evaluation system that includes peer review so that superior teachers can be rewarded, average ones encouraged, and poor ones either improved or terminated" (Gardner, 1983, p. 30). As a result of the report's recommendations, states rushed to enact legislation regarding teacher evaluation policy.

A study of educational policy from 1983-1992 found that following the publication of A Nation at Risk twenty states enacted their first requirements for the evaluation of teachers (Furtwengler, 1995). Furtwengler (1995) concluded that the 1980 's reform movement was one of accountability and increased professionalism in teaching. Despite this essential step towards improving the nation's teachers and schools through policy, concerns regarding their potential impact still existed. Veir and Dagley (2002), examined the impact of state statutes on teacher evaluation and found the criteria for evaluating teaching and teacher effectiveness inconsistent and lacking the strength to hold up in court when looking at teacher punishment or dismissal. As a result of their analysis, they provided recommendations for future legislation to include consistent language, a clearly stated purpose and timelines, and differentiate between formative and summative processes. While enacting legislation regarding teacher evaluation is an essential component to improving America's schools, if districts are not able to hold teachers accountable it may be a wasted effort. The legislation passed in the 1980's1990's not only paved the way for determining teacher effectiveness but also catapulted the country into a data driven accountability model requiring all core teachers be highly 
qualified in the subjects they teach.

The 2001 No Child Left Behind Act was a reauthorization of the 1965 Elementary and Secondary Education Act and hold schools accountable for the educational outcomes for all students by requiring states to report data by poverty, race, ethnicity, disability and limited English proficiency (NCLB, 2001). A critical component of NCLB was the requirement that all core teachers be "highly qualified" in the subjects they teach. This intervention was intended to counter a major concern in America's public schools that students of poverty and color are more likely to be taught by inexperienced and under qualified teachers (Borman \& Kimball, 2005; Darling-Hammond \& Berry, 2006). NCLB defines highly qualified as holding full certification, a bachelor's degree, and demonstrated competence in subject knowledge and teaching (NCLB, 2001). NCLB's insistence on highly qualified teachers in every classroom by the end of the 2005-2006 school year again forced states and local districts to rethink teacher evaluation, effectiveness, and accountability.

This NCLB focus is evident in the 2002 National Governors Association (NGA) report suggesting the six strategies to improving teacher evaluation were to; define teacher quality, focus evaluation policy on improving teaching practices, incorporate student learning into teacher evaluation, create professional accountability through developing career ladders, train evaluators in pre-service programs, and broaden participation in evaluation design (Goldrick, 2002). The six strategies approached teacher evaluation as a means of addressing instructional practices to improve student outcomes. An in-depth look at the first three NGA suggestions (define teacher quality, focus evaluation policy on improving teaching practices, and incorporate student learning 
into teacher evaluation) shows a major shift in measuring teacher quality and effectiveness through student outcomes. Hazi and Rucinski (2009) explain the majority of states adopting the NGA strategies emphasized more oversight and involvement in local evaluation practices and increased the data used in teacher evaluations.

A second essential element of NCLB was the insistence that schools make adequate yearly progress (AYP). AYP was a method of determining how every public school and district was progressing based on a number of factors, including standardized assessment scores (NCLB, 2001). The push for schools to meet AYP goals placed increased importance on student results. Valli and Buese (2007) found that in the post NCLB years the number and scope of teacher tasks increased even more hierarchically controlled. Therefore, teachers are asked to do more outside the classroom while also aligning teaching practices to allow for increased assessment scores. This concern has been echoed by previous research on evaluation as it often pressured teachers to redesign lessons or instruction that were more in line with the administrator's expectations (Garman \& Hazi, 1988). The shift to provide assessment driven instruction, or teaching to the test, creates a dilemma for evaluating administrators whose jobs may be on the line. While NCLB and NGA brought teacher preparation and professionalism to the forefront it was the accountability component that shaped the countries next major reform effort in determining teacher effectiveness and evaluations.

One of the boldest steps in defining teacher effectiveness was put in place by the federal government as a competition among states in a race for federal dollars. In his 2009 State of the Union Address, President Obama introduced a competition "to show the most innovative plans to improve teacher quality and student achievement" (State of the 
Union, 2009). As part of the American Recovery and Reinvestment Act (ARRA) of 2009 the Race to the Top (RTTT) competition was a $\$ 4.35$ billion contest designed to reform state and local school districts. This push by Obama is grounded in the idea that high quality teachers have the ability to improve student achievement. In her extensive review of teacher quality and student achievement, Darling-Hammond (2000) found that "while student demographic characteristics are strongly related to student outcomes, they are less influential in predicting achievement levels than variables assessing the quality of the teaching force" (p. 32). Though the study neglects evaluation data as a characteristic of quality teaching its use of several data sources provide a strong justification for improved teacher preparation and development. The findings by Darling-Hammond (2000) and the RTTT suggested methods of determining teacher effectiveness have raised concern among educators.

\section{Critical Issues in Teacher Evaluation}

The importance of RTTT's impact on teacher effectiveness and evaluation is in its definition of teacher effectiveness. The ARRA and RTTT defined a highly effective teacher as one whose students achieved at high rates (US Department of Education, 2009). Met with criticism from teachers unions this became an area of concern for educators as it suggested using standardized assessments to evaluate, compensate, and tenure teachers (Viteritti, 2011). The idea that teacher effectiveness could be measured by student growth allowed for the introduction of value added models in teacher evaluation systems. Value added models (VAM) are a component of teacher evaluations, which use the teachers' contributions to student growth, as measured by standardized assessments, for the basis of determining their effectiveness (Sanders \& Horn, 1995; Sanders \& 
Rivers, 1996; Springer et al.,, 2010; Wright, Horn \& Sanders, 1997). Though the use of VAM's as the sole measure of teacher effectiveness is met with skepticism (Kupermintz, 2003; Koedel \& Betts, 2011; Newton et al., 2010; Sass, Semykina, \& Harris, 2014), the suggestion that student growth be added as a factor in teacher evaluations has been accepted in several states.

VAM's have been a component of teacher evaluation in Tennessee since the early 1990s and the subject of extensive research (Sanders \& Horn, 1995; Sanders \& Rivers, 1996; Springer et al.,, 2010; Wright, Horn \& Sanders, 1997). Wright et al., (1997) identified two of the most important factors influencing student academic growth were the teacher and previous achievement level of the student. Students falling into the lower achievement groups experienced the largest gains more frequently than students in the higher achievement groups. The results by Wright et al., (1997) are echoed by Sanders and Rivers (1996), and further support the need for high quality teachers and school level supports to improve instructional practices. Kupermintz (2003), however, suggests caution when using the Tennessee model as it uses norm-referenced measures to rank teachers. Kupermintz argues this comparison does not accurately take into account the performance differences between teachers in high and low performaing schools. DarlingHammond et al., (2012) echo the concerns by Kupermintz (2003) arguing that VAM's do not accurately measure student achievement as they do not take into account the many factors influencing student achievement. Concerns with the validity of VAM's were also voiced when comparisons were made to principal evaluations (Harris, Ingle \& Rutledge, 2014; Jacob and Lefgren, 2008; Kimball \& Milanowski, 2009; Sass et al.,, 2014).

The value added measures as discussed by Hanushek and Rivkin's (2010) 
analysis of the economics of education suggests taxpayers are not getting an effective return on investment. According to Hanushek and Rivkin (2010),"despite the strength of the research findings, concerns about accuracy, fairness, and potential adverse effects of incentives based on a limited set of outcomes raise worries about the use of value added estimates in education personnel and policy decisions" (p. 8). In their examination of teacher evaluation validity, Kimball and Milanowski (2009) found significant variation between teacher evaluation scores and value added scores of student achievement. Kimball and Milanowski (2009) used a sequential mixed methods approach to better understand evaluator decision making. Kimball and Milanowski (2009) findings suggest considerable variation exists among evaluators and further indicate evaluator decisions to be complex functions of motivation, skill and context. Sass et al., (2014) found the correlation between principal ratings and teacher VAM modest at best and suggest principal evaluations of teachers' performance may be a valuable compliment to VAM. The lack of correlation between principal observations and VAM suggests that observation and VAM capture different perspectives of teacher effectiveness (Jacob \& Lefgren, 2008; Sass et al., 2014). These differences may be related to several factors including teacher characteristics, principal perception of teacher effectiveness, and principal perception of the teacher evaluation process.

Harris, Ingle, and Rutledge (2014) provide further support to the above findings in their comparative analysis of teacher effectiveness ratings and teacher value added measures. The mixed methods approach looked to identify the difference between value added measures and principals' impressions of teacher effectiveness. Harris et al., (2014) suggest principals give higher evaluation scores based on affective traits and perceived 
effort. With states tying teacher evaluations to contract renewal, promotion, salary, and/or tenure, the findings by Harris et al., are valid concerns and further support the need for future research on how principals assess classroom performance. The research suggesting that VAM's and principal observations are ineffective in capturing classroom performance independently is certainly cause for concern with teachers unions in collective bargaining districts.

Collective bargaining agreements (CBA) are an important piece of any teacher evaluation system. CBA's are negotiations between an employer and a group of employee's resulting in written agreements regarding working conditions. Historically teachers unions were able to protect their members but the increase in accountability measures and policy has diminished their strength (Murphy, Hallinger, \& Heck, 2013). In their research of CBA's in the state of Ohio, Ingle, Willis and Fritz (2014) found several instances where reduction in force provisions contradicted the state law. Ingle et al., further argue that a lack of variation among teacher evaluation ratings and the discrepancy between principal ratings and VAM's are likely the result of restrictive CBA's. This suggests that restrictions placed in CBA's by teachers unions may actually negatively influence a principals' ability to improve teaching practices.

Seiler et al., (2010) conducted an analysis of CBA's in Kentucky districts and found an overriding theme in Kentucky CBA's is that evaluation should not be punitive but rather a tool used to assist struggling teachers. Additionally, concerns among evaluating administrators were expressed regarding the inability of removing an ineffective teacher due to a number of previous positive evaluations. If SBTE is designed to improve instructional practices any restrictions placed on the process, through CBA's, 
may be in direct contradiction to the intent of the reform.

In many states and districts SBTE systems are drastically different from previous methods of assessing teacher performance. Several studies have discussed the concern over the time required to successfully complete the evaluations with the myriad of tasks and demands placed on principals (Crum \& Sherman, 2008; Derrington \& Campbell, 2015; May \& Supovitz, 2010). Given the amount of time devoted to the evaluation of teachers, identifying the opportunity cost of the process can be viewed through both the financial and time management lenses. Whether teacher evaluation is a means of improving instruction or a process of removing ineffective teachers a look at the cost associated with replacing ineffective teachers is warranted.

Levy et al., (2012) estimated the teacher turnover costs in Boston and found variation from school to school. Further, they are dependent on the content area of the teacher, and supports they receive. Estimated school costs for replacing teachers in both high and low turnover schools ranged from $\$ 1,995$ to $\$ 5,157$ per teacher. Levy et al., found the difference in turnover costs between high turnover schools and low turnover schools "was in the time principals spent recruiting and supporting new teachers, and the time veteran teacher spent mentoring novice colleagues” (Levy et al.,, 2012, p. 127). With the increased tasks placed on principals as a result of accountability measures this is cause for concern as it further demonstrate the importance of reducing teacher turnover. The findings by Levy et al., illustrate the importance of SBTE systems focus on developing teachers and improving instructional practices. Principals effective in supporting teachers will likely devote less time to recruiting and hiring and more time on improving the instruction in their classrooms. This increase in support should lead to 
higher retention rates and better prepared teachers.

\section{Ongoing Reform Efforts in Teacher Evaluation}

The federal funding associated with RTTT challenged states to modify evaluation processes to include multiple measures of teacher effectiveness. One such evaluation system that is currently practiced in several states is the based off the Charlotte Danielson Framework for Effective Teaching (1996). Danielson (2001) suggests teacher evaluation systems should be comprised of three major components; a clear definition of good teaching, a fair and reliable method to elicit evidence of good teaching, and trained evaluators who can make consistent evidence based judgments. The Danielson framework looks to improve student achievement through best practices associated with planning and preparation, classroom environment, instruction, professional responsibilities. Milanowski, Kimball, and White (2004) identify this concept as a concern and suggest the "potential of standards based teacher evaluation for improving student achievement depends on the link between practices described by the standards and student learning” (p.2). Milanowski et al., (2004) use this argument to support the need for determining the relationship between teacher evaluation scores and value added measures of student achievement.

Milanowski, et al., (2004) replicated a quantitative study in three separate school districts to identify the relationships between student achievement and teacher evaluation scores. Despite concerns with sample size and inconsistency among grades tested at the three sites, the findings suggest a positive correlation between teacher evaluation scores and student achievement. Milanowski et al., (2004) indicate that though the effects are small to moderate in size, they "could add up to a substantial advantage for a student with 
two or three consecutive teachers rated at the distinguished rather than proficient level" (p. 14). The findings by Milanowski et al., (2004) become increasingly important as schools look to improve classroom instruction, meet predetermined benchmarks, and close achievement gaps.

Borman and Kimball (2005) looked at the distribution of quality teachers, as measured by evaluation scores, and whether high quality teaching was related to better outcomes among different student populations. Their findings support the work of Milanowski et al., (2004) in that better teaching is directly related to increased student learning outcomes. Borman and Kimball (2005) not only found an unequal distribution of teachers with lower evaluation scores, but that "teachers rated higher on the teacher evaluation system do not appear to be reducing gaps in achievement between low-and high-achieving students and students from low income or minority backgrounds" (p. 17). The studies on teacher evaluation and student achievement bring to light the question of how one should define quality classroom instruction and if it accurately captures a teachers' effectiveness.

\section{SBTE a Different Method of Measuring Teacher Effectiveness}

In many cases, Standards Based Teacher Evaluation (SBTE) systems are drastically different from their predecessors. SBTE are a method of teacher evaluation which may use multiple methods of determining teacher effectiveness including principal observation, peer observation, student voice, and/or VAM. Previous evaluation systems typically used check lists or vaguely written standards for determining teacher effectiveness. Rather than being used as a means of improving instructional practices, they were often seen as a time consuming formality designed to remove incompetent 
teachers (Darling-Hammond, Wise \& Pease, 1983). Much of the issue with previous systems was the heavy emphasis on the principals' subjective opinion. Because of these limitations previous research suggests teacher evaluation has had minimal impact on improving teaching practices (Peterson, 1995; Darling-Hammond et al.,, 1983). To address these concerns a variety of SBTE systems have emerged over the course of the past decade including Danielson Framework (1996), Stronge (2005), and Marzano (2013). While each of the models differ from one another in terms of the evaluation rubric, each utilizes multiple measures of determining teacher effectiveness.

The idea of the SBTE system is that a broader, less subjective view of the teacher is provided by utilizing multiple measures of teacher effectiveness. Kentucky's recently adopted Danielson Framework consists of four domains: planning and preparation, classroom environment, instruction and professional responsibilities. Each of the domains include anywhere from four to six subdomains. This is markedly different from Kentucky's previous teacher performance indicators which included 10 standards with anywhere from nine to fourteen sub standards. The Danielson Framework, which was adapted for the Kentucky Department of Education, rates teachers on a scale of 1-4 and uses the terms ineffective, developing, accomplished and exemplary. One major difference between the new and old systems is the shift from a teacher focus with the old model to a student centered approach in the Danielson Framework.

Kentucky Revised Statute 156.557(1)(c), (2) and (3) also known as the Professional Growth and Effectiveness System was passed in 2013 as part of House Bill 180. The bill redesigned the way educators were evaluated and focused heavily on student college and career readiness. According to the Kentucky Department of 
Education, the purpose of PGES is to provide a system of support to improve the performance of certified school personnel. KRS 156.557 mandates that evaluations include formative and summative evaluations with feedback occurring through conferences. The policy provides guidelines focused on growth and support and is drastically different from its predecessor in that its components require a tremendous amount of time on the part of the evaluating administrator.

Kentucky's new SBTE is made up of teacher observations, student growth, student voice, and peer observations. For evaluation purposes the two primary components are teacher observation and student growth. KRS 156.557 outlines the basic guidelines for teacher evaluation and states "the evaluation system shall include a plan whereby the person evaluated is given assistance for professional growth" and goes onto suggest "the system shall also specify the process to be used when corrective actions are necessary" (KRS.156.557, (c) 5). The language in KRS 156.557 supports the KDE's purpose of teacher evaluation as a mechanism for improving classroom instruction. The major concerns among Kentucky Educators is the amount of time required to successfully implement the system while providing quality feedback and supports (Dodson, 2015). Whether or not all Kentucky districts are implementing the policy with fidelity is a question that could significantly impact the overall success of the new system.

Dodson (2015) examined public school principal's perceptions of the new Kentucky teacher evaluation system. The focus of the qualitative study was on the training to become a certified evaluator and the extensive amount of time each evaluation took to complete. The author used open ended survey questions for principals in schools piloting the program in the year leading into full accountability. Dodson (2015) found 
that while principals believe the new system has the ability to improve the schools instructional program, there were concerns with the process for training evaluators, the online platform used to input the data, and the amount of time required to effectively provide supports to all teachers.

The implementation of PGES and the teacher evaluation component SBTE has changed the way administrators evaluate classroom instruction. In an era of high stakes accountability principals are pulled in a number of directions as they attempt to meet the schools state mandated growth goal. SBTE, such as Kentucky's use of the Danielson Framework (Danielson, 1996), may provide a strong platform to improve classroom instruction, but if principals are not effective in their implementation of the system it may prove to be less effective than the previous system. Furthermore, it may have negative implications for the implementation of future school reforms and the school climate.

Much of the recent research on SBTE implementation is qualitative (Derrington \& Campbell, 2015; Vekeman, Devos \& Tytens, 2014) thus providing a deeper understanding of the specific issues principals face during policy implementation. Derrington and Campbell (2015) found significant concerns related to the time needed to successfully implement SBTE. Derrington and Campbell's (2015) three year study revealed that even when district officials attempted to support principals with time concerns additional issues surfaced. The results suggest that when principals are tasked with leading mandated initiatives the amount and types of support they receive directly influence their ability to successfully implement the initiative. Furthermore, successful implementation requires an understanding of principal concerns and efficacy.

Ruffini, Makkonen, Tejwani, and Diaz (2014) conducted a study of school 
districts in Arizona during a pilot year of implementing a new teacher evaluation system. The authors used survey data from principals and teachers to explore the implementation process in 10 different school districts. Survey data reveals that principals and teachers view the new evaluation system, which is based on the Danielson Framework, as a credible form of determining teacher effectiveness. A key finding were that concerns over time constraints limited the implementation process. Results of the teacher survey reveal teachers have confidence in their principals to accurately rate their performance (63\% agreed), while $61 \%$ indicated the process has not improved the climate and culture in their school. Additionally, the results suggesting concerns over the amount of time needed to complete the new system may have refocused the principals' priorities. Absent in the analysis was survey data from principals. Though data was collected qualitatively through interviews and focus groups the study neglected to provide data from the individuals tasked with the implementation process. To better understand the implementation process the authors would have benefited from comparing survey results from both principals and teachers.

Vekeman, Devos and Tuytens (2014) offer the idea that leader efficacy and the relationship between principal and teacher play an important role in policy implementation. Vekeman, Devos, and Tuytens (2014) conducted a case study of Flemish principals' implementation of a new teacher evaluation policy. More specifically, the authors looked to analyze if discrepancies existed between principal implementation and teacher expectation for policy implementation. Findings suggest successful implementation is related to the standard set by principals and the expectations teachers had for implementation. Furthermore, how principals made sense of and valued 
teacher evaluation led to varying degrees of acceptance by the teachers of the policy.

Principals that valued the policy as a means of improving instruction, and were able to articulate that to teachers, saw higher degrees of alignment with teacher expectations. While Vekeman, Devos and Tuytens (2014) analysis lacks generalizability due to sample size and setting, the study offers value to the important role principals play in shaping the educational climate in their buildings.

The changing expectations placed on schools through accountability measures have challenged states and school districts to adopt or reform new methods of evaluating teaching. The body of research suggesting the important link between teacher effectiveness and student achievement (Hanushek, 2011; Harris \& Sass, 2011) has led states across the country to implement SBTE systems. In many cases SBTE systems are in direct contrast to previous systems which were primarily used to remove ineffective teachers. The new system allows for multiple measures of teacher effectiveness including observations from principal and peers, student voice, and VAM's. How teacher effectiveness is measured and the validity of SBTE systems have raised concerns among teachers and the unions that support them.

Despite concerns regarding the use of VAM's (Darling-Hammond, AmreinBeardsley, Haertel, \& Rothstein, 2012; Murphy, Hallinger \& Heck, 2013, Rothstein, 2008) and the relatively weak correlation between principal ratings and VAM's (Kimball and Milanowski, 2009; Harris, Ingle \& Rutledge, 2014) they continue to play an important role in evaluation process. One of the biggest barriers faced by principals will be how they support staff with the implementation of a new evaluation system that determines their effectiveness. The idea of changing traditional school systems is a 
tremendous challenge and one that will take a great deal of patience by school officials. Teachers, many of whom have been evaluated by the same system for their entire careers, will be forced to reevaluate instructional practices and willing to release some control to students. This will be an important hurdle to overcome as changing teaching behaviors could prove to be a difficult task. While research on teacher evaluation is available in the existing literature, little is known about how efficacious principals are with the task of implementing these new systems in their buildings. With principals playing a crucial role in the school culture and climate how they perceive and implement SBTE systems in their school will likely determine the overall success or failure of the reform.

\section{Self-Efficacy in Education}

The theoretical framework guiding this study is based on Social Cognitive Theory (SCT), specifically the construct of self-efficacy, which will be used to analyze the relationship between the variables. Self-efficacy is based on the research by Bandura $(1977,1986,1997,2000)$ and is explained as an individuals perceived ability to carry out the actions leading to desired outcomes. Self-efficacy beliefs influence the actions, effort, and perseverance in successful task attainment. It is important to understand that self-efficacy is a measure of an individual's perceived ability rather than actual ability and is directly related to effort and the manner in which individuals approach a given task. Highly efficacious individuals are much more likely to accomplish a task.

Therefore, SCT implies individuals who are not confident in their academic ability they are less likely to put forth the effort necessary to overcome the barriers to success. Usher and Pajares (2008) found that higher performing students are more resilient, better problem solvers, and work harder. This same concept applied to school leaders may have 
tremendous implications for the success or failure of school reform implementation.

Bandura (1997) identified the four sources of self-efficacy to include: mastery experience, vicarious experience, social persuasion and affective state. The first source, mastery experience, encompasses previous experiences that an individual has had with the task and is arguably the most important in one's ability to influence an individual's attitude towards the task. Whether positive or negative, the previous experience shapes the individuals approach and level of efficacy for task attainment. The second source, vicarious experiences, are those based on the experience of others. Individuals draw conclusions, based on the experience of others, which in turn shape their perceptions and ultimately their believed capacity. The third source of efficacy is social persuasion or encouragement and support from outside sources. In the context of the present study this could come in the form of support from state and district level staff. The final source of efficacy is the affective state, or the individuals' ability to adjust to and deal with adversity. How principals deal with the final source will become an essential component to their success, as they will likely have issues they did not plan for, and how they adjust will impact the staffs' perception of the reform. Each of the sources not only draw on previous experiences but also the individuals ability to motivate staff and deal with the barriers to successful task completion.

Bandura (1997) indicates self-efficacy is context specific therefore individuals may be highly efficacious for one task and not another. SCT suggests that both internal and external factors shape and influence efficacy levels. Bandura (1989) offers that it is the interaction between personal, behavioral, and environmental factors that shape an individual's ability. It is from this interaction that efficacy levels are developed. These 
multidirectional factors are the basis of Bandura's (1989) concept of Triadic Reciprocal Causation (TRC). Reciprocal causation suggests the factors "interact and influence each other bidirectionally (Bandura, 1989). A primary component of SCT is self-efficacy, which acts as the personal factor of the triadic model. Figure 1 illustrates the triadic interaction.
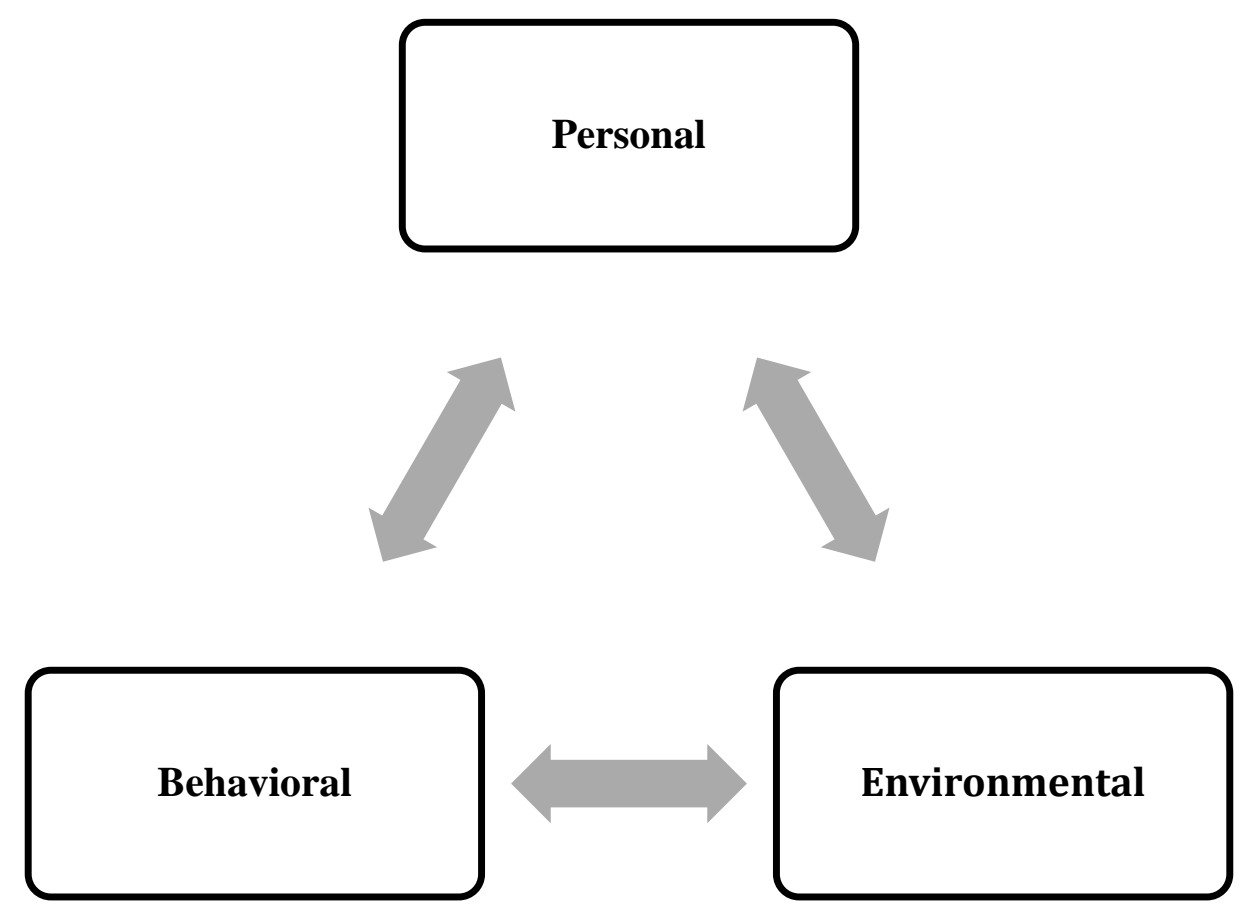

Figure 1. Triadic Reciprocal Causation in Social Cognitive Theory (Bandura, 1989)

Understanding the factors that influence self-efficacy provides an important perspective to the present study as schools look to build the capacity of both teachers and administrators. The idea of self-efficacy has long been studied in a variety of contexts in the educational setting, from academic motivation (Zimmerman, 2000; Schunk, 1991), collective teacher efficacy (Bandura, 1997; Goddard et al.,, 2000; Goddard, 2001), goal setting (Pajares, 1996), academic outcomes (Multon, Brown, \& Lent, 1991), teacher experience (Tschannen-Moran \& Hoy, 2007), teacher burnout (Skaalvik \& Skaalvik, 
2010), and job satisfaction (Caprara, Barbaranelli, Steca \& Malone, 2006). Findings support the idea that individuals with high levels of self-efficacy are more likely to be successful with task accomplishment.

Tschannen-Moran and Gareis (2007) suggest efficacy can be important in a number of settings but offers tremendous insight into the unique role of the principal. With the increase in accountability measures driving school reform, principals must work to develop high levels of efficacy with their staff in hope of translating it to student selfefficacy and improved academic outcomes. This study looks to fill the gap in previous research between principal motivation and principals' sense of efficacy (TschannenMoran \& Gareis, 2004) and explore the perceived self-efficacy of principals for the implementation and support of the new teacher evaluation system. More importantly it seeks to determine if the behavioral, and environmental factors in the TRC model are predictors of the personal factor. The section below will further explain the methods of measuring self-efficacy, and review the literature on teacher and principal self-efficacy (PSE).

\section{Measuring Self-Efficacy in Educational Settings}

Bandura (1997) purports self-efficacy is a powerful predictor of behavior. Woolfolk, Rosoff, and Hoy (1990) identify a consistent relationship between teacher characteristics and student learning. Other results indicate students of highly efficacious teachers have been shown to outperform their peers in classrooms with teachers of lower levels of self-efficacy (Moore \& Esselman, 1992). If self-efficacy is a strong predictor of behavior and accomplishing desired outcomes, capturing an individual's level of selfself-efficacy becomes an important part of predicting successful task completion. The 
method used to capture an individual's level of self-efficacy has been reviewed in several studies (Coladarci \& Fink, 1995; Gibson \& Dembo, 1984, Riggs \& Enochs, 1990; Tschannen-Moran, Woolfolk Hoy \& Hoy, 1998; Tschannen-Moran \& Hoy, 2001) and been the cause of much debate among scholars.

In many cases the method of determining teacher self-efficacy have been context specific and adapted to answer specific research questions. Early measures of teacher's self-efficacy included the, Responsibility for Student Achievement (Guskey, 1981), Teacher Locus of Control (Rose \& Medway, 1981), Ashton Vignettes (Ashton, 1982), and the Teachers Sense of Efficacy (Gibson and Dembo, 1984). Riggs and Enochs (1990) designed one of the first subject specific measures known as the Science Teaching Efficacy Belief. Though many of the instruments were met with criticism due to conflicting beliefs regarding the theory behind them (Coladarci \& Fink, 1995; Gusky \& Passaro, 1994), they provided a starting point for the development of future instruments. Tschannen-Moran and Woolfolk Hoy (2001) developed the Ohio State teacher Effiacy Scale (OSTES), a three factor instrument, which looked to capture teacher efficacy in engagement, instruction, and management. The instrument provides strong reliability and validity as evidenced by alpha levels of .94 for the overall scale, .87 for engagement, .91 for instruction, and .90 for management. In their confirmatory analysis of the OSTES, Roberts and Henson (2001) suggest moving the OSTES from the three factor model designed by Tshannen-Moran and Woolfolk Hoy (2001) to a two factor model. Roberts and Henson (2001) identified the Chronbach alpha for the two factor model at .89. Despite the suggestions by Roberts and Henson (2001) the OSTES, also called the teacher sense of efficacy scale (TSES), has been used in several studies looking 
at teacher self-efficacy (Tschannen-Moran \& Hoy, 2007; Wolters \& Daugherty, 2007).

Much like the concerns with measuring teacher efficacy, capturing efficacy levels of principals has proven challenging due to inconsistency with the validity of the various instruments. Early measures of principal efficacy were adapted from instruments used to measure teacher efficacy. Hillman (1986) adapted efficacy instruments for students, teachers, and principals. To measure principal efficacy the author used a series of scenarios that required principals to determine the probable outcome of a situation by selecting one of four choices. Analysis of the instrument revealed Cronbach alpha's ranging from .57 to .86 for each of the original eight sub scales. Subscales were then collapsed to four resulting in correlation coefficient of .91 for all items. Concerns however have been raised with the scoring method and theoretical framework being more closely aligned towards attribution theory than self -efficacy (Tschannen-Moran \& Gareis, 2004).

In an earlier study, Dimmock and Hattie (1996), designed a measure of principal efficacy requiring principals to respond to a series of vignettes. Principals were asked to rate their responses based on a 10 point Likert scale. Vignettes were organized into six areas of principal functioning: school development planning, teaching, learning and curriculum, managing staff, budgeting, managing parents, and managing the school environment. The authors surveyed 104 high school principals and assistant principals in the state of Ohio. Factor analysis with Varimax rotation resulted in communalities ranging from .21 to .44 . Item correlations were also low, ranging from .34 to .61 . As a result it was concluded the instrument was not a reliable measure of PSE.

In attempting to identify an effective method of measuring principal self-efficacy 
Tschannen-Moran and Gareis (2004) designed the Principals' Sense of Efficacy Scale (PSES), an 18 item instrument using a 9-point Likert scale, was determined to be valid and reliable as evidenced by Chronbach alphas of .91 for the overall scale and .86 to .89 for the subscales. An important finding was the emergence of three factors; efficacy for management, efficacy for instructional leadership, and efficacy for moral leadership. The three factors were the result of a factor analysis run on the original 50 items of the PSES. Despite the relatively low response rate of 28\%, Tschannen-Moran and Gareis (2004) contended the PSES to be a promising instrument for future studies in other settings, and in determining the antecedents and outcomes of PSE.

Smith and Guarino (2006) developed the Principal Self Efficacy Scale, a 14 item two factor instrument, which uses a 4 point Likert scale. The two factors include instructional leadership and management. Smith and Guarino (2006) administered the survey to 284 principals in several states across the country examining principal efficacy for facilitating effective instructional environments. Results were examined using confirmatory factor analysis and each subsection was determined to be statistically significant $(p<.01)$. Factor loadings for instructional leadership ranged from .59 to .69 while loadings for management ranged from .44 to .77. Internal consistency produced Chronbach Alpha's with coefficients of .86 for instructional leadership and .74 for management. Smith and Guarino (2006) then used stepwise regression to predict efficacy for management and efficacy for instructional leadership based on the following factors; principal gender, number of years as an educator, number of years as a principal at the current school, number of years as a principals, school enrollment, and percentage of students on free and reduced lunch. Results illustrate gender, enrollment and 
percentage of free/reduced lunch were successful predictors of self-efficacy for instructional leadership. Regression predicting efficacy for management suggest free/reduced lunch (beta $=.177, p=.046$ ) was the sole significant predictor. The results by Smith, et al., (2006) suggest higher efficacy principals are working with higher proportions of low SES students.

\section{Empirical Evidence on Principal Self-Efficacy}

Current studies investigating principal self-efficacy are inconsistent in their findings and the use of measurement. Research has examined principal efficacy and school characteristics, leadership behaviors, teacher effectiveness, and student achievement. If self-efficacy is a predictor of successful task completion, identifying the level of principal self-efficacy during a reform in teacher evaluation will be critical to improving classroom instructional practices. While literature on principal efficacy is available, much of its focus is on developing leaders (Normore, 2007), engagement, burnout and job satisfaction (Federici \& Skaalvik, 2012), experience (Fisher, 2012), and accountability (McCullers \& Bozeman, 2010).

DeMoulin (1992) measured efficacy levels of 375 principals using the Career Awareness Index (CAI), a 100 item instrument. The study measured efficacy differences between school levels. The use of a One-Way ANOVA analyzed the mean efficacy scores of principals from each of the three school levels. Post Hoc Scheffe indicated significant differences between elementary and middle school principals and between elementary and secondary principals. Personal and school variables were also subject to factor analysis with orthogonal rotation. Results reveal high efficacy principals across all three levels had fewer additional duties and used fewer sick days. Consequently 
principals with lower levels of efficacy reported lower salaries, higher building enrollments, additional duties, and used higher numbers of sick or personal days.

While the results by DeMoulin (1992) provide valuable insight into school level characteristics, the use of the CAI to capture principal self-efficacy is an area of concern. The instrument is divided into three sections. Section one examines performance attributes, section two character assessment, and section three measured the relationship between motivation, confidence, and stress to determine perceived self-efficacy. It was from the third section that efficacy levels were captured. Efficacy scores range from 0 to +30 for positive efficacy and 0 to -40 for negative efficacy. Scores on the positive side suggested high levels of efficacy while levels closer to -40 suggest lower levels of efficacy. The use of the CAI, an unvalidated measure of self-efficacy, is a weakness of the study by DeMoulin (1992). Despite the concerns regarding the DeMoulin (1992) study it provides insight into the antecedents that shape and possibly predict principal efficacy levels.

Osterman and Sullivan (1996) conducted a qualitative study of 12 first year principals in New York City public schools. The authors investigated the perceptions of the factors that support or restrict their efforts to bring school change. Responses were scored based on whether they were optimistic or pessimistic in their ability to bring change. Optimistic responses were considered high efficacy while pessimistic responses were deemed low efficacy. Findings suggest problem-solving ability created the largest gap between high and low efficacy principals with highly efficacious principals being more flexible and adaptable. The authors found that school size and socioeconomic status of the students was unrelated to principal self-efficacy. The findings regarding 
school characteristics have been echoed in several other studies and open the door to research on the factors or experiences that play the largest role in efficacy development.

Guarino, Strom, and Adams (2006) explored PSE in several states. Smith et al., (2006) designed and used the Principals Self Efficacy Scale to determine the relationship between PSE and various demographic variables such as years of experience, percentage of students qualifying for free and reduced lunch, and school enrollment. Stepwise regression analysis determined that the percentage of students qualifying for free and reduced lunch produced significant results for Self-Efficacy in Instructional Leadership $\left(R^{2}=.195\right)$ and Self-Efficacy in Management $\left(R^{2}=.177\right)$. Additionally, student enrollment produced significant results $\left(R^{2}=.154\right)$ for Self-Efficacy in Instructional Leadership but not Self-Efficacy in Management. The results by Smith et al., (2006) are of particular interest as they imply highly efficacious principals are in some of our more complex school settings.

McCullers and Bozeman (2010) used the PSES to determine the extent to which Florida principals believed the goals of "federal and state accountability measures were actually attainable, and to what degree they believed their efforts actually help achieve these goals" (p.56). McCullers and Bozeman (2010) utilized hierarchical multiple linear regression and found higher levels of efficacy with attaining state goals (as measured by growth) rather than federal goals associated with NCLB. McCullers and Bozeman (2010) determined that when the goals appeared to be realistic principals had higher levels of self-efficacy. McCullers and Bozeman grouped variables into the factors associated with Social Cognitive Theory and the idea of Triadic Reciprocal Causation. Results suggest personal factors accounted for $24.3 \%$ of the variance explained when 
measuring NCLB goal attainability and $10.1 \%$ variance explained when measuring the Florida School Grades Plan. Environmental factors such as student socioeconomic status and school governance did not significantly contribute to the model in either NCLB or the Florida School Grades Plan. The findings of importance in this study are the principals' believed ability to lead faculties to produce learning gains. When principals viewed goals as realistic and attainable they produced higher efficacy levels. Results suggest higher levels of efficacy beliefs associated with intentional leadership behavior aimed at making changes in curriculum and instruction.

Fisher (2014) qualitatively examined the relationship between PSE and work experience of 123 principals in Israel. The findings by Fisher (2014) provide a unique perspective to Bandura (1997) in that PSE was highest among first year principals as measured by the PSES. Bandura (1997) suggested that self-efficacy develops based on a variety of experiences suggesting the greater the experiences the higher the level of efficacy. Fisher (2014) found efficacy levels highest during the first year as principal with a significant drop in the years 2-5. Efficacy levels then increased after the fifth year and stabilized at year 10. The findings imply that first year principals are highly efficacious because they have not had the same work related experiences and are not fully aware of how difficult certain tasks, such meeting state and federal benchmarks, are to achieve. The findings by Fisher (2014) show that PSE in fact drops over time and offer the possible explanation that principals in their first year are naive enough to think they still have total control over the events and activities required of the job.

In an attempt to identify if PSE can be improved through training or professional development, Airola, Bengston, Davis, and Peer (2014) examined a small group of 
principals in Arkansas. Airola et al., (2014) examined the relationship between principals involvement in SSP, an external support program designed to develop school leaders in low performing schools. Principals were grouped into one of three cohorts based on the number of years involved in the program. Cohort 1 were principals in their third year of the SSP program, Cohort 2 principals were in their second year and Cohort 3 were principals in their first year of the program. Self-efficacy was measured using Tschannen-Moran and Gareis (2004) PSES and scores were provided for efficacy for management, efficacy for instructional leadership and efficacy for moral leadership. In order to account for the small sample size the authors used Kruskal-Wallis and Wilcoxon rank sum test to evaluate differences among cohorts and determined principal involvement in the program led to higher levels of instructional leadership efficacy ( $p$ value $=.02$ ). Mean scores provide valuable information as it indicates efficacy for management was the lowest rating of the three with principals in Cohort 1( $M=6.75, S D$ $=1.05)$ producing the highest followed by Cohort $2(M=6.50, S D=1.33)$ and then Cohort $3(M=5.94, S D=1.17)$. Self-efficacy scores for instructional leadership and moral leadership produced similar scores and indicate higher mean scores for each year of involvement in the SSP program. Despite concerns with the low sample size $(N=27)$ and highly contextual nature of the study it does provide evidence to support principals have lower efficacy levels with managing the day to day responsibilities of the job.

Principals' importance in transforming schools cannot be understated. The level of principal and teacher self-efficacy can greatly influence a student's academic success (Goddard, 2001; Tschannen-Moran \& Hoy, 2007). Research suggests principal selfefficacy can positively influence school conditions related to improved student outcomes 
(Goddard, 2001; Tschannen-Moran \& Gareis, 2005; Tschannen-Moran \& Hoy, 2007;

Leithwood \& Jantzi, 2008; McCullers \& Bozeman, 2010). In an era of high stakes accountability, principals must be confident in their ability to implement reforms. Understanding principal efficacy for policy implementation has implications for future training and professional development at both the school and district level. Each of the studies on self-efficacy looked at accountability measures and the principals perceived level of efficacy with accomplishing those tasks. To date little research is available on PSE in the context of implementing a school wide reform initiative in an era of accountability (White-Smith \& White, 2009). Furthermore, much of the research on efficacy is outcome focused rather than the antecedents that may shape efficacy levels (Chen \& Bliese, 2002). It is from this gap that this study will examine the factors that influence and possibly predict principal efficacy for the implementation of a SBTE reform.

\section{Summary of Literature}

Federal and state accountability measures have changed the role of the principal over the course of the past 30 years. NCLB, RTTT, and ESSA have increased the expectations for both teacher quality and student achievement as measured by standardized assessments. Increased accountability measures have placed a great deal of emphasis on supporting teachers and measuring their effectiveness. As a result, SBTE systems have changed the way teachers are evaluated. These SBTE systems are drastically different from previous teacher evaluation systems, which were primarily designed as a means of removing ineffective teachers. Many SBTE systems include a large percentage of the teachers overall score related to student growth. The student 
growth goals, designed in collaboration with school administration, then become a critical component of the teachers summative evaluation. Teachers with an unclear understanding or negative perceptions of SBTE run the risk of less than favorable evaluations. This places increased pressure on principals to clearly articulate the expectations for SBTE within their buildings and provide teachers with the supports needed to be successful.

With the increased demands placed on principals, and the historical challenges of implementing school based reforms, the approach principals take with the implementation of a new teacher evaluation system will play an important role in its success or failure. Research on self-efficacy suggests that high levels of efficacy translate into successful outcomes (Bandura, 1997; Goddard, 2001; Tschannen-Moran \& Hoy, 2007). This is evidenced by the body of research on student (Zimmerman, 2000; Schunk, 1991; Pajares, 1996), teacher (Bandura, 1997; Goddard, 2001), and principal (Smith et al., 2006; Tschannen-Moran \& Hoy, 2007; McCullers \& Bozeman, 2010; Fisher, 2014) self-efficacy. Despite the extensive literature on self-efficacy in the educational setting, a largely unexplored area is identifying the factors that potentially influence PSE during a school wide reform. The literature reviewed in this chapter suggests the role of the principal and the perception of teachers regarding school reforms are critical to successful implementation. Therefore, ensuring our nations principals are efficacious in their ability to lead school based reforms becomes essential not only to the success of the SBTE reform but also to the implementation of future school based reforms. 


\section{CHAPTER THREE METHODOLOGY}

\section{Introduction}

The purpose of this study was to examine the relationship between school related factors, principals' perception of teacher evaluation, experience, and efficacy for standards based teacher evaluation (SBTE) implementation. The research question that guided the study was; to what extent do school demographics, principal experience, and principal perceptions of teacher evaluation predict principal self-efficacy for SBTE implementation. Chapter 2 illustrated how the role of the principal has changed due to increased accountability measures and reform movements such as SBTE systems. Additionally, it provided evidence of the role principal efficacy plays in the implementation of school reform efforts. This chapter describes the theoretical framework, research design, research question, participants, data sources, measures, data collection procedures, data analysis, methodological limitations, and assumptions.

\section{Research Design}

A non-experimental cross sectional survey design was used to examine the relationship between school characteristics and principal experience, perception of SBTE, and self-efficacy. Johnson (2001) indicates that non-experimental research design is important in educational settings when variables, such as school characteristics and principal experience cannot be manipulated. The cross sectional survey design included collecting survey data from principals at the conclusion of the second cycle of the new 
teacher evaluation system in one urban school district. Timing of the survey allowed the researcher to capture efficacy levels as principals worked through the implementation of the new system. This quantitative study uses a correlational research design. Creswell (2014) explains correlational research design uses correlational statistics to describe and measure the degree or association between two or more variables. A non-experimental cross sectional correlational research design was selected to examine the relationship between school related factors, and principal perception of SBTE, experience, and efficacy for SBTE implementation. Within this context and because the variables were not manipulated this was not a causal study, but instead descriptive and correlational.

\section{Hypothesis}

The following are the hypotheses regarding the primary question that guides the study:

\section{Hypothesis: Principal Self-Efficacy for Implementation of SBTE}

- School demographics, principal experience, and principal perception of teacher evaluation will be predictors of principal efficacy for SBTE implementation.

- Null $\left(\mathrm{H}_{0}\right)$ - School demographics, principal experience, and principal perception of teacher evaluation will not predict principal efficacy for SBTE implementation.

- Alternative $\left(\mathrm{H}_{1}\right)$ - School demographics, principal experience, and principal perception of teacher evaluation will predict principal efficacy for SBTE implementation. 


\section{Data Sources}

Surveys were distributed electronically using Qualtrics survey software to 133 principals during the second week in February, 2016. Self-administered surveys were used as they are a favorable form of data collection that is cost-effective and maintain anonymity of respondents (McMillan \& Schumacher, 2010). Of the 133 schools selected to participate in the study 89 are elementary (66\%), 23 middle (17\%), 18 high (13\%), and three are classified as special or combined due to the inclusion of more than one school level. For the purpose of this study and to avoid disproportionate groupings, special and combined schools were assigned to the high school grouping.

\section{Participants}

Because principals are tasked with providing leadership for the implementation of SBTE systems they were the target sample in the study and range in age, sex, race, and years of experience. In total, 89 principals from schools in a large urban district completed the online survey, which resulted in a response rate of $67 \%$. For the purpose of this analysis the only personally identifiable information requested were years of experience as a principal and years of experience as a principal in their current school. To maintain anonymity Deal County Public Schools (DCPS) will serve as the pseudonym for the district being studied. All participants are part of DCPS, a district located in one Southeastern state. DCPS is among the top 30 largest school district in the United States and made up of over 100,000 students. The demographic make-up of the students is 47.9\% white, $36.1 \%$ African American, and $16.1 \%$ classified as other. Additionally, $65.1 \%$ of the students qualify for the federal free/reduced lunch program, an indicator of socioeconomic status (Retrieved from 2014-2015 KDE School Report Card). The district 
is also made up of 6,117 certified teachers all of whom will be evaluated under a new SBTE system during the 2015-2016 school year. Teacher retention rate, or those teachers who returned to their same school from the previous year was $87.2 \%$ for the entire district (Retrieved from DCPS Data books).

Academic data for the district reveals that the number of students scoring Proficient or Distinguished in reading and math are areas for concern with greater than $50 \%$ of students at all levels scoring Novice or Apprentice. Table 1 provides the percentage of students scoring Proficient or Distinguished in reading, math, science and social studies. Science scores were only captured at the high school level but indicate that $62.4 \%$ of the students scored Apprentice or Novice. Social studies scores were captured at all school levels, and had the highest overall percentage of students scoring Proficient or Distinguished. In social studies, high schools (55.7\%) produced the highest total followed by elementary (54\%), and middle school (47.2). The results indicate less than half of the students in this school district are scoring Proficient or Distinguished on state standardized assessments. With teacher evaluation scores in some grade levels tied directly to these assessments this data becomes an important part of determining teacher effectiveness based on SBTE.

\section{Table 1}

Number of students scoring proficient or distinguished on state standardized assessments during the 2014-2015 school year

\begin{tabular}{lcccc}
\hline & $\begin{array}{c}\text { Reading } \\
\% \text { P/D }\end{array}$ & $\begin{array}{c}\text { Math } \\
\% \text { P/D }\end{array}$ & $\begin{array}{c}\text { Science } \\
\% \text { P/D }\end{array}$ & $\begin{array}{c}\text { Social Studies } \\
\% \text { P/D }\end{array}$ \\
\hline Elementary & 48.1 & 47.9 & NA & 54.0 \\
Middle & 45.6 & 35.7 & NA & 47.2 \\
High & 49.1 & 38.9 & 37.6 & 55.7 \\
\hline \% P/D = combined percentage of students scoring Proficient and Distinguished
\end{tabular}

$\% \mathrm{P} / \mathrm{D}=$ combined percentage of students scoring Proficient and Distinguished 
Table 2 reports the descriptive statistics of the participants. Specifically, $61 \%$ were elementary school principals, $22 \%$ high school principals, and $15 \%$ middle school principals $(15 \%)$. Overall experience as a principal shows elementary principals have the most experience $(M=6.61, S D=4.79)$, followed by high school principals $(M=6.02$, $S D=4.74)$, and middle school $(M=4.71, S D=3.56)$. Data for principal experience in their current school shows elementary principals again have the highest average $(M=$ $5.22, S D=4.07)$, followed by middle school $(M=4.07, S D=2.89)$, and high school $(M$ $=2.95, S D=2.25)$. Results suggest that high school principals $(N=20)$ turn over more frequently as evidenced by the lowest mean score and the lowest maximum number of years in their current building at 8 years. Elementary principals $(N=55)$ on the other hand have the highest mean score for both overall experience and experience in their current school suggesting elementary principals are either much more willing or able to stay in their role as principal.

Table 2

Principal Experience

\begin{tabular}{lcccccc}
\hline & $N$ & $\%$ & $M$ & $S D$ & Min & Max \\
\hline Overall Experience & & & & & & \\
$\quad$ Elementary & 55 & 61 & 6.61 & 4.79 & 1 & 19 \\
$\quad$ Middle School & 14 & 15 & 4.71 & 3.56 & 1 & 12 \\
$\quad$ High School & 20 & 22 & 6.02 & 4.74 & 1 & 20 \\
Experience at Current School & & & & & & \\
$\quad$ Elementary & 55 & 61 & 5.22 & 4.07 & 1 & 17 \\
$\quad$ Middle School & 14 & 15 & 4.07 & 2.89 & 1 & 12 \\
$\quad$ High School & 20 & 22 & 2.95 & 2.25 & 1 & 8 \\
\hline Mean & & & & & &
\end{tabular}




\section{Measures}

To answer the research question and capture principal perceptions of SBTE and efficacy levels, a three-part survey, titled Principal Appraisal Inventory, was distributed electronically to all principals in DCPS. Online survey distribution was chosen due to the economy, convenience, and simplicity (Sue \& Ritter, 2012). Surveys consisted of three parts and were administered via email through Qualtrics Survey Software. The first section of the survey focused on obtaining demographic information such as years of experience, school location number, school category type, and number of evaluating administrators. Section two consisted of a modified version of the Principals Sense of Efficacy Scale (PSES) designed by Tschannen-Moran and Gareis (2004) and was chosen to identify the level of principal self-efficacy for the implementation of SBTE. Part three consisted of 9 questions regarding principal perceptions of SBTE and was a modified version of a previous instrument titled Teacher Perception Survey (Forsyth \& Adams, 2015).

The PSES was adapted from a previous measure of teacher efficacy developed by Tschannen-Moran and Wolfolk (2001). The PSES is an 18 item instrument using a nine point Likert scale and asks principals to respond to the statement "in your current role as a principal, to what extent can you." The 18 items are divided into three subscales consisting of 6 items in each. Subscales include principal efficacy for management, principal efficacy for instructional leadership, and principal efficacy for moral leadership. Factor loadings ranged from .53 to .82 for the subsection efficacy for management, .45 to .81 for the section measuring efficacy for instructional leadership, and .42 to .81 in the final subsection which measured efficacy for moral leadership. Factor loadings provide 
the weights and correlation between the individual items and the factor. The results of the PSES suggest strong correlation between each of the individual items within each subscale.

To answer the research question and identify PSE for the implementation of SBTE, the PSES was modified by reducing it from eighteen to twelve items, thus reducing it from three factors to two. The two remaining factors, efficacy for management and efficacy for instructional leadership, were selected based on the literature (Appendix A). The six questions, which measured efficacy for moral leadership, were removed because they did not address the research question and provided no additional value to the study. In the PSES principals receive a score based on the mean of all twelve items. Subscales were scored based on the mean of the 6 items making up that particular the section. The PSES Likert scale was reduced from nine to five options. Likert scale options included "none, very little, some, moderate, a great deal'" While Bandura (2006) suggests avoiding a scale with too few steps, the reduction from nine to five items still provides variation in responses while keeping consistent with the five item scale in part three of the principals' survey. Further, my dissertation committee provided guidance on the reduction of the Likert scale options.

Part three of the Principal Appraisal Inventory was a modification of the Teacher Perception Survey (TPS) administered to provide annual assessments of the health of public schools. The original survey consists of 10 sections: Transformational Leadership Behavior, Organizational Citizenship Behavior, Teacher Workplace Isolation, Teacher Leader Evaluation, Collective Teacher Efficacy, Student Readiness to Learn, Critical Friends Group Performance, Trust in District Administration, Faculty Trust in Parents, 
and a final section collecting background information on participants. Each section asked participants to rate their opinion on several statements. The number of statements in each section ranged from a low of 5 to a high of 10. A six point Likert scale was used with options ranging from "strongly disagree, disagree, somewhat disagree, somewhat agree, agree, strongly agree". For the purpose of the present study, the items in the Teacher Leader Evaluation (TLE) section were used. The TLE consists of 9 items and asked participants to respond to the following statement, "please indicate the extent to which you agree or disagree with each of the following statements about the Teacher/Leader Effectiveness observation and evaluation process. The purpose of this section was to capture teacher leader perspectives of an evaluation and observation process.

The TLE was modified to answer the research question. The first modification was made to the opening statement. The new statement read, "please indicate the extent to which you agree or disagree with each of the following statements about the Teacher Performance Growth and Effectiveness System". Additionally, the Likert scale was reduced from 6 to 5 items with "strongly disagree, disagree, neither disagree or agree, agree, strongly agree" as the options. The reduction in the scale were also based on the recommendation of the dissertation committee and allowed for consistency with the items in section two of the Principal Appraisal Inventory. Individual responses were modified to reflect the DCPS SBTE system with any mention of TLE being replaced with SBTE (Appendix B). Items sought to measure principal perspectives of SBTE and its ability to improve teaching. Principals' received a score based on the sum of all nine responses. 


\section{Validation of Survey Instruments}

Creswell (2014) offers that modification of an original survey instrument may influence the validity and reliability and therefore requires reestablishment of validity. According to Fraenkel and Wallen (2003) validating refers to the degree to which inferences can be made based on the results of the instrument. Since the original PSES was modified it was necessary to have each of the survey items reviewed for quality and clarity. To test for overall quality and clarity of the Principal Appraisal Inventory, surveys were sent for review to ten assistant principals (AP's) in the district being studied. AP's were selected to review the protocols due to their role as evaluating administrators and familiarity with the evaluation and implementation process. Feedback was received from 8 of the ten individuals. Three AP's were at the elementary, two at the middle school, and three at the high school level. Suggestions focused on the clarity of several statements in section 2 of the Principal Appraisal Inventory. No suggestions were offered for part three, which looked at perception of SBTE. Based on the feedback from the AP's slight modifications to the wording and instructions were made to provide greater reliability and clarity of the statements looking to answer the research question.

\section{Procedures}

Principals were surveyed during the second week in February, allowing for the completion of several SBTE components including meetings to clarify teacher growth plans, establish student growth goals, and conduct at least two observations and post observation conferences. In addition to the principal observations, each teacher received a peer observation from a colleague in their respective buildings. Surveys were distributed via email and included a brief introduction explaining the purpose of the 
survey. As part of the introduction, confidentiality of all schools and individual participants were assured along with a statement informing them how the results would benefit the district and them as practitioners (Appendix C).

Surveys were sent out via email on February 10, 2016 to all individuals in the districts principal email distribution list. Sue and Ritter (2012) provide guidelines which have online surveys open for three weeks with reminders being sent on a weekly basis. Seven days after the surveys were distributed, a reminder email was sent to all principals who had not completed the survey. After the third week (21 calendar days) of the survey being sent, it was closed and data were downloaded from Qualtrics into an excel spreadsheet. Data were organized, coded, and incomplete responses removed. In total, 9 surveys were removed due to being incomplete or failure to include the school location number. School location number was needed to gather school characteristic information such as enrollment, percentage of students qualifying for free and reduced lunch, number of evaluating administrators, teacher retention rate, and school status in meeting their AMO goal. Data were then loaded into SPSS for analysis.

\section{Analytics}

To answer the research question, hierarchical multiple linear regression (HLR) were employed to examine the predictive validity of school characteristics, principal experience and principal perception of teacher evaluation on principal self-efficacy. HLR was chosen as the preferred approach to determine the extent to which the variable groupings contribute to the explained variance of the outcome (Tabachnick \& Fidell, 2001; Petrocelli, 2003). HLR "involves theoretically based decisions for how predictors are entered into the analysis" (Petrocelli, 2003, p. 9). In this case, the predictor variable 
blocks were based on Bandura's (1978) triadic reciprocal causation. HLR has previously been used to determine the extent to which variable groups predict PSE (McCullers \& Bozeman, 2010). As with the present study, McCullers and Bozeman (2010) used Bandura's (1978) triadic reciprocal causation to group the variables and predict PSE. School characteristic data such as enrollment, percentage of students qualifying for free and/or reduced lunch, teacher retention rate, number of certified teachers, number of teachers per evaluating administrators, and the schools status on reaching AMO were retrieved from the districts data books. Data were selected to provide an accurate picture of the students, staff, and academic environment. Early analysis and inspection of VIF revealed multicollinearity with the number of teachers and student enrollment $(V I F=$ 27.65). Consequently, the number of teachers variable was removed and the student enrollment variable remained. The inclusion of both number of teachers and student enrollment in the same variable block would have increased the likelihood of a Type 1 error. As such, the removal of the number of teachers variable allowed for a better assessment of the importance of the variables.

Variable blocks were created based on Bandura's (1978) Triadic Reciprocal Causation and the interaction between Personal, Behavioral, and Environmental factors. The present study uses three variable blocks of predictors: Block 1 included school characteristics: school level (1 elementary, 2 middle school, 3 high school), school met Annual Measureable Objective (AMO) during the 2014-2015 school year ( 0 , did not meet AMO, 1 met $\mathrm{AMO}$ ), percentage of students qualifying for free and reduced lunch, teacher retention rate, enrollment, and average number of teachers per evaluating administrator in each school. Block 2 included principal experience: overall principal 
experience and principal experience in current school; and, Block 3 principal perception of teacher evaluation was measured by the sum of all items on part three of the Principal Appraisal Inventory. The first block served to control for school characteristics prior to entry of the second block, principal experience, and the third block, principal perception of teacher evaluation.

HLR was selected as the preferred method of answering the research question to determine which variables, and variable blocks are significant predictors of principal selfefficacy. Variables and variable blocks were selected and organized based on the three factors outlined in Bandura's SCT (1977, 1978, 1986, 1997). Stevens (2009) suggests that when data are nested or grouped in this way the use of multilevel modeling is preferred to avoid violation of the assumption. Model-data fit were judged according to the contribution of each variable block for explaining principal efficacy to SBTE implementation and based on a statistically significant improvement in adjusted $R^{2}$.

SPSS software was used to examine the results with PSE serving as the DV while the variable groupings of school climate, principal experience, and principal perception served as the IV's. Therefore, I was interested in predicting PSE from the predictor variables of school characteristics, principal experience, and principal perception. When conducting the analysis, IV's and the DV were entered into the appropriate boxes and the methods box was left at Enter. The use of Enter as the method, as opposed to stepwise, was selected as it placed all variables into the equation regardless of whether they were significant.

Reading the output file focused on three main components. The model summary included the $R, R^{2}$, and adjusted $R^{2}$ statistic, which provide the proportion of variance that 
can be explained in PSE based on the IV of school characteristics, principal experience, and principal perception of SBTE. For the purpose of this study the adjusted $R^{2}$ statistic was used. The adjusted $R^{2}$ was selected as it is a more conservative measure by adjusting based on the number of variables entered (Stevens, 2009). The HLR model summary provided results for each variable block, the change in $R^{2}$, and the significant $\mathrm{F}$ change. These provide insight into the degree of influence each variable block has on the DV.

The second output used in the analysis was the ANOVA table and the significance statistic located in the far right column. The ANOVA table provided levels for each IV variable block. In this section I was looking to see if the significance level was less than .05 which would suggest a significant finding. If the model is significant we can reject the null hypotheses that the model has no predictive value. The third section of the output file is the coefficients tables. This section provides data for the predictor equation. If the model proves to be significant the use of standardized coefficient beta will be used. In a statistically significant finding, the standardized coefficient beta indicates that for every unit increase in the predictor variable the DV will increase by the beta amount. Therefore, the larger the beta number, the greater the increase in the DV and ultimately the predictability of the model. Additionally it provides the significance level for all variables within in each variable block. The inclusion of the significance levels in each variable block show the influence each additional variable provides to the overall model. Tables include the beta statistic which indicates that for every lincrimate increase in the predictor variable the DV will increase by the beta amount. Also included in the coefficients table is the VIF statistic, or 
variance inflation factors, which allows for the identification of multicollinearity within the model (Petrocelli, 2003).

\section{Methodological Limitations}

As researcher I acknowledge the study has several limiting and delimiting factors. First, the sample used in this study was restricted to only one school district a Southeastern state. Therefore generalizations cannot be made to principals of schools outside the district being studied. Second, to improve the balance of schools in each level any school categorized as a special or combined school was moved to the high school grouping. As a result Annual Measurable Objective (AMO) status for the combined schools was reflective of the high school portion of that particular school. Third, the scope of the study was restricted to principal efficacy during the first year of implementing a reform in the teacher evaluation system. Furthermore, surveys were administered at the end of the second cycle rather than the end of the school year. Since little is known about principal efficacy in this context, the results of this study do not necessarily extend to other reform implementations. Finally, this study uses modified versions of existing survey protocols. The purpose of modifying the surveys was to reflect the new teacher evaluation system being implemented in the district being studied. Modifying the instruments allowed for statements which specifically address SBTE and allows for a more accurate interpretation of the findings. To ensure validity and clarity with the modified survey documents a peer review of 8 assistant principals was used to provide feedback on the survey protocols. 


\section{Assumptions}

The following assumptions relate to the methodology and survey protocols. First, it was assumed that participants understood their role in the SBTE process. As such, it was assumed that principals understood each of the components, instructional focus, and managerial requirements for implementing the new system in their schools. Second, it was assumed that all participants provided honest and reliable responses to each of the survey items. Finally, it was assumed that principals would comprehend each of the items on both survey protocols, and teachers would comprehend each of the items on the survey protocol. The final assumption was addressed through the validation of the survey instruments by AP's in the district.

\section{Summary of Chapter}

This chapter discussed the research design, participants, data collection, survey instruments, limitations, and assumptions. The purpose of this study was to examine the relationship between school characteristics, principal experience, principal perception of SBTE, and principal self-efficacy for SBTE implementation. This study included principals from 1 Kentucky school district as they implemented a new method of evaluating teachers. Surveys were sent during the second of three cycles to capture perception and self-efficacy beliefs as principals worked through the implementation process. Survey items were specific to SBTE and focused on self-efficacy for management and self-efficacy for instructional leadership. Responses to the PSES provided information on the daily practices of principals.

Understanding the sources of self-efficacy for SBTE implementation will allow for improved supports. The information collected from the survey data of principals and 
teachers with the implementation of SBTE provides valuable information with regard to teacher evaluation and reform implementation. Furthermore, the results extend the current literature on PSE and teacher evaluation. The research design used in this study protected the anonymity of the participants and their schools by removing all identifying information in the presentation of data. The analysis of the above described procedures and results will be described in Chapter 4. 


\section{CHAPTER FOUR}

\section{RESULTS}

The discussion in Chapter Four centers on the results of the survey instrument titled, Principal Appraisal Inventory. The chapter outlines the results of the survey as they relate to both the theoretical framework and research question. As outlined in previous chapters, the purpose of this study is to examine the relationship between school related factors, principal perception of teacher evaluation, principal experience, and principal self-efficacy for standards based teacher evaluation (SBTE) implementation. Furthermore, it sought to answer the following research question: To what extend do school demographics, principal experience, and perception of teacher evaluation predict self-efficacy for SBTE implementation? Descriptive and inferential statistics are presented for each of the variable blocks and research question. A hierarchical linear regression model was used and variables were grouped into one of three blocks. Three variable blocks were used to predict principal self-efficacy for SBTE implementation from school characteristics (Block 1), principal experience (Block 2), and principal perception of SBTE (Block 3). Variable blocks were based on Bandura' SCT (1977, 1986, 1987, 1997) and the concept of Triadic Reciprocal Causation. 


\section{Survey Responses}

For this study, the targeted population were 133 principals in one large urban school district in a Southeastern U.S. state. Out of the total target population of 133 principals, 98 responded (73\%) to the survey. Of the 98 principals who began the survey, four did not complete the last two sections and an additional five did not indicate their school location number. Incomplete surveys were removed from the final analysis leaving a total of 89 participants and a final response rate of $67 \%$. The Principal Appraisal Inventory consisted of three sections.

Section one inquired about background information including school location number, school level, total years of experience as a principal, years of experience as a principal in their current school, and the number of evaluating administrators in their school. School location numbers were only used to capture school characteristic information such as school level, enrollment, number of certified teachers per evaluating administrator, percentage of students on free and reduced lunch, AMO status, and teacher retention rate.

Section two included twelve items measuring the principals' level of self-efficacy. Each of the twelve items were categorized into one of two areas, self-efficacy for management and self-efficacy for instructional leadership. Questions 1, 2, 4, 5, 6, and 7 measured the principals' self-efficacy for instructional leadership, while questions $3,8,9$, 10,11 , and 12 measured the principals' self-efficacy for management. The categories of self-efficacy for management and self-efficacy for instructional leadership were based on the original PSES survey designed by Tschannen-Moran and Gareis (2004). The third section used a modified version of the Teacher Perception Survey (Forsyth \& Adams, 
2015) and consisted of 9 items and a 5 point Likert scale. In section three principals received a score based on the sum of all nine items.

Table 3 presents the final grouping of schools used for the analysis. Principals were initially given five options for identifying which school level, elementary, middle, high, combined, or special school they associated themselves with. Elementary schools $(N=54)$ made up $60 \%$ of all responses, middle schools $(N=13)$ made up $14.6 \%$ of responses, high schools $(N=16)$ made up $18 \%$ of all responses, combined schools and special schools $(\mathrm{N}=6)$ made up $6.7 \%$ of the responses. To ensure balance within school groups, principals identifying as a combined or special school were assigned to the high school grouping. As such, school characteristic information was reflective of the high school. Final grouping of schools show elementary schools (61.79\%) make up the largest number of participating principals, followed by high school (22.47\%), and then middle school $(15.73 \%)$.

Table 3

Final School Level Groupings

\begin{tabular}{lcc}
\hline & $N$ & $\%$ \\
\hline Elementary School & 55 & 61.79 \\
Middle School & 14 & 15.73 \\
High School & 20 & 22.47 \\
\hline
\end{tabular}

\section{Variables}

The following variables and subsequent groupings were used to answer the research question and predict PSE for SBTE implementation. Block 1, (school characteristics) included school level, student enrollment, percentage of students qualifying for free and/or reduced lunch, number of certified teachers per evaluating 
administrator, annual measurable objective (AMO) status, and teacher retention rate. Block 2 (principal experience) included overall principal experience and principal experience in their current school. Block 3 (Principal Perception of SBTE) consisted of the sum scores of the nine items in the Principal Appraisal Inventory. In the paragraphs below the variable blocks and descriptive statistics are provided.

\section{School Characteristics}

Table 4 reports the descriptive statistics for school characteristics divided by level. School characteristics grouping was the first variable block entered into the regression analysis and represented the Environmental component of Bandura's Triadic

Causation. School characteristics consisted of percentage of students on free and reduced lunch, AMO status, number of teachers per administrator, student enrollment, and teacher retention rate. Results suggest that student enrollments were highest in the high school $(M=1367, S D=475)$, followed by the middle school $(M=897, S D=429)$, and then elementary $(M=530, S D=137)$. Percentage of students qualifying for free and/or reduced lunch had reverse findings with elementary schools having the highest average $(M=70.98 \%, S D=21.20)$, followed by middle school $(M=69.12 \%, S D=15.75)$ and then high school $(M=61.34 \%, S D=21.19)$.

Teacher retention rate remained relatively consistent throughout the school levels and ranged from a low in the middle school $(M=87.21)$ to a high in the elementary school $(M=90.07)$. Number of teachers per evaluating administrators reveal middle school $(M=13.88)$ administrators have fewer teachers to evaluate as compared to elementary $(M=16.73)$ and high school $(M=18.77)$. These results become important for further examination of self-efficacy for management levels of principals. AMO 
status shows the majority of schools $(N=48)$ did meet the AMO goal for the 2014-2015 school year. Schools in this category were coded as met (1) or did not meet AMO (0). The highest percentage of schools not meeting AMO were middle school (57\%), followed by high school (45\%), and elementary school (43\%).

Table 4

School Characteristics by School Level

\begin{tabular}{lcccc}
\hline & $M$ & $S D$ & Min & Max \\
\hline Elementary & & & & \\
$\quad$ Enrollment & 528 & 137.62 & 284 & 735 \\
\% Free and Reduced Lunch & 70.98 & 21.20 & 20 & 96 \\
$\quad$ Teacher Retention Rate & 90.07 & 7.52 & 68 & 100 \\
$\quad$ Teachers per Administrator & 16.74 & 5.53 & 4 & 39 \\
Middle School & & & & \\
Enrollment & 897 & 429 & 174 & 1317 \\
\% Free and Reduced Lunch & 69.12 & 15.75 & 41 & 89 \\
Teacher Retention Rate & 87.21 & 6.56 & 75 & 100 \\
Teachers per Administrator & 13.88 & 3.67 & 9 & 22.33 \\
High School & & & & \\
Enrollment & 1367 & 475 & 406 & 2076 \\
\% Free and Reduced Lunch & 61.34 & 21.19 & 20 & 86 \\
Teacher Retention Rate & 88.53 & 7.32 & 71 & 96 \\
Teachers per Administrator & 18.77 & 4.56 & 4 & 39 \\
\hline$M=$ Mean & & & & \\
$S D=$ Standard Deviation & & & &
\end{tabular}

\section{Principal Experience}

Table 5 reports the range of principal experience both overall and at their current school. The second variable block included in the regression analysis was the respondents experience as a principal. Overall principal experience, and principal experience at their current school were chosen by the participants by selecting the best option from a drop down box in part one of the principal survey. Principal experience ranged from a minimum of one year to a maximum of 20 years. Levels of principal experience show a 
fairly even distribution among the groupings with 4-8 years of experience as a principal having the highest number (39\%). Overall principal experience shows that $35 \%$ of principals were in 1-3 year range, 39\% were 4-8 year range, and $24 \%$ fell into the 9 or more year range. Data on principal experience in their current school suggest that the majority of participants (49\%) have been in their current school for less than three years. In all, $49 \%$ of principals had been in their current school for $1-3$ years, $37 \%$ for $4-8$ years, and $13 \%$ had 9 or more years in their current school. Data reveal that the majority of principals are either new to the position or their current school.

Table 5

Principal Experience

\begin{tabular}{lcc}
\hline & $N$ & $\%$ \\
\hline Principal Experience & 32 & 35.95 \\
1-3 years & 35 & 39.32 \\
4-8 years & 22 & 24.71 \\
9 or more years & & \\
Principal Experience at Current School & 44 & 49.43 \\
1-3 years & 33 & 37.07 \\
4-8 years & 12 & 13.60 \\
9 or more years & & \\
\hline
\end{tabular}

\section{Principal Perception of SBTE}

The final variable block consisted of principal perceptions of SBTE. Table 6 provides the summative scores for the principal perceptions of SBTE by grade level. Principal perception was measured by calculating the sum of the nine items in the final section of the Principal Appraisal Inventory. Results suggest principals view SBTE as having the ability to improve classroom instructional practices. Principals in high schools $(M=35.70, S D=3.87)$ produced the highest mean score followed by elementary school $(M=34.78, S D=4.00)$ and middle school $(M=34.27, S D=3.36)$. This data 
suggests high school principals have a stronger view of SBTE as having the ability to improve classroom practices.

Table 6

Summative Scores for the Principal Perception of SBTE

\begin{tabular}{lccccc}
\hline & $N$ & $M$ & Min & Max & SD \\
\hline Elementary & 55 & 34.78 & 25 & 44 & 4.00 \\
Middle & 14 & 34.27 & 27 & 42 & 3.36 \\
High School & 20 & 35.70 & 28 & 43 & 3.87 \\
Total & 89 & 34.91 & 25 & 44 & 3.87 \\
\hline
\end{tabular}

$M=$ Mean

$S D=$ Standard Deviation

Table 7 reports the means and standard deviations for each of the nine items in the principal perception section of the Principal Appraisal Inventory. Individual items in the principal perception section suggest that principals are generally pleased with the feedback they provide teachers. The lowest mean score produced by principals was item 2 which suggested the amount of time required to complete the evaluation process was not worth their time. While item one indicates principal perceive SBTE as describing effective teaching $(M=3.93, S D=.915)$, responses to item 6 suggests they did not feel it fairly reflects teaching effectiveness $(M=3.66, S D=.856)$. Additionally, principals $(N=$ $89)$ indicated SBTE does help develop teachers. $(M=3.66, S D=.856)$ as evidenced by the responses to item 5. Overall principals perceive SBTE as describing and defining effective teaching but that the process may not effectively develop teachers due to the time required to complete each of the necessary components. 
Table 7

Principal Perception of SBTE

\begin{tabular}{|c|c|c|c|c|}
\hline & $M$ & Min & $\operatorname{Max}$ & $S D$ \\
\hline SBTE describes effective teaching & 3.93 & 1 & 5 & .915 \\
\hline $\begin{array}{l}\text { The evaluation process takes more time than the results } \\
\text { are worth }\end{array}$ & 3.47 & 1 & 5 & 1.08 \\
\hline Face to face feedback was provided after each observation & 4.52 & 2 & 5 & .605 \\
\hline $\begin{array}{l}\text { Aligning teaching practices with the SBTE rubric will } \\
\text { help teachers improve instruction }\end{array}$ & 4.00 & 2 & 5 & .691 \\
\hline The evaluation process helps develop teachers & 3.66 & 2 & 5 & .856 \\
\hline $\begin{array}{l}\text { The evaluation process fairly reflects teaching } \\
\text { effectiveness }\end{array}$ & 3.66 & 2 & 5 & .852 \\
\hline $\begin{array}{l}\text { The SBTE rubric clearly defines standards for teaching } \\
\text { effectiveness }\end{array}$ & 3.88 & 1 & 5 & .850 \\
\hline $\begin{array}{l}\text { I am satisfied with the discussion of performance I have } \\
\text { with my teachers }\end{array}$ & 4.00 & 2 & 5 & .640 \\
\hline I am satisfied with the feedback I provide teachers & 3.83 & 2 & 5 & .757 \\
\hline
\end{tabular}

\section{Principal Sense of Self-efficacy Scale Results}

Table 8 provides the descriptive statistics for the results of the modified version of the PSES. Overall self-efficacy levels for all surveyed principals $(N=89)$ produced scores in the top half of the rating scale $(M=3.82, S D=.66)$. Survey results reveal that principals rated themselves higher in the area of self-efficacy for instructional leadership $(M=3.98, S D=.68)$ over self-efficacy for management $(M=3.66, S D=.79)$, suggesting the time requirements of the new system are an area of concern. Data presented in Table 8 provides support for the results in Table 7 suggesting concerns over the increased time commitment associated with SBTE. 
Table 8

Principal Self-Efficacy

\begin{tabular}{lccccc}
\hline & $N$ & $M$ & Min & Max & SD \\
\hline Self-Efficacy for Management & 89 & 3.66 & 2.00 & 5 & .79 \\
Self-Efficacy for Instructional Leadership & 89 & 3.98 & 2.33 & 5 & .68 \\
Overall Self-Efficacy & 89 & 3.82 & 2.42 & 5 & .66 \\
\hline
\end{tabular}

$M=$ Mean

$S D=$ Standard Deviation

Table 9 reports descriptive statistics for the PSES delineated by each sub scale and school level. Of the twelve items in the Principal Sense of Self-efficacy Scale, none of the items falling into the management category had a mean score over 3.88 (Appendix D). Data show self-efficacy for management is higher $(M=3.71, S D=.81)$ at the elementary school as compared to middle school $(M=3.68, S D=.65)$ and high school $(M=3.52, S D$ $=.84)$. Self-efficacy for instructional leadership was also higher in the elementary school $(M=4.07, S D=.65)$ as compared to middle school $(M=3.94, S D=.68)$ and high school $(M=3.73, S D=.70)$. Overall self-efficacy levels by school level suggest elementary principals are more efficacious $(M=3.89, S D=.66)$ as compared to middle $(M=3.80$, $S D=.56)$ and high school $(M=3.63, S D=.66)$. 
Table 9

Principal Self-efficacy by School Level

\begin{tabular}{|c|c|c|c|c|c|c|}
\hline & & $N$ & $M$ & Min & $\operatorname{Max}$ & $S D$ \\
\hline $\begin{array}{l}\text { Self-Efficacy for } \\
\text { Management }\end{array}$ & Elementary & 55 & 3.71 & 2 & 5 & .81 \\
\hline & $\begin{array}{c}\text { Middle } \\
\text { High }\end{array}$ & $\begin{array}{l}14 \\
20\end{array}$ & $\begin{array}{l}3.68 \\
3.52\end{array}$ & $\begin{array}{l}2.83 \\
2.50\end{array}$ & $\begin{array}{c}4.67 \\
5\end{array}$ & $\begin{array}{l}.65 \\
.84\end{array}$ \\
\hline $\begin{array}{l}\text { Self-Efficacy for } \\
\text { Instructional Leadership }\end{array}$ & Elementary & 55 & 4.07 & 2.33 & 5 & .65 \\
\hline & $\begin{array}{c}\text { Middle } \\
\text { High }\end{array}$ & $\begin{array}{l}14 \\
20\end{array}$ & $\begin{array}{l}3.94 \\
3.73\end{array}$ & $\begin{array}{l}2.33 \\
2.50\end{array}$ & $\begin{array}{l}5 \\
5\end{array}$ & $\begin{array}{l}.68 \\
.70\end{array}$ \\
\hline Overall Self-Efficacy & $\begin{array}{c}\text { Elementary } \\
\text { Middle } \\
\text { High }\end{array}$ & $\begin{array}{l}55 \\
14 \\
20\end{array}$ & $\begin{array}{l}3.89 \\
3.80 \\
3.63\end{array}$ & $\begin{array}{l}2.42 \\
2.58 \\
2.58\end{array}$ & $\begin{array}{c}5 \\
4.58 \\
5\end{array}$ & $\begin{array}{l}.66 \\
.56 \\
.66\end{array}$ \\
\hline
\end{tabular}

$M=$ Mean

$S D=$ Standard Deviation

\section{Predicting Principal Self-Efficacy}

To answer the research question, a hierarchical multiple linear regression (HLR) analysis was used to predict principal self-efficacy based on school characteristics, principal experience, and principal perception of teacher evaluation. HLR was based on the sequential entry of variables (e.g., \% of students on free and reduced lunch, school level, school meeting annual measurable objective, teacher retention rate, student enrollment, number of teachers per evaluating administrator, principal experience, principal experience at current school, and principal perception of teacher evaluation) to predict principal self-efficacy for the implementation of a reform in the teacher evaluation system. Preliminary analysis indicated no reason to challenge assumptions of homoscedasticity and multicollinearity (Petrocelli, 2003). For each result, the following three variable blocks were used: Block 1: school characteristics, Block 2: principal experience, and Block 3: principal perception of teacher evaluation. Further, principal 
self-efficacy for SBTE implementation will be analyzed using both the overall scale and two subscales of principal self-efficacy for management and principal self-efficacy for instructional leadership.

HLR principal self-efficacy. Table 10 reports the results of the first HLR analyses. The analysis included Block 1 (school characteristics), Block 2 (principal experience), and Block 3 (principal perception of teacher evaluation) to predict principal self-efficacy. At Step 1, school characteristics did not contribute to the model, $F(6,81)=$ $1.600, \mathrm{p}>.05$, and explained only $4 \%$ of the variance in principal self-efficacy as evidenced by the adjusted $R$ square. Step 2 included the addition of principal experience and principal experience in their current school, which resulted in accounting for an additional $1.9 \%$, which was not statistically significant, $F(8,79)=1.213, \mathrm{p}>.05$. Model summary suggests Sig. F Change of .859 and $R^{2}$ change of .003. At step 2, the ANOVA reveals a change in Sig levels from .158 to .303 suggesting principal experience provided no significant value to PSE. The inclusion of principal perception in Step 3 yielded significant results, $F(9,78)=4.362, \mathrm{p}<.001$. Principal perception resulted in a Sig F Change from .859 to .000 and $R^{2}$ change of .003 to .225 . The final regression accounted for $25.8 \%$ of the total variance explained as indexed by the adjusted $R^{2}$ statistic. The sole significant component factor with the greatest unique contribution to the variance in the overall model was principal perception, standardized beta $=.504$. These results suggest principal perception of SBTE was the strongest predictor of PSE in the model. 
Table 10

HLR Analyses Predicting Principal Self-Efficacy

\begin{tabular}{|c|c|c|c|c|}
\hline \multirow[t]{2}{*}{ Variable } & \multicolumn{4}{|c|}{ Estimates } \\
\hline & $A R^{2}$ & $\Delta R^{2}$ & $B$ & $S E$ \\
\hline Step 1 & .040 & & & \\
\hline$\%$ Free and Reduced Lunch & & & .007 & .004 \\
\hline School Level & & & .014 & .117 \\
\hline School Meeting AMO & & & .164 & .142 \\
\hline Number of Teachers Per Evaluating Admin & & & -.007 & .015 \\
\hline Student Enrollment & & & .000 & .000 \\
\hline Teacher Retention Rate & & & .003 & .010 \\
\hline Step 2 & .019 & .003 & & \\
\hline$\%$ Free and Reduced Lunch & & & .007 & .004 \\
\hline School Level & & & .022 & .121 \\
\hline School Meeting AMO & & & .176 & .148 \\
\hline Number of Teacher per Evaluating Admin & & & -.006 & .015 \\
\hline Student Enrollment & & & .000 & .000 \\
\hline Teacher Retention Rate & & & .003 & .010 \\
\hline Principal Experience & & & .011 & .021 \\
\hline Principal Experience at Current School & & & -.005 & .028 \\
\hline Step 3 & .258 & $.225 * *$ & & \\
\hline$\%$ Free and Reduced Lunch & & & .005 & .003 \\
\hline School Level & & & -.082 & .107 \\
\hline School Meeting AMO & & & .094 & .129 \\
\hline Number of Teachers Per Evaluating Admin & & & -.024 & .013 \\
\hline Student Enrollment & & & -5.06 & .000 \\
\hline Teacher Retention Rate & & & .004 & .009 \\
\hline Principal Experience & & & .001 & .019 \\
\hline Principal Experience at Current School & & & .006 & .025 \\
\hline Principal Perception of Teacher Evaluation & & & $.087 * *$ & .017 \\
\hline$* p<.05$ & & & & \\
\hline$* * p<.01$ & & & & \\
\hline$A R^{2}=$ Adjusted $R$ Square & & & & \\
\hline$\Delta R^{2}=$ Change in $R$ Square & & & & \\
\hline$B=$ Unstandardized Beta Coefficients & & & & \\
\hline$S E=$ Standard errors & & & & \\
\hline
\end{tabular}

HLR principal self-efficacy for management. The second analysis used the

HLR model to examine the PSES subscale of self-efficacy for management (see Table

11). At Step 1, school characteristics did not contribute to the model, $F(6,81)=1.071, p$ 
$>.05$, and explained $.5 \%$ of the variance in principal self-efficacy for management. Step 2 included the addition of principal experience and principal experience in their current school, which resulted in accounting for a reduction of $-1.3 \%$, which was not statistically significant, $F(8,79)=.860, p>.05$. Model summary data suggest a Sig F Change of .754 and $R^{2}$ Change of .007. ANOVA reveals Sig level increased from .387 in step 1 to .554 in step 2. This indicates that principal experience provided no additional value to the model. This lack of significance was seen in each of the individual component factors. As with the previous analysis, the inclusion of principal perception in Step 3 did produce significant results, $F(9,78)=2.164, p=.001$. The final regression accounted for $10.7 \%$ of the total variance explained as indexed by the adjusted $R^{2}$. Model summary data in step 3 reveal $R^{2}$ change of .120 and Sig levels of .034. As with the previous model principal perception, standardized beta $=.367$, provided the greatest contribution to the model. 
Table 11

HLR Analyses Predicting Principal Self-Efficacy for Management

\begin{tabular}{|c|c|c|c|c|}
\hline \multirow[t]{2}{*}{ Variable } & \multicolumn{4}{|c|}{ Estimates } \\
\hline & $A R^{2}$ & $\Delta R^{2}$ & $B$ & $S E$ \\
\hline Step 1 & .005 & & & \\
\hline$\%$ Free and Reduced Lunch & & & .007 & .005 \\
\hline School Level & & & .043 & .143 \\
\hline School Meeting AMO & & & .085 & .173 \\
\hline Number of Teachers Per Evaluating Admin & & & -.015 & .018 \\
\hline Student Enrollment & & & .000 & .000 \\
\hline Teacher Retention Rate & & & .016 & .012 \\
\hline Step 2 & -.013 & .007 & & \\
\hline$\%$ Free and Reduced Lunch & & & .007 & .005 \\
\hline School Level & & & .057 & .148 \\
\hline School Meeting AMO & & & .105 & .180 \\
\hline Number of Teacher per Evaluating Admin & & & -.014 & .018 \\
\hline Student Enrollment & & & .000 & .000 \\
\hline Teacher Retention Rate & & & .015 & .013 \\
\hline Principal Experience & & & .017 & .026 \\
\hline Principal Experience at Current School & & & -.007 & .035 \\
\hline Step 3 & $.107 *$ & .120 & & \\
\hline$\%$ Free and Reduced Lunch & & & .006 & .004 \\
\hline School Level & & & -.034 & .141 \\
\hline School Meeting AMO & & & .033 & .170 \\
\hline Number of Teachers Per Evaluating Admin & & & -.030 & .018 \\
\hline Student Enrollment & & & -6.34 & .000 \\
\hline Teacher Retention Rate & & & .016 & .012 \\
\hline Principal Experience & & & .009 & .025 \\
\hline Principal Experience at Current School & & & .002 & .033 \\
\hline Principal Perception of Teacher Evaluation & & & $.076 * *$ & .022 \\
\hline$* p<.05$ & & & & \\
\hline$* * p<.01$ & & & & \\
\hline$A R^{2}=$ Adjusted $R$ Square & & & & \\
\hline$\Delta R^{2}=$ Change in $R$ Square & & & & \\
\hline$B=$ Unstandardized Beta Coefficients & & & & \\
\hline$S E=$ Standard errors & & & & \\
\hline
\end{tabular}


HLR principal self-efficacy for instructional leadership. The final analysis used HLR to examine the PSES subscale of self-efficacy for instructional leadership. Table 12 provides the results of this analysis. At Step 1, school characteristics did contribute to the model, $F(6,81)=2.356, p=.038$, and explained $8.5 \%$ of the variance in principal selfefficacy for instructional leadership. Results suggest school characteristics play an important role in principal self-efficacy (PSE) for instructional leadership. Step 2 included the addition of principal experience and principal experience in their current school, which resulted in accounting for an additional $6.3 \%$, which was not statistically significant, $F(8,79)=1.728, p>.05$. Model summary data suggest Sig. F Change of .982 and an $R^{2}$ Change .000 . As with the previous two analysis the inclusion of principal perception in Step 3 did produce significant results, $F(9,78)=6.229, p<.001$. Model summary data in step 3 indicates an $R^{2}$ change of .269. The standardized beta coefficient in this model was .550 . The final regression accounted for $35.1 \%$ of the total variance explained as indexed by the adjusted $R^{2}$ statistic. 
Table 12

HLR Analyses Predicting Principal Self-Efficacy for Instructional Leadership

\begin{tabular}{|c|c|c|c|c|}
\hline \multirow[t]{2}{*}{ Variable } & \multicolumn{4}{|c|}{ Estimates } \\
\hline & $A R^{2}$ & $\Delta R^{2}$ & $B$ & $S E$ \\
\hline Step 1 & $.085^{*}$ & & & \\
\hline$\%$ Free and Reduced Lunch & & & .006 & .004 \\
\hline School Level & & & -.015 & .118 \\
\hline School Meeting AMO & & & .242 & .142 \\
\hline Number of Teachers Per Evaluating Admin & & & .002 & .015 \\
\hline Student Enrollment & & & .000 & .000 \\
\hline Teacher Retention Rate & & & -.010 & .010 \\
\hline Step 2 & .063 & .000 & & \\
\hline$\%$ Free and Reduced Lunch & & & .006 & .004 \\
\hline School Level & & & -.013 & .122 \\
\hline School Meeting AMO & & & .247 & .149 \\
\hline Number of Teacher per Evaluating Admin & & & .002 & .015 \\
\hline Student Enrollment & & & .000 & .000 \\
\hline Teacher Retention Rate & & & -.010 & .011 \\
\hline Principal Experience & & & .004 & .022 \\
\hline Principal Experience at Current School & & & -.003 & .029 \\
\hline Step 3 & $.351 * *$ & .269 & & \\
\hline$\%$ Free and Reduced Lunch & & & .005 & .003 \\
\hline School Level & & & -.130 & .103 \\
\hline School Meeting AMO & & & .155 & .125 \\
\hline Number of Teachers Per Evaluating Admin & & & -.018 & .013 \\
\hline Student Enrollment & & & -3.76 & .000 \\
\hline Teacher Retention Rate & & & -.009 & .009 \\
\hline Principal Experience & & & -.007 & .018 \\
\hline Principal Experience at Current School & & & .010 & .024 \\
\hline Principal Perception of Teacher Evaluation & & & $.098 *$ & .016 \\
\hline$* p<.05$ & & & & \\
\hline$* * p<.01$ & & & & \\
\hline$A R^{2}=$ Adjusted $R$ Square & & & & \\
\hline$\Delta R^{2}=$ Change in $R$ Square & & & & \\
\hline$B=$ Unstandardized Beta Coefficients & & & & \\
\hline$S E=$ Standard errors & & & & \\
\hline
\end{tabular}




\section{Summary}

Results reveal the majority of principals participating in the study were at the elementary school level (61.79\%). School level data suggest elementary schools had the lowest enrollment $(M=528)$, highest percentage of students qualifying for free/reduced lunch $(70.98 \%)$, fewest certified teachers $(M=31.69)$, and highest teacher retention rate (90.7\%). Middle schools provided the lowest teacher retention rate $(87.21 \%)$ and lowest average number of teachers per administrators $(M=13.88)$. Unsurprisingly, high schools had the highest enrollment $(M=1367)$, along with the highest number of teachers $(M=$ 82.55) and highest average of teachers per administrator. Experience levels reveal the majority of principals are new to the position or their current school. Perceptions of SBTE are consistent with self-efficacy levels revealing concerns with the amount of time required to complete each of the tasks associated with the new system. Data from school characteristics, experience, and perceptions become important in examining self-efficacy levels. The results reveal larger schools and higher numbers of teachers per administrator, which were greater at the high school level, produced the lowest selfefficacy scores in the area of management $(M=3.52)$.

Results of the HLR in predicting PSE from school characteristics, principal experience, and principal perception of SBTE suggest the only significant component factor with the greatest unique contribution to the variance in all models was principal perception. As principal perception was included at step 3 in each of the models it produced standardized bet coefficients ranging from .367 to .550 . HLR model predicting principal self-efficacy suggests principal perception of SBTE accounted for $25.8 \%$ of the variance as indicated by the adjusted $R^{2}$ while producing a standardized beta coefficient 
of .504. Principal self-efficacy for instructional leadership produced statistically significant results during Block 1, school characteristics, and Block 3 principal perception of teacher evaluation. This model produced the highest standardized beta (.550) when principal perception was included into the model.

While the HLR for PSE for management did not produce significant results until the inclusion of principal perception as evidenced by standardized beta coefficient of .367 , it does provide insight into concerns regarding time management and the principals ability to successfully implement SBTE. The results in this analysis suggest if principals view SBTE as a worthwhile process, they are much more efficacious in their ability to implement the reform in their buildings. Chapter 5 will use the results provided in Chapter 4 to discuss the implications and provide directions for future research. 


\section{CHAPTER FIVE}

\section{DISCUSSION}

This study examined the relationship between school related factors, and principal experience, perception of teacher evaluation, and self-efficacy for the implementation of standards based teacher evaluation (SBTE). Bandura's (1977, 1978, 1997) Social Cognitive Theory (SCT) was used as the lens to analyze predictors of principal selfefficacy. Previous studies have examined principal perceptions of teacher evaluation implementation (Derrington \& Campbell, 2015). However, this study provides an extension of the literature to capture self-efficacy levels of principals as they worked through the implementation of a SBTE system in one Southeastern school district. Chapter 1 provided a justification for the study based on the literature and included a brief overview of the purpose, methods, and limitations. Chapter 2 summarized the relevant literature and framed the study by illustrating how accountability measures have changed the method of determining teacher effectiveness and ultimately the role of the principal. Chapter 3 discussed the research question and methodological approach, while Chapter 4 included the results of the research question examined. This chapter discusses the contribution of the results to both practice and the existing literature. In the ensuing discussion, a summary of the main results, the results as they relate to the theoretical framework, implications, and directions for future research are provided.

To answer the research question, a non-experimental correlational research design was used to capture principal self-efficacy levels as they worked through SBTE 
implementation in their buildings. School characteristic data and principal survey responses were used to categorize variables based on Bandura's Triadic Reciprocal Causation (1978). Variables were grouped into environmental, personal, and behavioral characteristics and entered into hierarchical multiple linear regression (HLR) equation in an attempt at predicting principal self-efficacy (PSE). Data were analyzed using HLR and self-efficacy predictors were examined for overall principal self-efficacy, selfefficacy for management, and self-efficacy for instructional leadership.

The theoretical framework guiding the study was Social Cognitive Theory and the idea of Triadic Reciprocal Causation (Bandura 1978). Triadic Reciprocal Causation (TRC) allowed for analyzing the interaction between variables and was used to determine if school characteristics, principal experience and principal perception of SBTE are predictors of PSE. The reciprocal nature of the variables in this study are important as districts look to implement and support mandated reforms. Figure 2 illustrates the factors with the variable groupings associated for each. Behavioral factors (B) include principal experience and principal perception of SBTE while the environmental factors (E) are school characteristics such as enrollment, number of evaluating administrators, percentage of students qualifying for free and reduced lunch, teacher retention rate, and annual measurable objective (AMO) status. The personal factor $(\mathrm{P})$ of the triad is the individual's level of self-efficacy. To predict PSE for SBTE implementation, this study focused on the interaction between $\mathrm{E}-\mathrm{P}$ and $\mathrm{B}-\mathrm{P}$. 


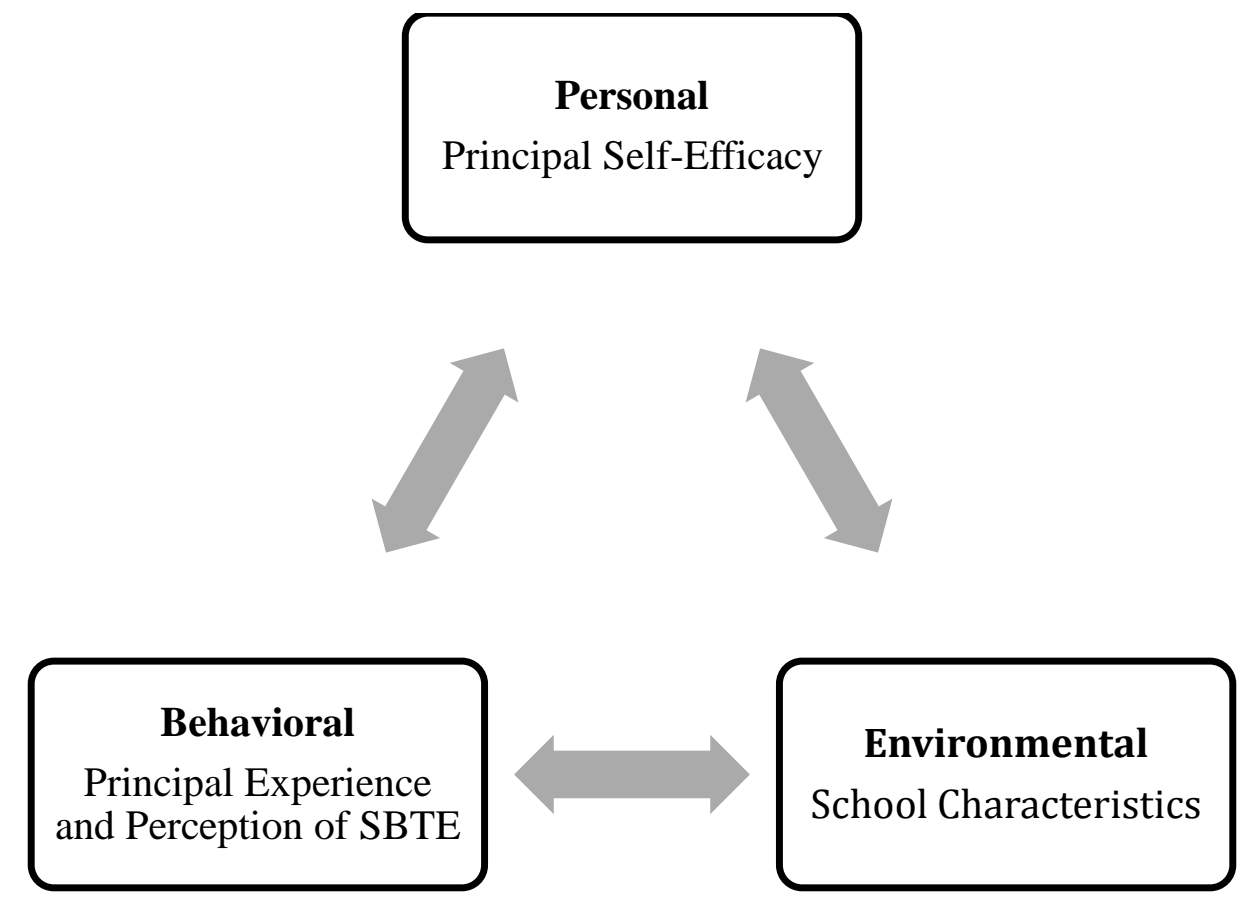

Figure 2. TRC Factors and Variable Grouping (Bandura, 1978)

\section{Summary of Results}

Previous literature has identified the changing role of school principals as a result of increased accountability (Goodwin, Cunningham \& Childress, 2003; Hallinger \& Murphy 2013; Valentine \& Prater, 2011). More recently SBTE systems have been implemented in many of our nation's schools and resulted in mix findings regarding their accuracy in measuring teacher effectiveness (Harris, et al.,, 2014; Kupermintz, 2003; Murphy, Hallinger \& Heck, 2013). To date limited research on principal self-efficacy for SBTE implementation is available in the existing literature. This study modified existing surveys to identify principals' perceptions of SBTE and their self-efficacy levels for its implementation. The results provide insight into principal self-efficacy for future school based reforms. Identifying predictors of PSE will allow district officials to design training which meets the varied needs of the principals and schools tasked with 
implementing reforms. Survey data and HLR analysis resulted in three main results. First, management concerns related to the amount of time required to accomplish each of the individual tasks associated with SBTE were revealed. Second, principal perception of SBTE was the critical variable resulting in the statistical significance for each of the models. Third, principal experience did not contribute to PSE. Based on the results, I must accept the null hypothesis that principal experience and school related factors are not predictors of PSE. I can however reject the null hypothesis that principal perception of SBTE will predict PSE. A review of the key results and the relationship to the theoretical framework is provided next.

\section{Supporting Principal Implementation of SBTE}

The first key finding surfaced through the analysis of survey data and descriptive statistics. Item analysis of section three of the Principal Appraisal Inventory identified principal perceptions of SBTE and supports existing literature expressing concern with the amount of time required to complete the tasks within a SBTE system (Derrington \& Campbell, 2015; Dodson, 2015; Ruffini et al.,, 2014). Derrington and Campbell (2015) found high self-efficacy principals had fewer additional duties while low self-efficacy principals had more duties and higher enrollments. Derrington and Campbell's (2015) findings are consistent with the present study as the results suggest high school principals rated themselves lowest in the area of self-efficacy for management. High school principals $(N=20)$ had the highest average student enrollment, highest number of teachers, and highest teacher per administrator ratio. Therefore, school characteristics at the high school level suggest an increased workload and additional challenges associated with managing the school. 
Surprising were that the number of evaluating administrators in each building was not a significant variable in predicting PSE for SBTE implementation. School characteristic data suggests the number of teachers per evaluating administrator range from a low in the middle school $(M=13.88, S D=3.67)$ to a high on the high school $(M=$ $18.77, S D=4.56)$ with elementary schools falling in the middle $(M=16.74, S D=5.53)$. With management as an area of concern for principals at all school levels, it would seem that having additional administrators would alleviate some of the additional pressures. It is unclear why the number of evaluating administrators was not a significant predictor. One possibility is that the external supports neglected to provide suggestions or a framework for how to effectively distribute the leadership among the additional evaluating administrators.

Dodson (2015) investigated principals during a pilot year of SBTE and also found concerns over the amount of time required to complete each of the tasks associated with SBTE. The present study's results support Dodson (2015) as evidenced by principal selfefficacy ratings for management $(M=3.66, S D=.79)$ being lower than self-efficacy for instructional leadership $(M=3.98, S D=.68)$, indicating management concerns by principals at all school levels. Interestingly, statement 2 in the perception section of the Principal Appraisal Inventory, which asked principals to rate if the evaluation process takes more time than the results are worth, produced the lowest mean score of all nine items $(M=3.47, S D=1.08)$. This suggests that though managing the additional tasks are an area of concern, principals perceive SBTE as worthwhile. Results of the present study are consistent with the existing literature (Dodson, 2015; Ruffini, et al.,, 2014) indicating principals perceive SBTE systems as an improvement over previous instruments. 
Time and management concerns are related to the environmental factor of the TRC model. Variables in the environmental factor include school characteristics of $\%$ free and reduced lunch, school level, AMO status, number of teachers per administrator, student enrollment, and teacher retention rate. Results suggest that environmental factors did not contribute to the model for overall PSE or PSE for management. It did however contribute to the model for PSE for instructional leadership. School factors accounted for $8.5 \%$ of the variance as indicated by the adjusted $R^{2}$ statistic. One possibility for these results were the environmental variable did not include the number of teachers in their summative year of evaluation. Teachers in their summative year of evaluation require a minimum of three principal observations, whereas teachers in a non-summative year require only one. Therefore, schools with a high number of new teachers, or teachers in their summative year, have additional principal observations which would likely increase management concerns.

Smith, et al., (2006) also used school characteristics as the environmental factor in predicting principal self-efficacy and concluded free and reduced lunch and student enrollment yielded significant results $\left(R^{2}=.145, P<.001\right.$, beta $\left.=.195, p=.001\right)$. The present study produced similar results for free/reduced lunch with standardized beta coefficients of .193. Therefore, it appears the present study confirms the research literature results in that free/reduced lunch is a successful predictor of PSE. These results imply that principals in some of our more challenging schools are also the most efficacious. Further, the results suggest how we prepare and support principals for reform implementation are ineffective in providing the experiences necessary to successfully manage schools within the new evaluation system. 
Bandura (1997) explains the sources of self-efficacy to be rooted in experiences (mastery and vicarious experience), support (social persuasion), and an individual's ability to overcome adversity (affective state). With the role of the principal changing due to a shift towards higher accountability, principals must effectively manage the school and provide instructional leadership. It is clear from the results of this study and previous research that a major concern is with managing the additional tasks associated with SBTE systems. Derrington and Campbell (2015) argue effective implementation of SBTE systems requires principals to employ a collaborative or distributed approach to move beyond management concerns. Therefore, principal leadership approaches should look to build the capacity of school staff through providing mastery experiences and supports attributed to Banduras self-efficacy source of social persuasion (Bandura, 1997).

This study did not investigate district level support of principals. External supports are associated with the self-efficacy source of social persuasion. The additional tasks associated with SBTE likely influenced the principals daily schedule. Unintended consequences of implementing SBTE are the opportunity costs incurred. With observations, feedback sessions, and paperwork increased under the new system it will be interesting to see how principals reallocate their time. Derrington and Campbell (2015) indicate the increased workload resulted in additional time being spent outside of school at night and on the weekends. As a result, district officials should be concerned with the quality and effectiveness of the evaluations along with the personal wellbeing of principals.

The results of the present study are particularly salient when considering the changing role of the principal. Previous literature suggests the role of the principal has 
shifted away from the managerial leader to an instructional or transformational leader (Goodwin, Cunningham \& Childress, 2003; Hallinger, 1992). The present study's results related to management offer further support to those suggesting effective principals must utilize a transformational approach by building the capacity of staff (Hallinger, 2003, 2009; Spillane et al.,, 2004). As the research literature suggests, leadership styles are multidimensional (Marks \& Printy, 2003; Urick \& Bowers, 2011). Therefore, the results of the present study indicate the need for principals to incorporate multiple leadership styles and find a balance between managerial and instructional leadership. Concerns regarding the principal's ability to effectively manage the additional duties associated with SBTE systems will require contextually relevant supports which take into account school factors, principal perception, and principal self-efficacy.

Key finding one suggests a need for consistent and appropriate support for the principals implementing SBTE systems. How principal preparation programs and school districts develop self-efficacy for managing these additional SBTE tasks will likely determine the fidelity of implementation. Therefore, principal preparation programs and school districts should provide the opportunity for mastery and vicarious experiences along with the continued supports needed to effectively maintain SBTE systems in schools. Failure to do so will result in varied levels of implementation and the inconsistent application of SBTE in the schools throughout the district being studied. These concerns certainly warrant a second look at the use of SBTE as a viable means of improving instruction. If principals are struggling with managing STBE it may be advantageous to investigate the opportunity cost of maintaining them as a practice. 


\section{Principal Perception of SBTE}

The second key finding was that principal perception of SBTE was the greatest contributor of PSE in all 3 models, and was most significant when predicting PSE for instructional leadership. This suggests principals who view SBTE as a means of improving instruction are more efficacious with SBTE implementation. Given the complexity of generating change in schools, understanding principal perceptions and selfefficacy is essential for effective implementation and support of school based reforms. The present study's results related to principal perception of SBTE support Vekeman, Devos and Tuytens (2014) who determined how principals made sense of and valued teacher evaluation led to varying degrees of acceptance by the teachers. DarlingHammond et al., (1983) argue teacher evaluation will vary based on the principals' view of effective teaching. Urick and Bowers (2014) suggest principal perception determines principal behavior and ultimately the extent to which school leaders influence change. The existing literature reinforces the important role principal perception plays in SBTE implementation. Given the results of the present study and existing literature it would be advantageous to ensure principals implementing school reforms, specifically SBTE, have positive perceptions of the reform.

In the present study principals who produced higher results on the perception statements also had higher levels of self-efficacy. As Bandura $(1986,1997)$ suggests highly efficacious individuals are more likely to overcome adversity and successfully accomplish a task. The evidence provided in chapter 4 illustrates that for every unit increase in principal perception, PSE increased .504 as evidenced by the standardized beta coefficients. Therefore, it can be concluded that the behavioral factor, specifically 
principal perception, influenced PSE, PSE for management, and PSE for instructional leadership. This suggests that if states and school districts implement SBTE systems as a means of improving classroom instruction it would be advantageous to create a positive perception among principals. Principal training and supports should be designed to illicit positive perceptions of SBTE by clearly articulating its purpose, benefits, intended outcomes and remove managerial barriers.

Principal perception was assigned to the behavioral factor in the triad. Behavioral factors included principal experience, experience in their current school, and perception of SBTE. McCullers and Bozeman (2010) determined principal perception of goal attainability led to higher self-efficacy levels. The results by McCullers and Bozeman (2010) have implications for the present study when looking at a principal's ability to successfully implement SBTE in their buildings. If principals have positive perceptions of SBTE, and view it as a means of improving classroom instruction, they are much more likely to implement the system with fidelity. Interestingly, high school principals produced the highest perception mean scores $(M=35.70, S D=3.87)$ as compared to elementary $(M=34.78, S D=4.0)$ and middle schools $(M=34.27, S D=3.36)$. Since high school principals had the lowest self-efficacy mean scores $(M=3.63, S D=.66)$, one may conclude their overall perception of the new system would be lower in light of the management concerns. One possibility for these results are that the clearly defined rubric and systemic nature of SBTE is simply a much better measure of teacher effectiveness than the previous system. 


\section{Principal Experience}

The third key finding was related to principal experience. Interestingly, the results of the current study suggest principal experience and principal experience in their current school provides no statistical improvement in the model. In fact when looking at overall PSE the model summary suggests the adjusted $R^{2}$ reduces from .40 to .019 with the addition of the experience block. The results that experience was not related to PSE are consistent with those of Tschannen-Moran and Gareis (2004) but challenge those of Fisher (2014) who identified a relationship between principal experience and PSE. The results that experience provided no additional value are surprising considering Bandura's (1997) assertion that self-efficacy is developed through both mastery and vicarious experiences. If, as Bandura (1997) suggests, self-efficacy develops based on experiences it is unclear why principal experience provided no value to the model. A possibility is that the new evaluation system is complex, multilayered, and completely different from previous systems. Therefore, principals, regardless of years of experience are all in the same situation in terms of learning SBTE and how to effectively utilize it in their buildings.

In sum, Bandura $(1978,1997)$ suggests personal, behavioral, and environmental factors work bidirectionally to shape an individual's behavior. This study sought to investigate the interaction between the behavioral and personal factors along with the environmental and personal factors. Results suggest a positive relationship between the environmental factors of school characteristics and PSE for instructional leadership. Additionally, behavioral factors, specifically principal perception, has a strong relationship with overall PSE, PSE for management, and PSE for instructional leadership. 
Principal experience however provided no statistical value to any of the models, which is in direct contradiction to two of Bandura's (1997) self-efficacy sources. Given the increased pressure placed on principals these results are useful in identifying principal candidates for some of our nations more challenging schools. Furthermore, it provides justification for reevaluating leadership approaches and district level supports which look to build self-efficacy and positive perceptions of school based reforms.

\section{Implications for Practice and Policy}

This study has implications for both policy and practice and provides a contribution to the literature on principal self-efficacy and teacher evaluation. Principal self-efficacy influences their effectiveness as a leader, ability to overcome adversity, and ultimately task accomplishment. In today's high stakes accountability model of education highly efficacious principals are needed to lead our nation's schools. Identifying selfefficacy beliefs will allow for the recruitment and support of principals. This study produced three key results. The first result illustrated the concerns among principals related to the additional tasks associated with SBTE and suggests managing the new system provides challenges. The second result indicates principal perception of SBTE significantly contributed to PSE in each of the three models. Result three revealed principal experience was not a self-efficacy predictor. These results provide implications for both policy and practice and extend the literature on PSE and teacher evaluation.

Because SBTE in Deal Unified School District (DUSE) is mandated by the state's department of education this study has policy implications. Understanding principal selfefficacy and perceptions may help address concerns with the implementation of future reforms. Research on SBTE has been met with mixed reviews, much of it stemming from 
managing SBTE systems in schools (Crum \& Sherman, 2008; Derrington \& Campbell, 2015; May \& Supovitz, 2010). The present study provides support to the existing literature as evidenced by principals rating themselves lowest in the area of self-efficacy for management. With the amount of funding tied to SBTE systems determining the needs of principals cannot be left to chance or a one size fits all approach to training and support. If teacher evaluation is intended to improve classroom instruction, policy makers should focus their attention on removing the barriers to successful implementation. This study suggests the barriers include managerial tasks and perception of teacher evaluation.

With SBTE increasing the number of principal observations and managerial tasks, future policy that increases the workload of principals should provide additional supports. Understanding concerns and barriers to successful implementation requires timely support which takes into account the characteristics of individual schools and the principals that lead them. One concern that surfaced from the results were that unintended consequences may result from the increased workload placed on principals. With principals already being pulled in a number of directions throughout the day, the increased tasks associated with SBTE may result in inconsistent implementation. Given this concern, policymakers may use this information to provide contextually relevant supports based on the unique needs of the school and/or district. If, as the research literature suggests, implementation of school based reforms is left to the interpretation of the principals, SBTE systems may be implemented differently from school to school. Therefore, future policy should provide safeguards to ensure principals are held 
accountable for implementing and utilizing teacher evaluation as the policy is intended within their schools.

In terms of professional practice, this study submits that states and school districts looking to implement SBTE systems should identify systems of support for building principals. These systems of support should come in terms of improving the perception of teacher evaluation and address managerial concerns associated with SBTE. Research suggests principal perception directly influences school climate (Urick \& Bowers, 2011). Since teacher evaluation provides an extension of the schools instructional program it is directly related to the overall school climate. The degree to which principals understand and use the new evaluation system should be consistent throughout the schools in the district. Using the results of the present study, district officials should mitigate management concerns and communicate expectations for how SBTE will improve classroom instruction. The consistent implementation and individualized support will allow SBTE to be used as a means of supporting teachers and improving classroom instructional practices.

The results of this study also provide valuable insight into how principals are prepared. Previous research has determined when a focused attempt at building leader capacity takes place, a greater sense of self-efficacy occurs (Airola et al., 2014). University instructors and principal preparation programs would benefit from understanding the factors associated with self-efficacy levels and build capacity through the tenets of self-efficacy such as mastery and vicarious experiences. Curriculum in principal preparation programs should go beyond educational law and theory to include opportunities to experience reform implementation in the school setting. Furthermore, 
principal preparation programs should allow individuals to troubleshoot school problems in an attempt at addressing Bandura's fourth source, the affective state. Given how important principals are for teaching and learning, it is critical to enhance self-efficacy levels of the individuals tasked with leading our nation's schools.

This study used SCT and the idea of TRC as the theoretical framework (Bandura, 1978, 1997). TRC suggests a bidirectional interaction between behavioral, environmental, and personal factors. Results in this study support Bandura $(1978,1997)$ as the behavioral factor of principal perception and the environmental factors of school characteristics significantly contributed to the model in predicting PSE for instructional leadership. While the same interaction between the environmental and personal factors were not seen in overall self-efficacy and self-efficacy for management, the behavioral factor did significantly contribute to all three models. The results of this study extend the literature on principal self-efficacy to identify factors which may predict varying levels of self-efficacy among our school leaders. Previous literature has suggested experience (Fisher, 2014) and external supports (Airola et al., 2014) are related to PSE. Surprisingly, this study suggests overall principal experience and experience in their current school, did not significantly contribute to any of the three models and therefore were not successful predictors of PSE. Despite these results, opportunities for growth should be provided to principals through both mastery and vicarious experiences.

\section{Future Research}

The results of this study extend the literature on principal self-efficacy, standards based teacher evaluations, and implementation of school based reform. The study provides evidence that school characteristics and principal perception influence principal 
self-efficacy. Considering the important role principals play in designing and implementing the instructional program, and how educational policy effects their daily role, future research should focus on how principal implementation influences the effect of teacher evaluation on classroom instruction. Further examination should include teacher perception of principal implementation and the relationship between principal observation ratings and teacher value added model (VAM) scores.

Since principal perception of SBTE varied among the participants, identifying if principal perception of SBTE is related to teacher perceptions may provide valuable information for future training and professional development. Capturing teacher perceptions may come from their view their principal as an instructional leader or their view of SBTE as a measure of teacher effectiveness. Previous research on the relationship between principal observation ratings and VAM has produced varying results (Kupermintz, 2003; Koedel \& Betts, 2011; Newton et al., 2010; Sass, Semykina \& Harris, 2014). The present study captured principal self-efficacy for SBTE implementation. Future research examining the relationship between principal ratings and teacher VAM may allow principals and teachers to reexamine their approach to the evaluation process. Finally, the variables in the behavioral block were limited to principal perception and principal experience. Further investigation will be required to study and expand on the antecedents of PSE. More specifically, a qualitative exploration, identifying which environmental factors influence PSE for management may provide a greater understanding. To better understand the bidirectional relationship between the factors, additional variables in the behavioral block may also prove beneficial. Possible options may include information related to training and preparation or previous 
experiences with teacher evaluation. The information related to the training and preparation would align with Bandura's sources of self-efficacy and allow for a deeper understanding of principal leadership behavior.

\section{Conclusion}

SBTE systems are the result of increased accountability measures. They have changed the way principals lead their schools and directly influence their day to day schedule. With the increased pressure placed on schools and their leaders, it is critical that districts provide them with the supports they need to successful lead their schools. Self-efficacy is associate with successful task attainment, therefore, ensuring our nation's principals are efficacious becomes essential to their overall success.

This study illustrated the concerns related to managing the additional tasks associated with implementing a SBTE system in one Southeastern school district. Results suggest principals rated themselves higher in the area of self-efficacy for instructional leadership rather than self-efficacy for management. If SBTE systems are going to continue being a part of assessing teacher effectiveness policymakers and school districts must do a better job of ensuring principals have the tools necessary to effectively lead their schools. These results support previous research and bring to light the need to determine the types of support needed to successfully manage and lead our schools (Airola et al.,, 2014; Leithwood \& Jantzi, 208; Osterman \& Sullivan, 1996; TschannenMoran \& Gareis, 2005). It also reinforces the important role principal perception plays in self-efficacy levels. Results of this study show principal perception was the key variable in each of the HLR models. Therefore, a focus of policymakers and local school districts should be on clearly illustrating the purpose and benefit of having SBTE systems as the 
measure of teacher effectiveness. Improving principal perception of externally mandated reforms will likely increase self-efficacy levels and ultimately increase the likelihood that it will be implemented with the same level of fidelity among all schools. With the tremendous amount of funding associated SBTE systems we must ensure that they are implemented as intended and utilized as a means of improving classroom instructional practices. 


\section{REFERENCES}

Airola, D., Bengtson, E., Davis, D., \& Peer, D. (2014). Principals's sense of efficacy: The influence of the Arkansas Leadership Academy. Journal of Educational Administration, 52(6), 754-774.

Ashton, P., \& Crocker, L. (1987). Systematic study of planned variations: The essential focus of teacher education reform. Journal of Teacher Education, 38(3), 2-8.

Ashton, P. T. (1982). A Study of Teachers' Sense of Efficacy. Final Report, Volume I. National Institute of Education, Washington, DC.

Balfanz, R., Legers, N., West, T.C., \& Weber, L.M. (2007) Are NCLB's measures, incentives, and improvement strategies the right ones for the nation's low-performing high schools? American Educational Research Journal, 44(3), 559-593.

Bamburg, J. D., \& Andrews, R. L. (1991). School goals, principals, and achievement. School Effectiveness and School Improvement, 2(3), 175-191.

Bandura, A. (1977). Self-efficacy: toward a unifying theory of behavioral change. Psychological review, 84(2), 191.

Bandura, A. (1986). Social foundations of thought and action: A social cognitive theory. Prentice-Hall, Inc.

Bandura, A. (1989). Human agency in social cognitive theory. American psychologist, 44(9), 1175 .

Bandura, A. (1997). Self-efficacy: The exercise of control: New York: Freeman; 3-21.

Bandura, A. (2000). Cultivate self-efficacy for personal and organizational effectiveness. Handbook of principles of organization behavior, 2 179-200. 
Bandura, A. (2001). Social cognitive theory: An agentic perspective. Annual review of psychology, 52(1), 1-26.

Blase, J., \& Blase, J. (1999). Principals' instructional leadership and teacher development: Teachers' perspectives. Educational administration quarterly, 35(3), 349-378.

Borman, G. D., Hewes, G. M., Overman, L. T., \& Brown, S. (2003). Comprehensive school reform and achievement: A meta-analysis. Review of Educational Research, 73(2), 125230.

Borman, G. D., \& Kimball, S. M. (2005). Teacher quality and educational equality: Do teachers with higher standards-based evaluation ratings close student achievement gaps? The Elementary School Journal, 106(1), 3-20.

Bowles, F. D. (1973). Competency-based teacher education? The Houston Story. Educational leadership, 30(6), 510-512.

Brewer, D. J. (1993). Principals and student outcomes: Evidence from US high schools. Economics of Education Review, 12(4), 281-292.

Bush, G. W. (2001). No child left behind: US Department of Education Washington, DC.

Caprara, G. V., Barbaranelli, C., Steca, P., \& Malone, P. S. (2006). Teachers' self-efficacy beliefs as determinants of job satisfaction and students' academic achievement: A study at the school level. Journal of school psychology, 44(6), 473-490.

Chen, G., \& Bliese, P. D. (2002). The role of different levels of leadership in predicting self-and collective efficacy: evidence for discontinuity. Journal of Applied Psychology, 87(3), 549. 
Clipa, O. (2011). Teacher perceptions on teacher evaluation: The purpose and the assessors within the assessment process. Procedia-Social and Behavioral Sciences, 29, 158-163.

Coladarci, T., \& Fink, D. (1995). Correlations among measures of teacher efficacy: Are they measuring the same thing. Paper presented at the annual meeting of the American Educational Research Association, San Francisco.

Creswell, J. W., (2014). Research design: Qualitative, quantitative, and mixed methods approaches. Sage Publications.

Crum, K. S., \& Sherman, W. H. (2008). Facilitating high achievement: High school principals' reflections on their successful leadership practices. Journal of Educational Administration, 46(5), 562-580.

Cuban, L. (1993). How teachers taught: Constancy and change in American classrooms, 18901990: Teachers College Press.

Daly, A. J., Der-Martirosian, C., Ong-Dean, C., Park, V., \& Wishard-Guerra, A. (2011). Leading under sanction: Principals' perceptions of threat rigidity, efficacy, and leadership in underperforming schools. Leadership and Policy in Schools, 10(2), 171-206.

Danielson, C. (1996). Enhancing professional development: A framework for teaching. Alexandria, VA: Association for Supervision and Curriculum Development.

Danielson, C., \& McGreal, T. L. (2000). Teacher evaluation to enhance professional practice. ASCD.

Danielson, C. (2001). New trends in teacher evaluation. Educational leadership, 58(5), 12-15. Darling-Hammond, L. (2015). Can value added add value to teacher evaluation? Educational Researcher, 44 (2), 132-137. 
Darling-Hammond, L., \& Ball, D. L. (1997). Teaching for high standards: What policymakers need to know and be able to do. National Educational Goals Panel.

Darling-Hammond, L. (2000). Teacher quality and student achievement. Education policy analysis archives, 8,1 .

Darling-Hammond, L., Amrein-Beardsley, A., Haertel, E., \& Rothstein, J. (2012). Evaluating teacher evaluation. Phi Delta Kappan, 8-15.

Darling-Hammond, L., \& Berry, B. (2006). Highly qualified teachers for all. Educational leadership, 64(3), 14.

Darling-Hammond, L., Wise, A. E., \& Pease, S. R. (1983). Teacher evaluation in the organizational context: A review of the literature. Review of Educational Research, 53(3), 285-328.

DeMoulin, D. F. (1992). Demographic characteristics associated with perceived self efficacy levels of elementary, middle, and secondary principals. A paper presented at the annual meeting of the Mid-South Educational Research Association, November 92.

Derrington, M. L., \& Campbell, J. W. (2015). Implementing new teacher evaluation systems: Principals' concerns and supervisor support. Journal of Educational Change, 16(3), 305-326.

Desimone, L. (2002). How can comprehensive school reform models be successfully implemented? Review of Educational Research, 72(3), 433-479.

Dewey, J. (1938). Education and experience: New York: Macmillan.

Dodson, R. L. (2015). Kentucky principal perceptions of the state's new teacher evaluation system: A Survey Analysis. Educational Research Quarterly, 39(2), 53. 
Ellett, C. D., \& Teddlie, C. (2003). Teacher evaluation, teacher effectiveness and school effectiveness: Perspectives from the USA. Journal of Personnel Evaluation in Education, 17(1), 101-128.

Enochs, L. G., \& Riggs, I. M. (1990). Further development of an elementary science teaching efficacy belief instrument: A preservice elementary scale. School science and mathematics, 90(8), 694-706.

Federici, R. A., \& Skaalvik, E. M. (2012). Principal self-efficacy: Relations with burnout, job satisfaction and motivation to quit. Social Psychology of Education, 15(3), 295-320.

Fisher, Y. (2014). The timeline of self-efficacy: changes during the professional life cycle of school principals. Journal of Educational Administration, 52(1), 58-83.

Forsyth, P., \& Adams, C (2015). TPS Survey Instrument, University of Oklahoma

Fowler, F. C. (2009). Policy studies for educational leaders: An introduction. Allyn \& Bacon/Pearson.

Fraenkel, J. R., \& Wallen, N. E. (2003). The nature of qualitative research. How to design and evaluate research in education, 429-449.

Fullan, M. G., \& MA'rrt-raw, B. (1992). Getting Reform Right: What works and what doesn’t. Furtwengler, C. B. (1995). State Actions for Personnel Evaluation. Education policy analysis archives, 3,4 .

Gardner, D. P. (1983). A nation at risk. Washington, DC: The National Commission on Excellence in Education, US Department of Education.

Garman, N. B., \& Hazi, H. M. (1988). Teachers ask: Is there life after Madeline Hunter? Phi Delta Kappan, 669-672. 
Geijsel, F., Sleegers, P., Leithwood, K., \& Jantzi, D. (2003). Transformational leadership effects on teachers' commitment and effort toward school reform. Journal of Educational Administration, 41(3), 228-256.

Gibson, S., \& Dembo, M. H. (1984). Teacher efficacy: A construct validation. Journal of educational psychology, 76(4), 569.

Goddard, R. D. (2001). Collective efficacy: A neglected construct in the study of schools and student achievement. Journal of educational psychology, 93(3), 467.

Goddard, R. D., Hoy, W. K., \& Hoy, A. W. (2000). Collective teacher efficacy: Its meaning, measure, and impact on student achievement. American Educational Research Journal, $37(2), 479-507$.

Goldrick, L. (2002). Improving teacher evaluation to improve teaching quality. Issue Brief. National Governors' Association, Washington, DC. Center for Best Practices.

Goodwin, R. H., Cunningham, M. L., \& Childress, R. (2003). The changing role of the secondary principal. NASSP Bulletin, 87(634), 26-42.

Guskey, T. R. (1981). Measurement of the Responsibility Teachers Assume for Academic Successes and Failures in the Classroom. Journal of Teacher Education, 32(3), 44-51.

Guskey, T. R., \& Passaro, P. D. (1994). Teacher efficacy: A study of construct dimensions. American Educational Research Journal, 31(3), 627-643.

Guthrie, J. W., \& Springer, M. G. (2004). A Nation at Risk Revisited: Did" Wrong" Reasoning Result in" Right" Results? At What Cost? Peabody Journal of Education, 79(1), 7-35.

Hallinger, P. (1992). The evolving role of American principals: From managerial to instructional to transformational leaders. Journal of Educational Administration, $30(3)$. 
Hallinger, P. (2003). Leading educational change: Reflections on the practice of instructional and transformational leadership. Cambridge Journal of education, 33(3), 329-352.

Hallinger, P., \& Heck, R. (1999). Can leadership enhance school effectiveness? Educational management: Redefining theory, policy and practice, 178-190.

Hallinger, P., \& Heck, R. H. (1998). Exploring the principal's contribution to school effectiveness: 1980-1995. School Effectiveness and School Improvement, 9(2), 157-191.

Hallinger, P., Heck, R. H., \& Murphy, J. (2014). Teacher evaluation and school improvement: An analysis of the evidence. Educational Assessment, Evaluation and Accountability, $26(1), 5-28$.

Hallinger, P., \& Murphy, J. (1985). Assessing the instructional management behavior of principals. The Elementary School Journal, 217-247.

Hallinger, P., \& Murphy, J. F. (2013). Running on empty? Finding the time and capacity to lead learning. NASSP Bulletin, 0192636512469288.

Hanushek, E. A. (2011). The economic value of higher teacher quality. Economics of Education Review, 30(3), 466-479.

Hanushek, E. A., \& Rivkin, S. G. (2006). Teacher quality. Handbook of the Economics of Education, 2, 1051-1078.

Hanushek, E. A., \& Rivkin, S. G. (2010). Generalizations about using value-added measures of teacher quality. The American Economic Review, 267-271.

Hanushek, E. A., Kain, J. F., \& Rivkin, S. G. (1998). Teachers, schools, and academic achievement (No. w6691). National Bureau of Economic Research. 
Harris, D. N., Ingle, W. K., \& Rutledge, S. A. (2014). How teacher evaluation methods matter for accountability a comparative analysis of teacher effectiveness ratings by principals and teacher value-added measures. American Educational Research Journal, 51(1), 73112.

Hashweh, M. Z. (1987). Effects of subject-matter knowledge in the teaching of biology and physics. Teaching and teacher Education, 3(2), 109-120.

Haycock, K. (1998). Good teaching matters: How well-qualified teachers can close the gap. Thinking $k-16,3(2), \mathrm{n} 2$.

Hazi, H. M., \& Rucinski, D. A. (2005). Refocusing on the ritual of teacher evaluation: Implications for the future of supervision. Reflections of the Past, Visions for the Future, 154.

Hazi, H. M., \& Rucinski, D. A. (2009). Teacher evaluation as a policy target for improved student learning: A fifty-state review of statute and regulatory action since NCLB. Education policy analysis archives, 17(5), 1-22.

Heck, R. H., \& Hallinger, P. (2009). Assessing the contribution of distributed leadership to school improvement and growth in math achievement. American Educational Research Journal, 46(3), 659-689.

Hillman, S. J. (1986). Measuring self-efficacy: Preliminary steps in the development of a multidimensional instrument. A paper presented at the American Educational Research Association. San Francisco, CA.

Hoy, A. W., \& Spero, R. B. (2005). Changes in teacher efficacy during the early years of teaching: A comparison of four measures. Teaching and Teacher Education, 21(4), 343356. 
Ingle, W. K. (2015). How changes in teacher evaluation are reallocating principals' time. School Business Affairs, 81(4), 15-18.

Ingle, W. K., Willis, C., \& Fritz, J. (2014). Collective bargaining agreement provisions in the wake of Ohio teacher evaluation system Legislation. Educational Policy, 0895904814559249.

Jacob, B. A., \& Lefgren, L. (2008). Can principals identify effective teachers? Evidence on subjective performance evaluation in education. Journal of labor Economics, 26(1), 101136.

Jiang, J. Y., Sporte, S. E., \& Luppescu, S. (2015). Teacher perspectives on evaluation reform Chicago's REACH students. Educational Researcher, 44(2), 105-116.

Johnson, B. (2001). Toward a new classification of nonexperimental quantitative research. Educational Researcher, 30(2), 3-13.

Keedy, J. L. (2005). Reconciling the theory and practice schism in educational administration through practitioner-developed theories in practice. Journal of Educational Administration, 43(2), 134-153.

Kimball, S. M., \& Milanowski, A. (2009). Examining teacher evaluation validity and leadership decision making within a standards-based evaluation system. Educational Administration Quarterly, 45(1), 34-70.

Koedel, C., \& Betts, J. R. (2011). Does student sorting invalidate value-added models of teacher effectiveness? An extended analysis of the Rothstein critique. Education, 6(1), 18-42.

Kupermintz, H. (2003). Teacher effects and teacher effectiveness: A validity investigation of the Tennessee Value Added Assessment System. Educational evaluation and policy analysis, 25(3), 287-298. 
Labaree, D. F. (1997). Public Goods, Private Goods: The American struggle over educational goals. American Educational Research Journal, 34(1), 39-81.

Leithwood, K., Harris, A., \& Hopkins, D. (2008). Seven strong claims about successful school leadership. School leadership and management, 28(1), 27-42.

Leithwood, K., \& Jantzi, D. (2008). Linking leadership to student learning: The contributions of leader efficacy. Educational Administration Quarterly.

Levy, A. J., Joy, L., Ellis, P., Jablonski, E., \& Karelitz, T. M. (2012). Estimating teacher turnover costs: A case study. Journal of Education Finance, 38(2), 102-129.

Little, J. (2003). Inside teacher community: Representations of classroom practice. The Teachers College Record, 105(6), 913-945.

Louis, K.S., Leithwood, K., Wahlstron, K.L., \& Anderson, S.E. (2010). Investigating the links to improve student learning: Final report of research findings. Minneapolis: University of Minnesota.

Marks, H. M., \& Printy, S. M. (2003). Principal leadership and school performance: An integration of transformational and instructional leadership. Educational administration quarterly, 39(3), 370-397.

May, H., \& Supovitz, J. A. (2010). The scope of principal efforts to improve instruction. Educational Administration Quarterly, 47, 332-352.

Marzano, R. J., \& Toth, M. D. (2013). Teacher evaluation that makes a difference: A new model for teacher growth and student achievement. ASCD.

McCormick, M. J. (2001). Self-efficacy and leadership effectiveness: Applying social cognitive theory to leadership. Journal of Leadership \& Organizational Studies, 8(1), 22-33. 
McCullers, J., \& Bozeman, W. (2010). Principal self-efficacy: The effects of No Child Left Behind and Florida school grades. NASSP Bulletin.

McMillan, J. H., \& Schumacher, S. (2014). Research in education: Evidence-based inquiry. Pearson Higher Ed.

Medley, D. M. (1977). Teacher competence and teacher effectiveness. A review of processproduct research. American Association of Colleges for Teacher Education, Washington, D.C.

Milanowski, A. T., \& Heneman III, H. G. (2001). Assessment of Teacher Reactions to a Standards-Based Teacher Evaluation System: A Pilot Study*. Journal of Personnel Evaluation in Education, 15(3), 193-212.

Milanowski, A. T., Kimball, S. M., \& White, B. (2004). The Relationship between standardsbased teacher evaluation scores and student achievement: Replication and extensions at three sites consortium for policy research in education (CPRE)-University of Wisconsin Working Paper Series. TC, 4(01).

Monk, D. H., \& King, J. A. (1994). Multilevel teacher resource effects in pupil performance in secondary mathematics and science. The case of teacher subject matter preparation. Choices and consequences: Contemporary policy issues in education, 29-58.

Moore, W. P., \& Esselman, M. E. (1992). Teacher efficacy, empowerment, and a focused instructional climate: does student achievement benefit? A paper present at the Annual Conference of the American Educational Research Association, San Francisco, CA.

Multon, K. D., Brown, S. D., \& Lent, R. W. (1991). Relation of self-efficacy beliefs to academic outcomes: A meta-analytic investigation. Journal of counseling psychology, 38(1), 30. 
Murphy, J., Elliott, S. N., Goldring, E., \& Porter, A. C. (2007). Leadership for learning: A research-based model and taxonomy of behaviors 1. School Leadership and Management, 27(2), 179-201.

Murphy, J., Hallinger, P., \& Heck, R. H. (2013). Leading via teacher evaluation the case of the missing clothes? Educational Researcher, 42(6), 349-354.

Newton, X. A., Darling-Hammond, L., Haertel, E., \& Thomas, E. (2010). Value-added Modeling of teacher effectiveness: An exploration of stability across models and contexts. education policy analysis archives, 18(23), n23.

Normore, A. (2007). A continuum approach for developing school leaders in an urban district. Journal of Research on Leadership Education, 2(3), n3.

Obama, B. (2010). A blueprint for reform: The reauthorization of the Elementary and Secondary Education Act. ESEA Blueprint for Reform.

Obama, B. (2011). Remarks by the President in State of the Union Address. January, 27, 200.

Osterman, K., \& Sullivan, S. (1996). New principals in an urban bureaucracy: A Sense of Efficacy. Journal of School Leadership, 6(6), 661-90.

Paglis, L. L., \& Green, S. G. (2002). Leadership self-efficacy and managers' motivation for leading change. Journal of organizational behavior, 23(2), 215-235.

Pajares, F. (1996). Self-efficacy beliefs in academic settings. Review of Educational Research, $66(4), 543-578$.

Payne, C. M. (2008). So much reform, so little change: The persistence of failure in urban schools: Harvard Education Press Cambridge, MA.

Pearlmutter, S. (1998). Self-efficacy and organizational change leadership. Administration in Social Work, 22(3), 23-38. 
Peterson, K. (1995). Teacher evaluation. A comprehensive guide to new directions. Corwin Press.

Petrocelli, J. V. (2003). Hierarchical multiple regression in counseling research: Common problems and possible remedies. Measurement and evaluation in counseling and development, 36(1), 9-22.

Ravitch, D. (2001). Left back: A century of battles over school reform: Simon and Schuster.

Rigby, J. G. (2015). Principals' sensemaking and enactment of teacher evaluation. Journal of Educational Administration, 53(3), 374-392.

Riggs, I. M., \& Enochs, L. G. (1990). Toward the development of an elementary teacher's science teaching efficacy belief instrument. Science Education, 74(6), 625-637.

Roberts, J. K., \& Henson, R. K. (2001). A Confirmatory factor analysis of a new measure of teacher efficacy: Ohio State Teacher Efficacy Scale.

Rockoff, J. E. (2004). The impact of individual teachers on student achievement: Evidence from panel data. American Economic Review, 247-252.

Rose, J. S., \& Medway, F. J. (1981). Measurement of teachers' beliefs in their control over student outcome. The journal of educational research, 74(3), 185-190.

Rothstein, J. (2008). Teacher quality in educational production: Tracking, decay, and student achievement: National Bureau of Economic Research.

Ruffini, S. J., Makkonen, R., Tejwani, J., \& Diaz, M. (2014). Principal and teacher perceptions of implementation of multiple-measure teacher evaluation systems in Arizona. REL 2015-062. Regional Educational Laboratory West.3 
Sanders, W., \& Horn, S. (1995). An overview of the Tennessee Value-Added Assessment System (TVAAS) with answers to frequently asked questions. Knoxville, Tennessee: The University of Tennessee.

Sanders, W. L., \& Rivers, J. C. (1996). Cumulative and residual effects of teachers on future student academic achievement: Knoxville, TN: University of Tennessee Value-Added Research and Assessment Center.

Sanders, W. L., Wright, S. P., \& Horn, S. P. (1997). Teacher and classroom context effects on student achievement: Implications for teacher evaluation. Journal of Personnel Evaluation in Education, 11(1), 57-67.

Sass, T. R., Semykina, A., \& Harris, D. N. (2014). Value-added models and the measurement of teacher productivity. Economics of Education Review, 38, 9-23.

Schunk, D. H. (1991). Self-efficacy and academic motivation. Educational psychologist, 26(3-4), 207-231.

Seashore, K., Leithwood, K., Wahlstrom, K., \& Anderson, S. (2010). Investigating the links to improved student learning: Final report of research findings for the Wallace Foundation.

Sebastian, J., \& Allensworth, E. (2012). The Influence of Principal Leadership on Classroom Instruction and Student Learning A Study of Mediated Pathways to Learning. Educational Administration Quarterly, 48(4), 626-663.

Seiler, M. F., Chilton, K., Alexander, A., Cissel, G., Nelson, D., \& Olds, S. (2010). Analysis of Collective Bargaining Agreements in Kentucky districts: Legislative Research Commission. 
Skaalvik, E. M., \& Skaalvik, S. (2010). Teacher self-efficacy and teacher burnout: A study of relations. Teaching and teacher Education, 26(4), 1059-1069.

Smith, R. W., \& Guarino, A. (2005). Confirmatory factor analysis of the Principal Self-Efficacy Survey. Journal of Organizational Culture, Communications and Conflict, 9(1), 81.

Smith, W., Guarino, A., Strom, P., \& Adams, O. (2006). Effective teaching and learning environments and principal self-efficacy. Journal of Research for Educational Leaders, $3(2), 4-23$.

Spillane, J. P., Reiser, B. J., \& Reimer, T. (2002). Policy implementation and cognition: Reframing and refocusing implementation research. Review of educational research, 72(3), 387-431.

Spillane, J. P., Halverson, R., \& Diamond, J. B. (2004). Towards a theory of leadership practice: A distributed perspective. Journal of curriculum studies, 36(1), 3-34.

Springer, M., Ballou, D., Hamilton, L., Lockwood, V., McCaffrey, D., Pepper, M., Stecher, B., (2010). Teacher pay for performance: Experimental evidence from the Project on Incentives in Teaching. Nashville, TN: National Center on Performance Incentives.

Stevens, J. P. (2009). Applied multivariate statistics for the social sciences. Routledge.

Stronge, J. H. (2005). Evaluating teaching: A guide to current thinking and best practice. Corwin Press.

Stronge, J. H., Ward, T. J., \& Grant, L. W. (2011). What makes good teachers good? A crosscase analysis of the connection between teacher effectiveness and student achievement. Journal of Teacher Education, 62(4), 339-355.

Sue, V. M., \& Ritter, L. A. (2012). Conducting online surveys. Sage. 
Tabachnick, B. G., Fidell, L. S., \& Osterlind, S. J. (2001). Using multivariate statistics. Pearson.

Tschannen-Moran, M., \& Gareis, C. R. (2004). Principals' sense of efficacy: Assessing a promising construct. Journal of Educational Administration, 42(5), 573-585.

Tschannen-Moran, M., \& Gareis, C. R. (2007). Cultivating principals' self-efficacy: Supports that matter. Journal of School Leadership, 17(1), 89.

Tschannen-Moran, M., \& Hoy, A. W. (2001). Teacher efficacy: Capturing an elusive construct. Teaching and teacher Education, 17(7), 783-805.

Tschannen-Moran, M., Hoy, A. W., \& Hoy, W. K. (1998). Teacher efficacy: Its meaning and measure. Review of Educational Research, 68(2), 202-248.

Tuytens, M., \& Devos, G. (2010). The influence of school leadership on teachers' perception of teacher evaluation policy. Educational Studies, 36(5), 521-536.

Tyack, D. B. C. L. (1995). Tinkering toward utopia: A century of public school reform. Cambridge, Mass.: Harvard University Press.

Tyack, D. T. W. (1994). The "Grammar" of Schooling: Why has it been so hard to change? American educational research journal., 31(3), 453.

Umpstead, R., Pogodzinski, B., \& Lund, D. (2013). An Analysis of State Teacher Evaluation Laws Enacted in Response to the Federal Race to the Top Initiative. West's Education Law Reporter, 286(2), 795-823.

Urick, A., \& Bowers, A.J. (2011). What influences principals' perceptions of academic climate? A nationally representative study of the direct effects of perception on climate. Leadership and Policy in Schools, 10(3), 322-348. 
Urick, A., \& Bowers, A. J. (2014). What are the different types of principals across the United States? A latent class analysis of principal perception of leadership. Educational Administration Quarterly, 50(1), 96-134.

Usher, E. L., \& Pajares, F. (2008). Sources of self-efficacy in school: Critical review of the literature and future directions. Review of educational research, 78(4), 751796.

Valentine, J. W., \& Prater, M. (2011). Instructional, transformational, and managerial leadership and student achievement: High school principals make a difference. NASSP Bulletin.

Valli, L., \& Buese, D. (2007). The changing roles of teachers in an era of high-stakes accountability. American Educational Research Journal, 44(3), 519-558.

Vekeman, E., Devos, G., \& Tuytens, M. (2013). The influence of teachers' expectations on principals' sensemaking of a new teacher evaluation policy. Paper presented at the Annual Meeting of the American Educational Research Association.

Veir, C. A., \& Dagley, D. L. (2002). Legal issues in teacher evaluation legislation: A study of state statutory provisions. BYU Educ. \& $L J, 1$.

Viteritti, J. P. (2011). Federal Role in School Reform: Obama's Race to the Top, The. Notre Dame L. Rev., 87, 2087.

Waters, T., Marzano, R. J., \& McNulty, B. (2003). Balanced Leadership: What 30 years of research tells us about the effect of leadership on student achievement. A Working Paper.

White-Smith, K. A., \& White, M. A. (2009). High school reform implementation principals' perceptions on their leadership role. Urban Education, 44(3), 259-279. 
Wolters, C. A., \& Daugherty, S. G. (2007). Goal structures and teachers' sense of efficacy: Their relation and association to teaching experience and academic level. Journal of educational psychology, 99(1), 181.

Woolfolk, A. E., Rosoff, B., \& Hoy, W. K. (1990). Teachers' sense of efficacy and their beliefs about managing students. Teaching and teacher Education, 6(2), 137-148.

Wright, S.P., Horn, S.P., \& Sanders, W.L. (1997). Teacher and classroom context effects on student achievement: Implications for teacher evaluation. Journal of Personnel Evaluation in Education 11, 57-67

Young, I. P. (2008). The human resource function in educational administration: Pearson Merrill/Prentice Hall.

Young, M. D., Fuller, E., Brewer, C., Carpenter, B., \& Mansfield, K. (2007). Quality leadership matters. UCEA Policy Brief Series, 1(1), 1-8.

Zimmerman, B. J. (2000). Self-efficacy: An essential motive to learn. Contemporary educational psychology, 25(1), 82-91. 


\section{APPENDICES}

\section{Appendix A}

\section{Principal Implementation of SBTE Appraisal Inventory}

The following appraisal inventories are designed to help gain a better understanding of the challenges faced by principals with the implementation of the Teacher Professional Growth and Effectiveness System (SBTE) and their perceptions of the purpose and impact of the teacher evaluation process. The survey is divided into three parts. Part one requests background information, part two looks at the implementation of SBTE and contains twelve statements. Part three is designed to capture principal perceptions of the purpose of the teacher evaluation process and consists of nine statements. Final inventory data will not identify schools or individuals and all survey responses will be kept confidential.

\section{Please indicate the following}

School Location number -

School Level (Elementary, Middle, High School, Combined School, Special School)

Years of experience as a principal -

Years of experience as an administrator in your current school -

Total number of evaluating administrators -

Part I Directions: In your current role as principal, please rate your degree of confidence in accomplishing the statements below. You may choose any of the five possible responses

\begin{tabular}{lccccc}
\hline & None & $\begin{array}{c}\text { Very } \\
\text { Little }\end{array}$ & Some & Moderate & $\begin{array}{c}\text { A Great } \\
\text { Deal }\end{array}$ \\
\hline $\begin{array}{l}\text { Facilitate student learning in your } \\
\text { school through the instructional } \\
\text { practices outlined in SBTE }\end{array}$ & 1 & 2 & 3 & 4 & 5 \\
$\begin{array}{l}\text { Generate enthusiasm for shared } \\
\text { vision of SBTE throughout your } \\
\text { school }\end{array}$ & 1 & 2 & 3 & 4 & 5 \\
\hline
\end{tabular}


Handle the time demands of the job related to SBTE requirements (training, observation, post observation conferences, writing evaluation )

Manage change in your school towards the implementation of SBTE

Create a positive learning environment in your school through the concepts outlined in the SBTE rubric (respect, rapport, culture student behavior)

Raise student achievement on standardized tests through the instructional practices outlined in the SBTE rubric

Motivate teachers to implement the instructional strategies suggested through SBTE

Maintain control of your own daily schedule to conduct teacher observations and post observation conferences as required by SBTE

Manage the implementation of SBTE

Handle the paperwork and online data entry required of SBTE

Cope with the stress of the job with the additional duty of implementing 1 2 SBTE

Prioritize among competing 12 demands of the job 
Appendix B

\section{Principal Perceptions of SBTE}

Please indicate the extent to which you agree or disagree with each of the following statements about the Teacher Performance Growth and Effectiveness System (SBTE) observation and evaluation process.

Part II Directions: Please indicate your opinion about each of the questions below by selecting one of the five responses in the columns to the right. The scale of responses range from "Strongly Disagree" (1) to "Strongly Agree" (5) with "Neither Disagree or Agree" (3) representing the mid-point between the low and high extremes.

\begin{tabular}{|c|c|c|c|c|c|}
\hline & $\begin{array}{l}\text { Strongly } \\
\text { Disagree }\end{array}$ & Disagree & $\begin{array}{l}\text { Neither } \\
\text { Disagree } \\
\text { or Agree }\end{array}$ & Agree & $\begin{array}{l}\text { Strongly } \\
\text { Agree }\end{array}$ \\
\hline $\begin{array}{l}\text { SBTE describes effective } \\
\text { teaching }\end{array}$ & 1 & 2 & 3 & 4 & 5 \\
\hline $\begin{array}{l}\text { The SBTE evaluation process } \\
\text { takes more time than the results } \\
\text { are worth }\end{array}$ & 1 & 2 & 3 & 4 & 5 \\
\hline $\begin{array}{l}\text { Face to face feedback was } \\
\text { provided after each observation }\end{array}$ & 1 & 2 & 3 & 4 & 5 \\
\hline $\begin{array}{l}\text { Aligning teaching practices } \\
\text { with the SBTE rubric will help } \\
\text { teachers improve instruction }\end{array}$ & 1 & 2 & 3 & 4 & 5 \\
\hline $\begin{array}{l}\text { The SBTE evaluation process } \\
\text { helps develop teachers } \\
\text { instructionally }\end{array}$ & 1 & 2 & 3 & 4 & 5 \\
\hline $\begin{array}{l}\text { The SBTE evaluation process } \\
\text { fairly reflects teaching } \\
\text { effectiveness }\end{array}$ & 1 & 2 & 3 & 4 & 5 \\
\hline $\begin{array}{l}\text { The SBTE rubric clearly } \\
\text { defines standards for teaching } \\
\text { effectiveness }\end{array}$ & 1 & 2 & 3 & 4 & 5 \\
\hline
\end{tabular}


I am satisfied with the discussions of performance I

have with my teachers

following classroom

1

2

3

4

5

observations

I am satisfied with the feedback

I provide teachers regarding

professional growth plans,

student growth goals, and

1

2

3

4

5

classroom observations. 


\section{Appendix C \\ PRINCIPAL EFFICACY FOR THE IMPLEMENTATION OF A STANDARDS BASED TEACHER EVALUATION REFORM}

January 8, 2016

Dear Principal:

You are being invited to participate in a research study by answering the attached survey about principal self-efficacy for the implementation of a teacher evaluation reform. There are no known risks for your participation in this research study. The information collected may not benefit you directly. The information learned in this study may be helpful to others. The information you provide will allow for improved school based supports, and professional development offerings for principals during the implementation of future reforms. Your completed survey will be stored on a password-protected computer and will be destroyed after the study is complete. The survey will take approximately 5-10 minutes of your time.

Individuals from the Department of Educational Leadership, Evaluation, and Organizational Development, the Institutional Review Board (IRB), the Human Subjects Protection Program Office (HSPPO), and other regulatory agencies may inspect these records. In all other respects, however, the data will be held in confidence to the extent permitted by law. Should the data be published, your identity will not be disclosed.

Taking part in this study is voluntary. By completing this survey you agree to take part in this research study. You do not have to answer any questions that make you uncomfortable. You may choose not to take part at all. If you decide to be in this study you may stop taking part at any time. If you decide not to be in this study or if you stop taking part at any time, you will not lose any benefits for which you may qualify.

If you have any questions, concerns, or complaints about the research study, please contact: Dr. Gaetane Jean-Marie at (502) 852-0634

If you have any questions about your rights as a research subject, you may call the Human Subjects Protection Program Office at (502) 852-5188. You can discuss any questions about your rights as a research subject, in private, with a member of the Institutional Review Board (IRB). You may also call this number if you have other questions about the research, and you cannot reach the research staff, or want to talk to someone else. The IRB is an independent committee made up of people from the 
University community, staff of the institutions, as well as people from the community not connected with these institutions. The IRB has reviewed this research study.

If you have concerns or complaints about the research or research staff and you do not wish to give your name, you may call 1-877-852-1167. This is a 24 hour hot line answered by people who do not work at the University of Louisville.

Sincerely,

Gaëtane Jean-Marie, Ph.D.

Professor and Chair

Department of Educational Leadership, Evaluation, and Organizational Development College of Education and Human Development

University of Louisville

1905 South 1st Street

Louisville, KY 40292

Jason Neuss, Ed.D. Candidate

Department of Educational Leadership, Evaluation, and Organizational Development College of Education \& Human Development

University of Louisville

1905 South $1^{\text {st }}$ Street

Louisville, KY 40292 


\section{Appendix D}

Principal Sense of Efficacy Scale Survey Results: In your current role as principal, please rate your degree of confidence in accomplishing the statements below

$M \quad S D$

\section{Efficacy for Instructional Leadership}

Facilitate student learning in your school through the

$4.20 \quad .8003$

instructional practices outlined in SBTE

Generate enthusiasm for a shared vision of SBTE throughout

3.76

.8531

your school

Manage change in your school towards the implementation of

.7038

SBTE

Create a positive learning environment in your school through

.8282 the concepts outlined in the SBTE rubric (respect, rapport, culture, student behavior)

Raise student achievement on standardized tests through the instructional practices outlined in the SBTE rubric

Motivate teachers to implement the instructional strategies

suggested through SBTE

\section{Efficacy for Management}

Handle the time demands of the job related to SBTE

requirements (training, observation, post observation

conferences, writing evaluations)

Maintain control of your own daily schedule to conduct teacher observations and post observation conferences as required by SBTE

Manage the implementation of SBTE 
Cope with the stress of the job with the additional duty of

$3.57 \quad 1.0323$ implementing SBTE

Prioritize among competing demands of the job

3.81

.9030 


\title{
CURRICULUM VITAE
}

\author{
JASON K. NEUSS \\ 3705 Rock Bay Drive \\ Louisville, KY 40245 \\ (502) 552-9308 \\ jason.neuss@jefferson.kyschools.us
}

\section{EDUCATION}

Doctor of Education, Ed.D. ---:--:----:-------August, 2016

University of Louisville: Louisville, KY

Leadership, Evaluation, and Organizational Development

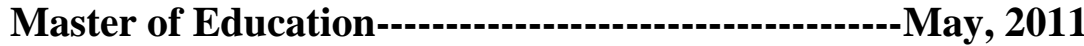

Educational Leadership Licensure

University of Louisville: Louisville, KY

Bachelor of Science in Education-------------------May, 1997

Learning and Behavioral Disorders

Western Kentucky University: Bowling Green, KY

\section{EDUCATIONAL EMPLOYMENT HISTORY}

2015-Current

2011-2015

2007-2011

\author{
Assistant Principal \\ Doss High School \\ Jefferson County Public Schools \\ Louisville, KY
}

Assistant Principal

Moore Traditional School

Jefferson County Public Schools

Louisville, KY

ECE Teacher

Louisville Male Traditional High School

Jefferson County Public Schools

Louisville, KY 
2004-2011

Head Track and Field Coach

Louisville Male Traditional High School

Jefferson County Public Schools

Louisville, KY

2002-2011

ECE Teacher

Moore Traditional High School

Jefferson County Public Schools

Louisville, KY

1997-2002

Special Education Teacher

Newark Memorial High School

Newark Unified School District

Newark, CA

\section{RECOGNITIONS}

- 2016: Selected by University of Louisville as a David L. Clark Scholar

- 2015: Inducted to the Kentucky High School Track and Field Hall of Fame

- 2014: Inducted to the Louisville Male Hall of Fame

- 2007-2008: Member of IDEAS as part of Jefferson County Public Schools aspiring leader programs

- 2007, 2008, 2009, 2010, 2011: AAA Boys Track and Field State Championship Coach

- 2007, 2008, 2009, 2010, 2011: AAA Boys Track and Field Coach of the Year 